Final Technical Report

\title{
Predicting Pattern Tooling and Casting Dimensions for Investment Casting, Phase III
}

December 2007

\section{Principal Investigators:}

Nick Cannell

Edison Materials Technology Center

Adrian S. Sabau

Oak Ridge National Laboratory

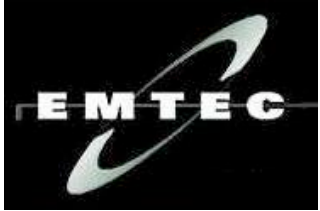




\section{DOCUMENT AVAILABILITY}

Reports produced after January 1, 1996, are generally available free via the U.S. Department of Energy (DOE) Information Bridge.

Web site http://www.osti.gov/bridge

Reports produced before January 1, 1996, may be purchased by members of the public from the following source.

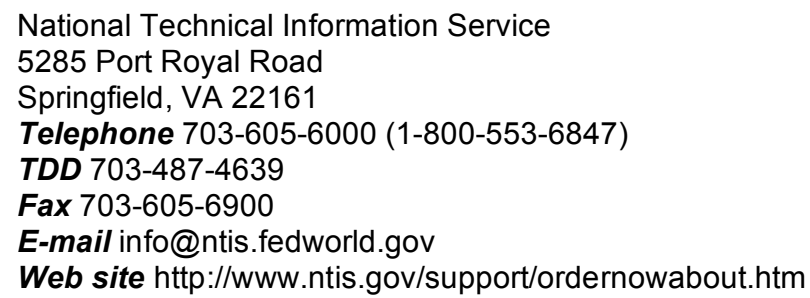

Reports are available to DOE employees, DOE contractors, Energy Technology Data Exchange (ETDE) representatives, and International Nuclear Information System (INIS) representatives from the following source.

Office of Scientific and Technical Information

P.O. Box 62

Oak Ridge, TN 37831

Telephone 865-576-8401

Fax 865-576-5728

E-mail reports@adonis.osti.gov

Web site http://www.osti.gov/contact.html 


\section{FINAL TECHNICAL REPORT}

Project Title:

DOE Award Number:

Project Period:

PI(s):

National Laboratory:

Project Team:
Predicting Pattern Tooling and Casting Dimensions for Investment Casting, Phase III

DE-FC36-04GO14230

June 1, 2004-September 30, 2007

Nick Cannell (EMTEC)

(216) 408-7706

ncannell@gmail.com

Adrian S. Sabau (ORNL)

(865) 241-5145

sabaua@ornl.gov

Recipient Organization: $\quad$ Edison Materials Technology Center (EMTEC)

3155 Research Blvd.

Kettering, OH 45420

Oak Ridge National Laboratory

\begin{tabular}{ll} 
Contact & Company \\
\hline Bill Schrey & Schrey \& Sons Mold \\
Bob Dzugan & Buycastings.com \\
Bob Horton & Precision Metalsmiths, Inc. \\
James A. Oti & J \& J, a DePuy Company \\
Jerry Donohue & Precision Colloids, LLC \\
Jerry Kovatch & Precision Metalsmiths, Inc. \\
Jerry Snow & Minco, Inc. \\
Jim Gardner & JEM Mfg. \\
Nip Singh & S \& A Consulting Group, LLP \\
Timothy Wolff & Argueso \& Co. \\
Mike Payne & Precision Castings, Inc. \\
Nick Cannell & EMTEC
\end{tabular}





\title{
Predicting Pattern Tooling and Casting Dimensions for Investment Casting, Phase III
}

\author{
Nick Cannell \\ Edison Materials Technology Center \\ Adrian S. Sabau \\ Oak Ridge National Laboratory
}

October 2007

\author{
Prepared by \\ OAK RIDGE NATIONAL LABORATORY \\ P.O. Box 2008 \\ Oak Ridge, Tennessee 37831-6283 \\ managed by \\ UT-Battelle, LLC \\ for the \\ U.S. DEPARTMENT OF ENERGY \\ under contract DE-AC05-00OR22725
}




\section{Acknowledgments and Disclaimer}

\section{Acknowledgments}

This report is based upon work supported by the U.S. Department of Energy, Energy Efficiency and Renewable Energy, Industries of the Future - Metal casting, under Award No. DE-FC36-04GO14230.

We would like to thank Srinath Viswanathan of ORNL, who initiated phase I of the project, M. Argueso \& Co., Inc., for providing the wax for this study; T. Wolf, P. A. Silverstein, W. R. Fricker, and I. Al-Rabadi of Argueso for assistance with the wax injection experiments; M. Radovic and R.M. Trejo of ORNL, for conducting rheometry measurements on filled waxes at HTML/ORNL, and W.D. Porter of ORNL for conducting high temperature dilatometry measurements for $17-4 \mathrm{PH}$ alloy.

Thanks also go to J. Snow, D. Scott, and B. Sneider of Minco, Inc., for shell investment and for embedding thermocouples within the shell; E. Hatfield for casting assistance; Z. Wu, a University of Tennessee graduate student, for obtaining the shrinkage factors from measured dimensions; J. Kovatch and R. Abramczyk of Precision Metalsmiths, Inc. (PMI), for conducting casting experiments; Allen Bransford and Mike Payne, Precision Castings of Tennessee, Inc., for providing access to their foundry; B. Schrey, of Schrey \& Sons Mold Co., for providing the sprue tooling; and Jim Gardner, J.E.M. Manufacturing, for casting design, providing wax patterns for the sprue, designing and coordinating the fabrication of a test bar, and coordinating wax injection, shell making, and casting at PCC, Inc., Viking Metalgraphics, Inc., and SeaCast, Inc; Schrey \& Sons, Inc and McCaughin, Inc. for providing the test bar wax patterns, Remet, Inc. for providing waxes, and Dr. G. M. Rowe of Abatech, Inc. for conducting DMA experiments and determining the discrete relaxation spectra for the torsion DMA data set, H. Lobo and T. Bethard of Datapoint Labs, Inc., for conducting DSC and thermal conductivity measurements.

\section{Disclaimer}

This report was prepared as an account of work sponsored by an agency of the United States Government. Neither the United States Government nor any agency thereof, nor any of their employees, makes any warranty, express or implied, or assumes any legal liability or responsibility for the accuracy, completeness, or usefulness of any information, apparatus, product, or process disclosed, or represents that its use would not infringe privately owned rights. Reference herein to any specific commercial product, process, or service by trade name, trademark, manufacturer, or otherwise, does not necessarily constitute or imply its endorsement, recommendation, or favoring by the United States Government or any agency thereof. The views and opinions of authors expressed herein do not necessarily state or reflect those of the United States Government or any agency thereof. 


\section{Contents}

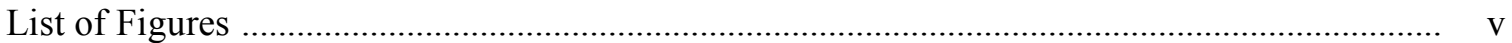

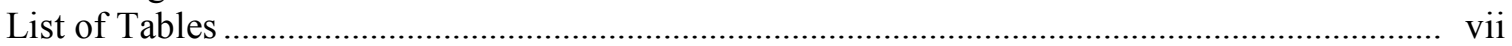

Abbreviations, Acronyms, and Symbols ........................................................................... viii

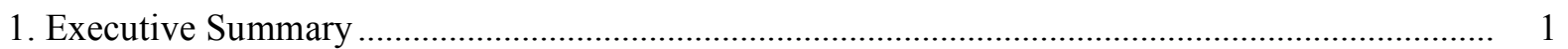

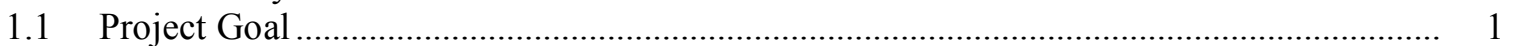

1.2 Summary of Project Achievements ................................................................ 2

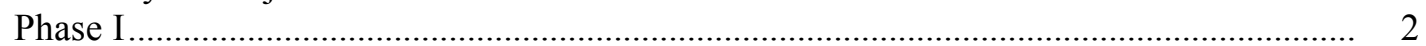

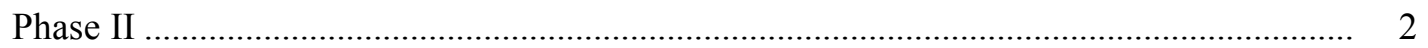

Phase III: Current Project .............................................................................. 3

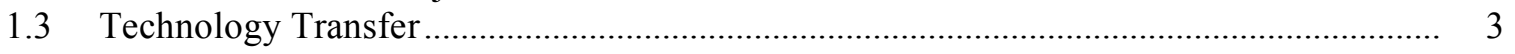

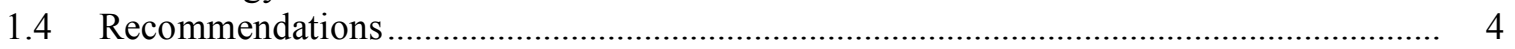

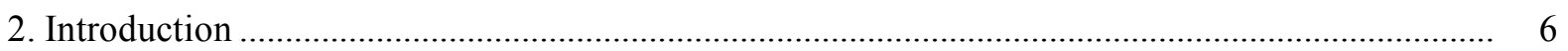

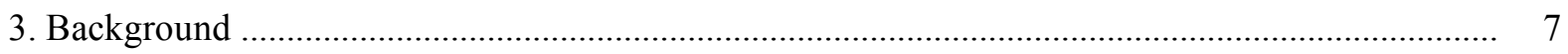

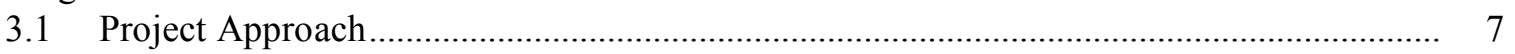

3.2 Review of Computer Models for Wax, Shell, and Alloy Deformation ............................... 7

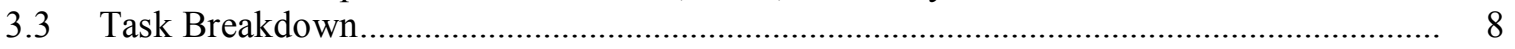

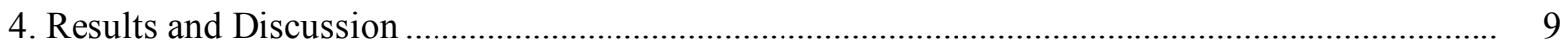

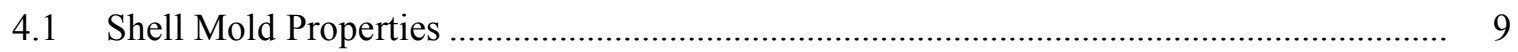

4.1.1 Material Property Data for Shell Molds ...................................................................... 9

4.1.2 Material Property Data for Fused-silica Shell Molds ............................................ 12

4.2 Alloy Properties and Mechanical Interaction for the Shell-Alloy System .......................... 13

4.2.1 Thermophysical Material Property for 17-4PH steel................................................ 13

4.2.2 Thermomechanical Material Property for 17-4PH steel ......................................... 15

4.2.3 Experimental Results for Alloy Shrinkage Factors ............................................ 18

4.2.4 Numerical Simulation Results for Casting Dimensions .......................................... 21

4.3 Measurements of Material Properties for Filled Waxes ................................................. 28

4.3.1 Thermophysical Properties of Waxes .................................................................. 28

4.3.2 Measurement techniques for thermomechanical properties of waxes ...................... 29

4.3.3 Viscoelastic property data of filled waxes ............................................................ 31

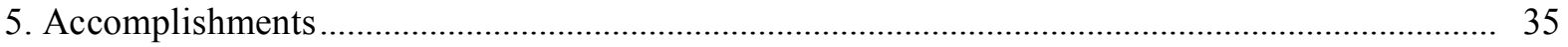

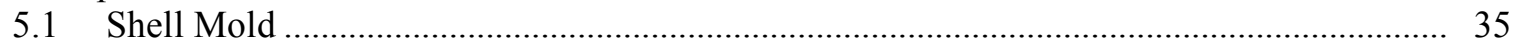

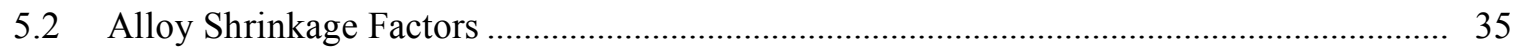

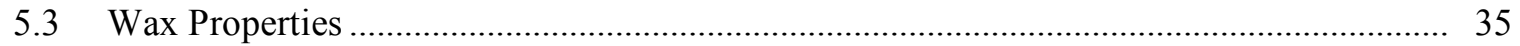

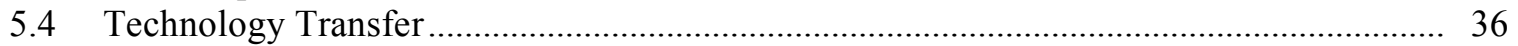

5.5 Publications and Patents Resulting from Project ......................................................... 36

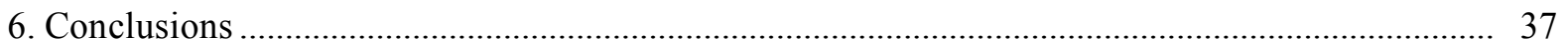

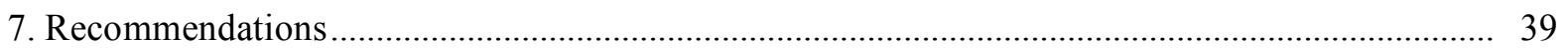

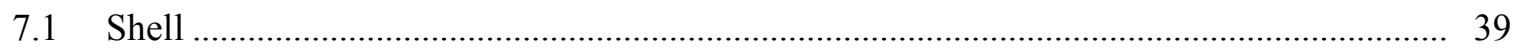

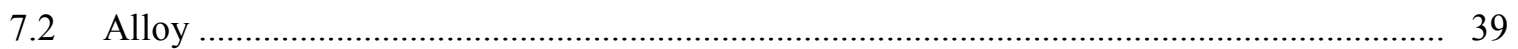

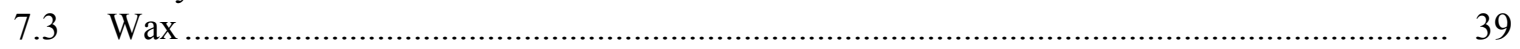


7.4 Technology Transfer........

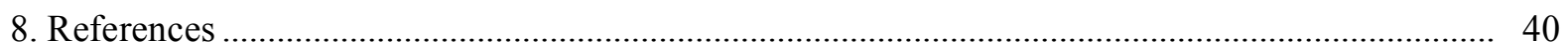

Appendices

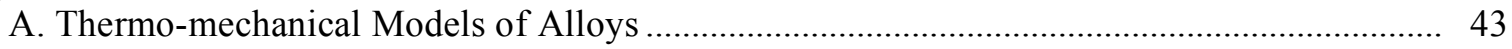

B. Constitutive Equations for Modeling Wax Deformation..................................................... 44

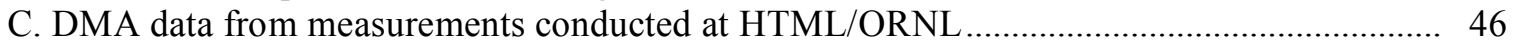

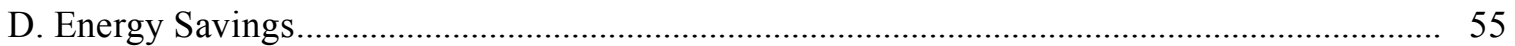




\section{List of Figures}

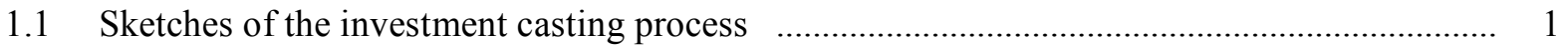

1.2 Dimensions in the investment casting process .................................................................. 2

1.3 Flow chart illustrating the steps necessary for obtaining the dimensions and ensuing shrinkage factors based on computer models .......................................................... 2

4.1 Measured linear thermal expansion for: (a) 17-4PH alloy and (b) shell mold ......................... 12

4.2 Thermophysical properties for 17-4PH alloy, (a) specific heat, (b) thermal conductivity, and (c) fraction solid, (d) density. Density was obtained from thermal expansion data on heating. .... 14

4.3 Measured linear thermal expansion for 17-4PH alloy on heating and cooling......................... 15

4.4 Modulus of elasticity for 17-4PH alloy (Experimental data from Rack, 1981) (a) over large temperature domain, (b) at high temperature ...................................................................... 16

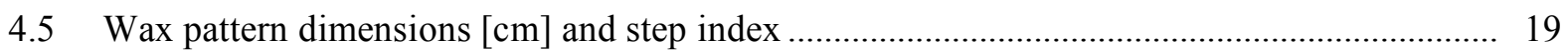

4.6 Pictures showing shell molds invested at Minco and cast at PMI: (a) wax pattern; $(b)$ shell mold; (c) steel casting.

4.7 Position of coordinate measurement points for $(a)$ the width dimensions and (b) length L2-5, between ends of Steps 2 and 5

4.8 Alloy shrinkage factors for the (a) width dimension and (b) length dimension, L2-5 ............ 21

4.9 Casting configuration for numerical simulations................................................................ 21

4.10 Evolution of the calculated solid fraction and temperature in the center of the steps .............. 22

4.11 Evolution of the calculated shrinkage the L5_2 dimension at the centerline for the (a) no-hole

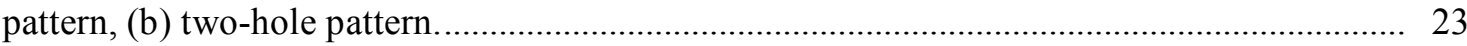

4.12 Evolution of the shrinkage the width dimension at the center of steps ..................................... 24

4.13 Comparison between the experimental results and computed results for the length dimension, L5_2: (a) part with no-holes and (b) part with two-holes

4.14 Comparison between experimental and computed shrinkage factors for the width dimension along the length: (a) part with no-holes and (b) part with two-holes. ..................................... 25

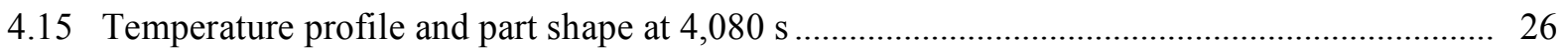

4.16 Equivalent plastic strain at 5,400s for the no-hole casting when thermal expansion used was that measured on (a) heating and (b) cooling

4.17 Equivalent plastic strain at 5,400s for the two-hole casting when thermal expansion used was that measured on (a) heating and (b) cooling

4.18 Density for Cerita ${ }^{\mathrm{TM}}$ F20-6 wax (a), specific heat (a) and thermal conductivity (b) for one unfilled wax, Cerita ${ }^{\mathrm{TM}} 29-51$ wax, and three filled waxes.

4.19 DMA experimental results for the (a) storage and (b) loss shear modulus (torsion) ............... 32

4.20 DMA experimental results for the (a) storage and (b) loss Youngs modulus (3-pt bending)... 33

4.21 Master curves for the storage (G') and loss moduli ( $\left.G^{\prime \prime}\right)$ obtained at the reference temperature of $40^{\circ} \mathrm{C}$ from experimental data on (a) torsion and (b) 3-point bending...

4.22 Linearized Arrhenius shift factor experimental data at $\mathrm{T}_{\mathrm{ref}}=40^{\circ} \mathrm{C}$ on (a) torsion and (b) 3-point bending, Cerita ${ }^{\mathrm{TM}}$ F20-6 wax .

A.1 True-strain true-stress data at temperatures of (a) 950 and (b) $1250{ }^{\circ} \mathrm{C}$............................... 43

A.2 True-strain true-stress data at a strain rate of $0.001 \mathrm{~s}^{-1}$ as a function of temperature used to estimate the yield stress 


\section{List of Tables}

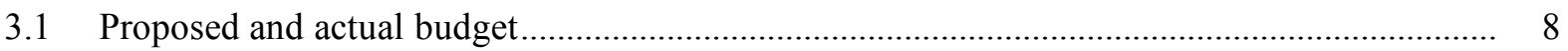

4.1 Shell systems used. The prime coat was zircon ................................................................. 9

4.2 Thermophysical properties available from suppliers and property needed for numerical

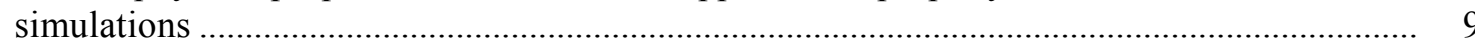

4.3 Thermo-mechanical properties available from suppliers and property needed for numerical

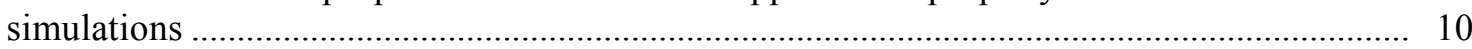

4.4 Thermophysical properties reported in the literature for the investment casting shell molds .. 11

4.5 Heat transfer coefficients at metal-mold interface ............................................................ 11

4.6 Mechanical properties reported in the literature for alumino-silicates.................................... 11

4.7 References for Measured Data on Material Property ......................................................... 14

4.8 Thermo-mechanical properties available for $17-4 \mathrm{PH}$ or $15-5 \mathrm{PH}$ stainless steels ................... 16

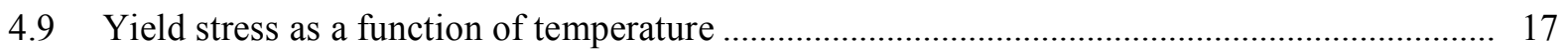

4.10 Mechanical properties for other steels than 17-4PH ......................................................... 18

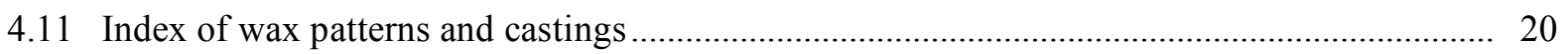

4.12 Properties for the F20-6 wax provided by the wax supplier ................................................. 28

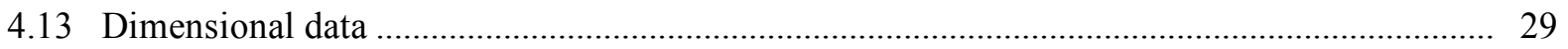

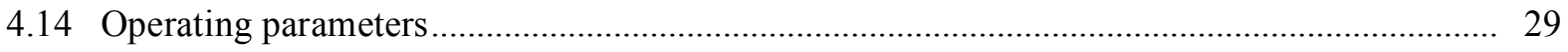

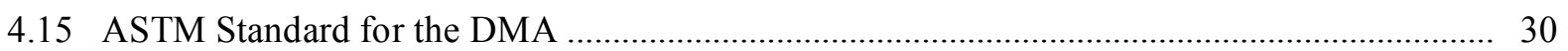

4.16 Tests used for determining wax properties ....................................................................... 31

4.17 Tests and fixtures recommended for investment casting waxes.............................................. 31

B.1 Relaxation times, $\lambda_{i}$, and relaxation strengths, $g_{i}$, determined from experimental measurements by nonlinear regression analysis .............................................. 44

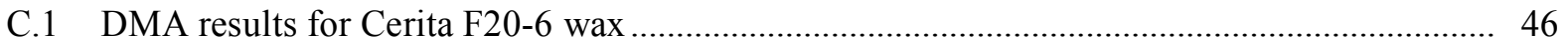

C.2 DMA results for Remet PC-15 wax (former RR-15) .......................................................... 49

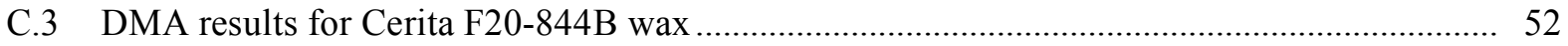

D.1 Comparison of energy used and energy saved for existing versus new technology ................ 56 


\section{Abbreviations, Acronyms, and Symbols}

$\begin{array}{ll}\text { ABAQUS } & \text { computer simulation program } \\ \text { 17-4PH } & \text { steel } \\ \text { AFS } & \text { American Foundry Society } \\ \mathrm{a}_{\mathrm{s}} & \text { alloy shrinkage } \\ \mathrm{c}_{\mathrm{s}} & \text { casting shrinkage } \\ \mathrm{C} 1, \mathrm{C} 2 & \text { thermocouples embedded in the shell cavity } \\ \text { CMM } & \text { coordinate measurement machine } \\ \text { DSC } & \text { differential scanning calorimeter } \\ \text { DTA } & \text { differential thermal analysis } \\ \text { EMTEC } & \text { Edison Materials Technology Center } \\ \text { HTC } & \text { heat transfer coefficient, W/m }{ }^{2} \mathrm{~K} \\ \text { ICI } & \text { Investment Casting Institute } \\ \mathrm{k} & \text { thermal conductivity } \\ \text { L2-5, L25 } & \text { length between steps } 2 \text { and } 5 \\ \text { ORNL } & \text { Oak Ridge National Laboratory } \\ \text { PCT } & \text { Precision Casting of Tennessee, Inc. } \\ \text { ProCAST } & \text { casting simulation software } \\ \text { PMI } & \text { Precision Metalsmiths, Inc. } \\ \text { T } & \text { temperature, units indicated in graphs or tables } \\ \mathrm{w}_{\mathrm{s}} & \text { wax shrinkage }\end{array}$





\section{Executive Summary}

The investment casting process allows the production of complex-shape parts and close dimensional tolerances. One of the most important phases in the investment casting process is the design of the pattern die. Pattern dies are used to create wax patterns by injecting wax into dies. The wax patterns are used to create a ceramic shell by the application of a series of ceramic coatings, and the alloy is cast into the dewaxed shell mold (Fig. 1.1). However, the complexity of shape and the close dimensional tolerances required in the final casting make it difficult to determine tooling dimensions.
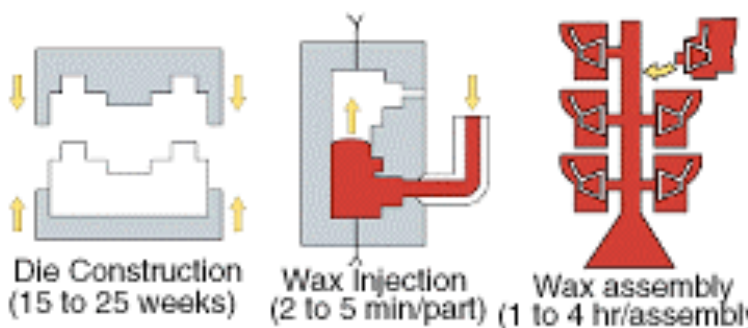

(2 to 5 min/part) (1 to 4 hriassembly)
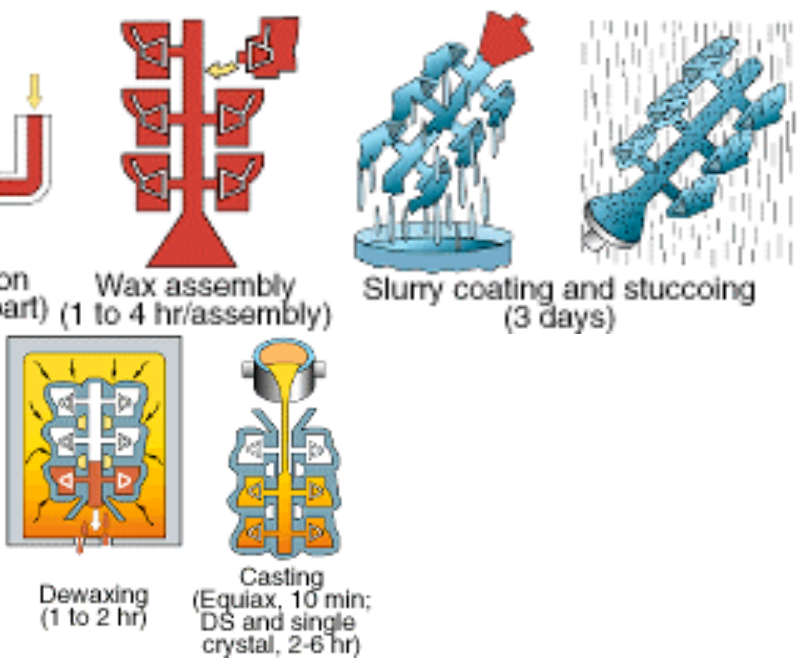

( 3 days)

Fig. 1.1. Sketches of the investment casting process (schematic from http://www.machinedesign.com).

In most cases, the mold geometry or cores restrict the shrinkage of the pattern or the cast part, and the final casting dimensions may be affected by time-dependent processes such as viscoelastic deformation of the wax, and viscoplastic creep and plastic deformations of the shell and alloy (Fig. 1.2). The pattern die is often reworked several times to produce castings whose dimensions are within acceptable tolerances.

\subsection{Project Goal}

The goal of this project was to predict casting dimensions for investment castings in order to meet blueprint nominal during the first casting run. Several interactions have to be considered in a coupled manner to determine the shrinkage factors: these are the die-wax, wax-shell, and shell-alloy interactions (as illustrated in Fig. 1.3). In this work, the deformations of the die-wax and shell-alloy systems were considered in a coupled manner. Future work is needed in order to deliver to industry a computer program in which all three systems are coupled for determining the dimensions of the wax pattern, the shell mold, and casting in a sequential but coupled manner. 


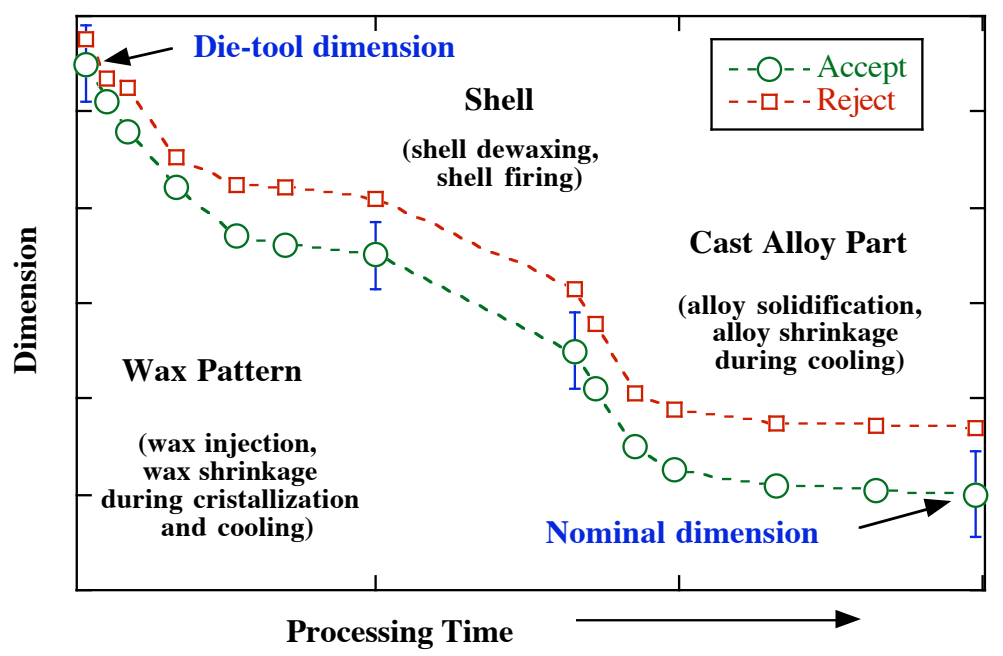

Fig. 1.2. Dimensions in the investment casting process.

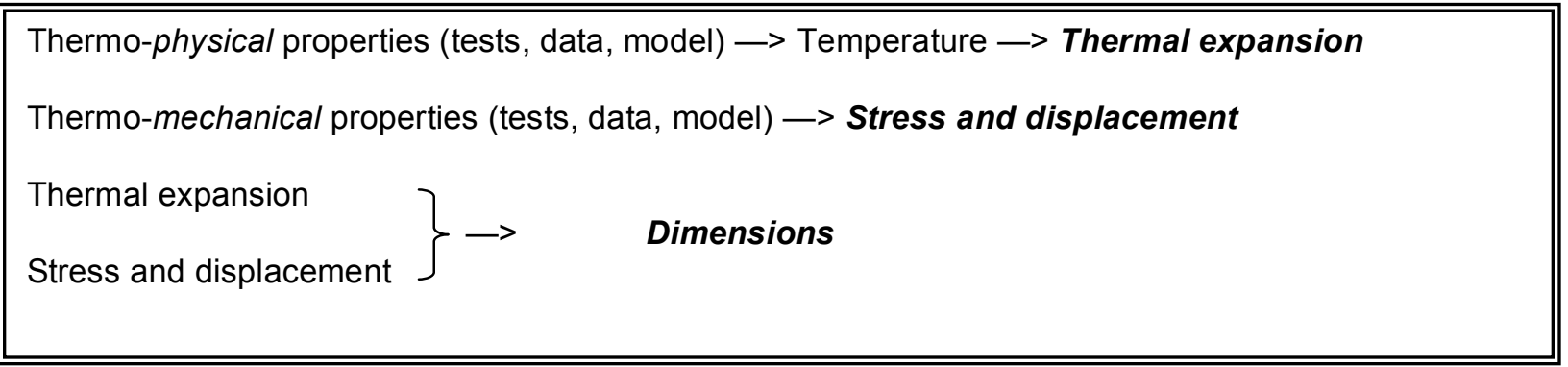

Fig. 1.3. Flow chart illustrating the steps necessary for obtaining the dimensions and ensuing shrinkage factors based on computer models.

\subsection{Summary of Project Achievements}

\section{Phase I}

The first part of the project involved preparation of reports on the state of the art for die-wax, waxshell, and shell-alloy processes. The primary R\&D focus during Phase I was on the wax material since the least was known about it. The main R\&D accomplishments during this phase were determination of procedures for obtaining the thermal conductivity and viscoelastic properties of an unfilled wax and validating those procedures.

\section{Phase II}

Efforts during Phase II focused on die-wax and shell-alloy systems. A wax material model was developed, and a die-wax model was successfully incorporated into and used in commercial computer programs. At that time, computer simulation programs had complementary features. A viscoelastic module was available in ABAQUS but unavailable in ProCAST, while the mold-filling module was available in ProCAST but unavailable in ABAQUS. Thus, the numerical simulation results were only in good qualitative agreement with experimental results, the predicted shrinkage factors being approximately 2.5 times larger than those measured. Significant progress was made, and results showed that the testing and modeling of wax material had great potential for industrial applications. 
Additional R\&D focus was placed on the fused-silica shell mold and A356 aluminum alloy system. The experimental part of the program was conducted at ORNL and commercial foundries, where wax patterns were injected, molds were invested, and alloys were poured. Significant effort was made to obtain temperature profiles in the shell mold. A model for thermal radiation within the shell mold was developed, and the thermal model was successfully validated using ProCAST. The alloy dimensions were obtained from numerical simulations only with coupled shell-alloy systems. The A356 alloy dimensions were in excellent quantitative agreement with experimental data, validating the deformation module.

\section{Phase III: Current Project}

Efforts during Phase III focused mainly on the shell-alloy systems. A high melting point alloy, 174PH stainless steel, was considered. The experimental part of the program was conducted at ORNL and commercial foundries, where wax patterns were injected, molds were invested, and alloys were poured. Shell molds made of fused silica and alumino-silicates were considered. A literature review was conducted on thermophysical and thermomechanical properties alumino-silicates. Material property data, which were not available from material suppliers, was obtained.

For all the properties of 17-4PH stainless steel, the experimental data available in the literature did not cover the entire temperature range necessary for process simulation. Thus, some material properties were evaluated using ProCAST, based on CompuTherm database. A comparison between the predicted material property data and measured property data was made. It was found that most material properties were accurately predicted only over several temperature ranges. No experimental data for plastic modulus were found. Thus, several assumptions were made and ProCAST recommendations were followed in order to obtain a complete set of mechanical property data at high temperatures. Thermal expansion measurements for the 17-4PH alloy were conducted during heating and cooling. As a function of temperature, the thermal expansion for both the alloy and shell mold materials showed different evolution on heating and cooling.

Numerical simulations were performed using ProCAST for the investment casting of 17-4PH stainless steel parts in fused silica molds using the thermal expansion obtained on heating and another one with thermal expansion obtained on cooling. Since the fused silica shells had the lowest thermal expansion properties in the industry, the dewaxing phase, including the coupling between wax-shell systems, was neglected. The shell mold was considered to be a pure elastic material. The alloy dimensions were obtained from numerical simulations. For 17-4PH stainless steel parts, the alloy shrinkage factors were over-predicted, as compared with experimental data.

Additional R\&D focus was placed on obtaining material property data for filled waxes, waxes that are common in the industry. For the first time in the investment casting industry, the thermo-mechanical properties of unfilled and filled waxes were measured. Test specimens of three waxes were injected at commercial foundries. Rheometry measurement of filled waxes was conducted at ORNL. The analysis of the rheometry data to obtain viscoelastic properties was not completed due to the reduction in the budget of the project (approximately $50 \%$ and $60 \%$ of DOE funds and cost-share from industrial partners were received, respectively).

\subsection{Technology Transfer}

The techniques developed in the program were documented in several publications and conference presentations. Detailed reports on alloy and shell mold materials were also issued to the participating companies. Through the ORNL work conducted in this project, the areas of material property 
measurement and modeling of material behavior has matured, allowing the software vendors to develop appropriate modules in their codes, the next steps in technology transfer. Over the course of the project, ORNL assisted ProCAST with advice, information, material property data, mesh files, ProCAST setup files.

Recommendations were made to Investment Casting Institute on measurement techniques for waxes. Recommendations for mechanical testing of waxes were made based on testing one unfilled wax and one filled wax, both used by the industry. The recommendations made could be used to establish new testing guidelines for waxes in the investment casting industry.

Commercial adoption of the technologies developed in this program took place through the active participation of the American Foundry Society, Edison Materials Technology Center, and the industrial partners participating in this work. Most of the property data and constitutive equations developed in this program were implemented in ProCAST, the leading casting simulation software for the investment casting industry, allowing immediate dissemination of the information to industry. As a result of this work, ProCAST implemented a viscoelastic module that is currently being tested.

\subsection{Recommendations}

This project laid the theoretical groundwork for predicting shrinkage factors. Further work on obtaining the alloy mechanical properties at high temperature needs to be performed. Numerical simulations need to be conducted based on more accurate mechanical properties and the accuracy of the deformation module needs to be assessed. Also, the creep properties of the shell molds must also be obtained, modeled, and validated. The analysis of the rheometry data for the filled wax must be completed. The potential for industrial applications of the wax testing must be assessed.

Future work is needed for delivering to the industry a computer program in which the die-wax, waxshell, and shell-alloy systems are coupled for determining the dimensions of the wax pattern, shell mold, and casting in a sequential but coupled manner.

For technology dissemination, it is now recommended that a new project be started and conducted to incorporate the proposed methodologies into commercial casting software. The software vendors should collaborate with a team of users. 



\section{Introduction}

For the investment casting process, the tooling depends on dimensional changes associated with the wax pattern, ceramic molds, and cast alloys. The nominal casting dimensions can be achieved provided that the die tools were dimensioned with appropriate degree of accuracy. In most cases, the mold geometry or cores restrict the shrinkage of the pattern or the cast part, and the final casting dimensions may be affected by time-dependent processes such as viscoelastic deformation of the wax, and viscoplastic creep and plastic yield of the shell and alloy. Although there is significant information in the literature on these processes, and mathematical models have been developed for continuous and direct chill casting, there has been little or no application to shaped castings. In particular, although many commercial casting codes have stress modules to predict elastic stress, they cannot predict dimensional change or model the effects of geometrical restraint, viscoelastic creep, viscoplastic creep, and plastic yield. These processes occur primarily in investment casting, due to the extended time the casting is at high temperature, and occur to a much lesser extent in other casting processes.

As a step towards predicting tooling dimensions, Sabau (2006) showed that, for the investment casting of aluminum alloys, alloy shrinkage factors were predicted with high degree of accuracy when the deformation of the mold is considered. Wax patterns are made by injecting wax into metal dies, ceramic shells are made by the successive application of ceramic coatings over the wax patterns, and the alloys are cast into the dewaxed shell molds. The dimensional changes associated with wax, shell mold, or alloy, are referred to as wax, shell mold, or alloy shrinkage factors (or tooling allowances), respectively. The usual practice to estimate the die tools' dimensions is by adjusting the nominal casting dimensions with the shrinkage factors.

To date, investment casting technology has been based on hands-on training and experience. Technical literature is limited to experimental, phenomenological studies aimed at obtaining empirical correlations for quick and easy application in industry. The pattern die is often reworked several times to produce castings whose dimensions are within acceptable tolerances. The complexity of shape and the close dimensional tolerances required in the final casting make it difficult to determine the appropriate pattern dimensions with existent casting simulation software except by trial and error.

Improvements in industrial dimensional practices are hindered by (a) the complexity of physical phenomena that determine casting dimensions; (b) the lack of thermophysical property data for the wax, shell, and alloy; and (c) the lack of well-established, validated thermomechanical models that describe the deformation of the wax, shell, and alloy. Although not all of the commercial packages have all the features pertinent to investment casting (e.g., input for radiation heat transfer), most can be used to design gating systems and minimize areas of solidification shrinkage. However, none of the commercial packages can be used for determining the pattern tooling dimensions. 


\section{Background}

The difference between the die dimensions and corresponding casting dimensions are usually referred to as the tooling allowances, or shrinkage factors. To determine the shrinkage factors, the die-wax, wax-shell, and shell-alloy interactions must be considered in a coupled manner.

\subsection{Project Approach}

The main approach of this project was to determine die tooling dimensions on the basis of material properties and process parameters. Shrinkage factors for the wax pattern, shell mold, and alloy casting were computed; and computational procedures and experimental methodologies were developed.

The technical execution of the project was carried out primarily by research staff at Oak Ridge National Laboratory (ORNL). The Edison Materials Technology Center (EMTEC) and industry participants was closely involved in the dissemination of the technology to the rest of the investment casting and foundry industry through the activities of the American Foundry Society (AFS) 4L Investment Casting Committee, the AFS Congress and ICI.

This program was conducted with substantial involvement by industrial members of the $4 \mathrm{~L}$ Investment Casting Committee. Industry members determined project deliverables; provided detailed information on wax, shell, and alloy materials and process variables; provided materials for testing; characterized materials; gave technical assistance; conducted experiments needed for model validation; conducted in-plant trials for the validation of developed technologies; and monitored progress.

\subsection{Review of Computer Models for Wax, Shell, and Alloy Deformation}

Wax deformation (die-wax interaction). At the start of phase III of this project, computer simulation programs for wax deformation had complementary features. A viscoelastic module was available in ABAQUS but unavailable in ProCAST, while the mold-filling module was available in ProCAST but unavailable in ABAQUS. Based on the work performed in phase I and II of this project, ProCAST has implemented a viscoelastic module, which now is being tested.

Shell deformation (wax-shell and shell-alloy interactions). Thermal expansion and shrinkage are the most important properties of the shell. The thermal expansion behavior of shell systems is very well reported in the literature (Straton et al.; Weddington et al., 1990; Snow 1995). Dimensional changes of the shell mold reported in the literature primarily take into account the thermal expansion characteristics of the shell. Computer models are unavailable for the numerical simulation of waxshell interaction. Computer simulations are available for the shell-alloy systems.

Modeling of alloy deformation (shell-alloy interaction). Data on mechanical properties, which are needed for the numerical simulation of alloy deformation, were not readily available, especially at high temperatures. The experimental data available for the Young's modulus was limited to $900{ }^{\circ} \mathrm{C}$. As with the thermophysical property data, the thermomechanical property data were measured and reported in several references at relatively low temperatures, i.e., $\mathrm{T}<0.5 \mathrm{~T}_{\mathrm{S}}$, where $\mathrm{T}_{\mathrm{S}}=1,430{ }^{\circ} \mathrm{C}$ is the solidus temperature. The data for yield strength near the solidus were not available and ProCAST recommendations were followed for setting the yield strength at those high temperatures. Plastic models with isotropic hardening are used in continuous casting modeling due to their easy 
computational implementation. A more complex treatment for thermo-mechanical behavior is the viscoplastic model, in which the strain rate dependence is considered. Fachinotti and Cardona (2003) reviewed data on mechanical behavior of steels, not precipitation hardening alloy in particular, and concluded that the strain-rate dependence at high temperature could have an important contribution to the mechanical behavior during continuous casting. Pierer et al. (2005) used the data provided by Kozlowski et al. (1992) for the Ramberg-Osgood and Norton's law for ST 52 steel.

\subsection{Task Breakdown}

The proposal original budget for the DOE funds was \$K 370, while only \$K 189 were received. Accordingly, the proposal original budget for the in-kind funds was reduced from \$K 567 to \$K 349 . Thus, the original scope of the project had to be narrowed.

Table 3.1 Proposed and actual budget.

\begin{tabular}{|l|l|l|l|l|l|}
\hline FY & 04 & 05 & 06 & 07 & Total \\
\hline DOE funds (original) \$K & 32 & 169 & 169 & - & 370 \\
\hline DOE funds (actual) \$K & 32 & 63 & 67 & 27 & 189 \\
\hline In-kind funds (original) \$K & 49 & 259 & 259 & - & 567 \\
\hline In-kind funds (actual) \$K & - & 311 & 26 & 12 & 349 \\
\hline
\end{tabular}

The tasks for this project were as follows:

Task 1: Design Die Molds For Wax Patterns

1.1 Select Part and Specify Design Requirements

1.2 Implement Design Requirements

1.3 Create Finite Element Meshes

1.4 Inject Wax Patterns.

1.5 Measure Wax Pattern Dimensions

Task 2: Obtain Properties of Filled Waxes and Determine Wax Shrinkage Allowance -

2.1 Measure Density and Thermal Expansion

2.2 Measure Thermal Conductivity and Specific Heat Capacity.

2.3 Measure Shear Modulus and Bulk Modulus

Task 3: Determine Shrinkage Allowance Due to Shell Molds-

3.1 Obtain Thermophysical Properties for the New Shell Materials.

3.2 Invest Shell Molds, Dewax Shell Molds, and Measure Shell Mold Dimensions

Task 4: Determine Alloy Shrinkage Allowance

4.1 Obtain Thermophysical and Thermomechanical Properties

4.2 Develop And Implement Constitutive Equations

4.3 Conduct Controlled Casting Experiments

4.4 Perform Numerical Simulations for Various Process Conditions

Task 5: Documentation and Technology Transfer

5.1 Write Reports on Shell, Wax, and Alloy Results and Approaches

5.2 Present results to professional meetings and review meetings 


\section{Results and Discussion}

In this work, deformations shell-alloy systems were considered in a coupled manner, but the coupled deformation of the wax-shell system was not considered. Therefore, the project contained tasks pertaining to each material and their interactions, which are described in distinct sections. Section 4.1 presents results for the work on shell mold material. Section 4.2 describes results for the alloy and shell-alloy deformation, and Section 4.3 deals with the wax materials.

\subsection{Shell Mold Properties}

In this section, the data on properties of alumino-silicates materials used for shell molds are reviewed. In addition, a zircon and fused silica shell system was selected (Sabau and Viswanathan, 2004), and either three or five backup coats were used. Material property data, which were not available from material suppliers, was obtained. The experimental part of the program was conducted at ORNL and commercial foundries, where wax patterns were injected, molds were invested, and alloys were poured. Due to the budget restrictions, project was funded at approximately $50 \%$ of the proposed amount, no temperature data were obtained from actual castings. For fused silica molds, the shell deformation during the prefiring phase was neglected, since the fused silica has a very low thermal expansion property, approximately five times less than that of any other shell mold material, ensuring that shell deformation during the prefiring is minimal.

\subsubsection{Material Property Data for Shell Molds}

In this section, the data on properties of alumino-silicates are reviewed. For this project, the investment of the shell molds and casting was conducted at three foundries (Table 4.1).

Table 4.1. Shell systems used. The prime coat was zircon.

\begin{tabular}{|l|l|}
\hline Company & Backup coats \\
\hline PCC & Alumino-silicate \\
\hline Viking Metalgraphics & Alumino-silicate \\
\hline SeaCast & Fused Silica \\
\hline
\end{tabular}

The shell mold suppliers provided property data that was measured. As shown in Tables 4.2 and 4.3, some properties, which are needed for the numerical simulation of thermal and deformation phenomena, were not available from the suppliers.

Table 4.2. Thermophysical properties available from suppliers and property needed for numerical simulations.

\begin{tabular}{|l|l|l|l|}
\hline Supplier & Material & $\begin{array}{l}\text { Available-Thermophysical } \\
\text { Properties }\end{array}$ & $\begin{array}{l}\text { Needed - Thermophysical } \\
\text { Properties }\end{array}$ \\
\hline $\begin{array}{l}\text { C-E } \\
\text { Minerals }\end{array}$ & Mulcoa 47 & $\begin{array}{l}\text { Density, Porosity, Reheat } \\
\text { Change (\% vol) }\end{array}$ & $\begin{array}{l}\text { specific heat, thermal } \\
\text { conductivity }\end{array}$ \\
\hline Remet & Remasil 48 & Density, Porosity & $\begin{array}{l}\text { specific heat, thermal } \\
\text { conductivity }\end{array}$ \\
\hline $\begin{array}{l}\text { Ransom \& } \\
\text { Randolph }\end{array}$ & - & Density & $\begin{array}{l}\text { specific heat, thermal } \\
\text { conductivity }\end{array}$ \\
\hline Minco & Fused silica & Yes & None \\
\hline
\end{tabular}


Table 4.3. Thermo-mechanical properties available from suppliers and property needed for numerical simulations

\begin{tabular}{|l|l|l|l|}
\hline Supplier & Material & $\begin{array}{l}\text { Available-Thermo- } \\
\text { mechanical Properties }\end{array}$ & $\begin{array}{l}* * * \text { Needed - Thermo- } \\
\text { mechanical Properties }\end{array}$ \\
\hline C-E Minerals & Mulcoa 47 & None & $\begin{array}{l}\text { Thermal expansion, Youngs } \\
\text { modulus, Poisson ratio }\end{array}$ \\
\hline Remet & Remasil 48 & $\begin{array}{l}\text { Coefficient of thermal } \\
\text { expansion, Thermal } \\
\text { expansion }\end{array}$ & $\begin{array}{l}\text { Youngs modulus, Poisson } \\
\text { ratio }\end{array}$ \\
\hline $\begin{array}{l}\text { Ransom \& } \\
\text { Randolph }\end{array}$ & - & none & $\begin{array}{l}\text { Thermal expansion, Youngs } \\
\text { modulus, Poisson ratio }\end{array}$ \\
\hline Minco & Fused silica & $\begin{array}{l}\text { Youngs modulus, Snow, } \\
\text { 2004) }\end{array}$ & $\begin{array}{l}\text { Thermal expansion, Youngs } \\
\text { modulus as a function of } \\
\text { temperature, Poisson ratio }\end{array}$ \\
\hline
\end{tabular}

***For large parts, or for shell molds that are exposed to high temperatures for long times, the creep properties are needed also.

The following properties were provided by Remet for the Remasil 48 shell mold: Density $(2.62 \mathrm{~g} / \mathrm{cc}$, Thermal expansion 5.3E-6 in./in./F, and Porosity (3.6).

A literature review was conducted on thermophysical properties alumino-silicates to find data on those properties that were not available from material suppliers (Table 4.3). It was found that the thermal conductivity was either constant, with values from 0.75 to $1 \mathrm{~W} / \mathrm{mK}$, or temperature dependent with increasing values. At high temperatures, such as those for the steel casting, the shell molds become semi-transparent, effect that can be thought of as an increase in thermal conductivity of the mold (for fused silica, Sabau and Viswanathan, 2004). This effect was not observed in the data shown in Table 4.4. This could be explained by the fact that Browne and Sayer (1995) and O'Mahoney and Browne (2000) investigated the properties of alumino-silicates for the investment casting of aluminum alloy, a relatively low temperature domain as compared to that for steel casting. The other studies were not performed for investment casting molds. Russell et al. (1987) obtained data for thermal conductivity, specific heat, and thermal expansion of mullite. Table 4.5 shows some data available for the heat transfer coefficients for alumino-silicates shell systems.

Achari and Satapathy (2003) showed data on Youngs modulus for mullite that was fabricated by isostatic pressing, extrusion, and ramming processes. A review of mechanical properties of aluminosilicates, including those of alumina, is presented in Table 4.6. Munro (2004) presented an analytical relationships for the temperature and porosity dependence of the elastic and bulk moduli of polycrystalline ceramics, which was applied for twenty four oxide ceramics, as:

$E(T, \phi)=229(1-1.17 \mathrm{E}-4 T)(1-\phi)^{3.33}$
$G(T, \phi)=166(1-1.16 \mathrm{E}-4 T)(1-\phi)^{3.15}$,

where $\mathrm{E}$ is the Youngs modulus, $\mathrm{G}$, bulk modulus, $\phi$, porosity, and $\mathrm{T}$, temperature. 
Table 4.4 Thermophysical properties reported for the investment casting shell molds.

\begin{tabular}{|c|c|c|c|c|}
\hline Property & Material & Values & Temperature $\left({ }^{\circ} \mathrm{C}\right)$ & Reference \\
\hline Emissivity & $\begin{array}{l}\text { alumino- } \\
\text { silicate }\end{array}$ & 0.615 & 400 to 700 & Browne and Sayer (1995) \\
\hline Emissivity & alumina & $0.8,0.8,0.4,0.4$ & $\begin{array}{l}\text { RT; 100; 1,100; } \\
1,600\end{array}$ & Touloukian (1972) \\
\hline $\begin{array}{l}\text { Thermal conductivity } \\
(\mathrm{W} / \mathrm{mK})\end{array}$ & $\begin{array}{l}\text { alumino- } \\
\text { silicate }\end{array}$ & 1.0 & 400 to 700 & Browne and Sayer (1995) \\
\hline $\begin{array}{l}\text { Thermal conductivity } \\
(\mathrm{W} / \mathrm{mK})\end{array}$ & molochite & $0.6,0.85,0.78,1.16$ & $\begin{array}{l}170,210,300, \\
325\end{array}$ & Browne and Sayer (1995) \\
\hline $\begin{array}{l}\text { Thermal conductivity } \\
(\mathrm{W} / \mathrm{mK})\end{array}$ & molochite & 0.75 & 400 to 700 & $\begin{array}{l}\text { O'Mahoney and Browne } \\
(2000)\end{array}$ \\
\hline $\begin{array}{l}\text { Thermal conductivity } \\
(\mathrm{W} / \mathrm{mK})\end{array}$ & mullite & $\begin{array}{l}2.1,1.4,1.2,1.1 \text {, } \\
1.0 \text {, and } 0.8\end{array}$ & $\begin{array}{l}\mathrm{RT}, 300,400, \\
500,700 \text {, and } \\
1,500\end{array}$ & Russell et al. (1987) \\
\hline Specific heat $(J / g K)$ & $\begin{array}{l}\text { alumino- } \\
\text { silicate }\end{array}$ & 0.8 & 400 to 700 & Browne and Sayer (1995) \\
\hline Specific heat $(J / g K)$ & molochite & $1.02,1.14$ & 300,700 & $\begin{array}{l}\text { O'Mahoney and Browne } \\
(2000)\end{array}$ \\
\hline Specific heat $(J / g K)$ & mullite & $\begin{array}{l}0.13901 * \ln (\mathrm{T}[\mathrm{C}])+ \\
0.28668\end{array}$ & RT to $1,400 \mathrm{C}$ & Goodson (1997) \\
\hline
\end{tabular}

Table 4.5. Heat transfer coefficient at metal-mold interface

(obtained for Inconel 718 alloy by Sahai and Overfelt, 2000)

\begin{tabular}{|c|c|c|}
\hline $\begin{array}{c}\mathrm{HTC} \\
\mathrm{W} / \mathrm{m}^{2} \mathrm{~K}\end{array}$ & $\begin{array}{c}\text { Metal Temperature } \\
{ }^{\circ} \mathrm{C}\end{array}$ & Casting Configuration \\
\hline 200 & 1,300 & cylinder \\
\hline 100 & 850 & cylinder \\
\hline 5,000 & 1,400 & plate \\
\hline 100 & 1,100 & plate \\
\hline
\end{tabular}

Table 4.6. Mechanical properties reported in the literature for alumino-silicates.

\begin{tabular}{|c|c|c|c|c|}
\hline Property & Material & Value & $\begin{array}{l}\text { Variables, } \\
\text { Temperature } \\
\left({ }^{\circ} \mathrm{C}\right) \\
\end{array}$ & Reference \\
\hline E, creep rate & \begin{tabular}{|l} 
Sintered, \\
porous \\
alumina \\
\end{tabular} & & $\begin{array}{l}\text { RT, } 1100 \\
\text { Porosity }\end{array}$ & Hammond and Elzey (2004) \\
\hline $\begin{array}{l}\text { E }(G P a), \text { Poisson } \\
\text { ratio, creep rate }\end{array}$ & $\begin{array}{l}\text { Sintered } \\
\text { Alumina }\end{array}$ & $\begin{array}{l}\mathrm{E}=417- \\
0.0525 * \mathrm{~T}\end{array}$ & & Munro (1997) \\
\hline$G(G P a)$ & \begin{tabular}{|l|} 
Sintered \\
Alumina \\
\end{tabular} & $\mathrm{G}=252 *(1-\phi)^{5}$ & Porosity & Munro (2001) \\
\hline $\begin{array}{l}\text { E (GPa) (green } \\
\text { shell) }\end{array}$ & molochite & $\begin{array}{l}1-3 \\
3-6\end{array}$ & $\begin{array}{l}\text { Shell thickness, } \\
\mathrm{z}<3.5 \mathrm{~mm} ; \\
\mathrm{z}>3.5 \mathrm{~mm}\end{array}$ & Jones et al. (2002) \\
\hline Creep rate & Fused silica & & 400 to 700 & Wereszczak et al. (2002) \\
\hline$E(G P a) ; G(G P a)$ & mullite & Eq. 4.1 and 4.2 & $\begin{array}{l}\text { Temperature; RT } \\
\text { to } 900 \text {; porosity }\end{array}$ & Munro (2004) \\
\hline
\end{tabular}




\subsubsection{Material Property Data for Fused-silica Shell Molds}

The thermal expansion of the shell mold was available from Snow (1995). The shell material shows extremely small thermal expansion on heating (Figure 4.1). Sintering is evidenced by a change from expansion to contraction at approximately $900^{\circ} \mathrm{C}$. The data were obtained by holding the shell mold for 2 hours at $1200^{\circ} \mathrm{C}$. During cooling, the thermal contraction of the shell is larger than the expansion for heating, reaching $0.3 \%$ at $200{ }^{\circ} \mathrm{C}$. Due to crystoballite formation, the thermal contraction occurs at a different rate from $200{ }^{\circ} \mathrm{C}$ to room temperature. The thermal expansion of the shell mold is still much smaller than the thermal expansion of the alloy. Since insignificant thermal expansion occurs during heating, the dimensions of the shell mold do not change from room temperature until the metal is poured. This distinct behavior during heating and cooling of the fused silica shell molds is very important since the shell dimensional changes prior to metal pouring can be neglected. For alumino-silicate molds, this is not the case since their thermal expansion is significantly larger than that of the fused silica molds. Moreover, since the shell is much less stiff than the steel, its contraction behavior below $1200{ }^{\circ} \mathrm{C}$ is expected to alter the gap between the mold and casting while inducing insignificant deformation in the steel casting.

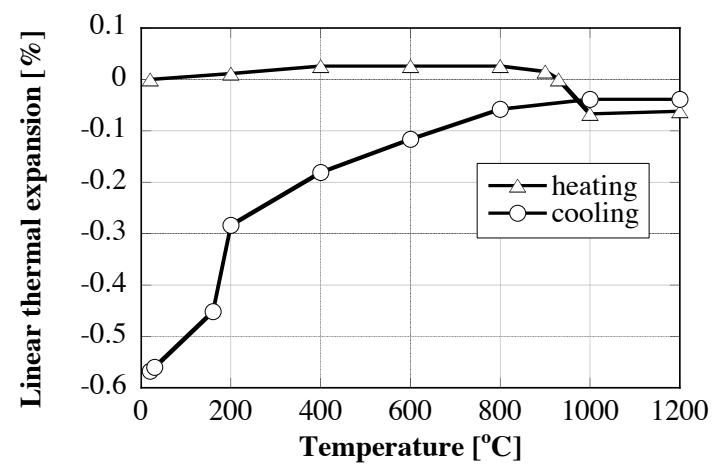

Figure 4.1. Measured linear thermal expansion for the shell mold (Snow, 1995).

The shell mold contained the following types of substrates: face coats, intermediate coats, backup coats, and seal coats. Each coat was generally made of two layers, a slurry layer and a stucco layer. In this study, zircon and fused silica shell materials were used (Sabau and Viswanathan, 2004). The shell mold had eight coats: a zircon prime coat, one intermediate coat, five backup coats, and one seal coat. The shell mold thickness was approximately $8.5 \mathrm{~mm}$.

In order to account for thermal radiation effects within the shell mold, the following relationship proposed by Sabau and Viswanathan, (2004) for temperature dependence of thermal conductivity, $k$, was used:

$$
k(T)=a_{k}+b_{k} T^{3}
$$

For a shell mold with a thickness of approximately $8.5 \mathrm{~mm}$, parameters $a_{k}$ and $b_{k}$ were found to be 0.48 and $3.6110^{-10}$, respectively (Sabau, 2005). The shell mold was considered to be a linear-elastic material, for which the Young's modulus at $25^{\circ} \mathrm{C}$ was approximately $2,586 \mathrm{MPa}$ (Snow, 2004). The temperature dependence of Young's modulus was that provided by Fukuhara and Sanpei (1994) and Munro (2004) for fused silica. 


\subsection{Alloy Properties and Mechanical Interaction for the Shell-Alloy System}

In this section, the first attempt to determine shrinkage factors for the investment casting of stainless steels is presented. For all the properties of $17-4 \mathrm{PH}$ stainless steel, the experimental data available in the literature did not cover the entire temperature range necessary for process simulation. Thus, some material properties were evaluated using ProCAST, based on CompuTherm database. A comparison between the predicted material property data and measured property data was made. It was found that most material properties were accurately predicted only over several temperature ranges. No experimental data for plastic modulus were found. Thus, several assumptions were made and ProCAST recommendations were followed in order to obtain a complete set of mechanical property data at high temperatures. Thermal expansion measurements for the 17-4PH alloy were conducted during heating and cooling. As a function of temperature, the thermal expansion for both the alloy and shell mold materials showed different evolution on heating and cooling.

Section 4.2 is concerned with determining the alloy tooling allowances from a combined analysis of heat transfer and deformation of the casting process. The shell molds were made of fused silica with a zircon prime coat, as shown in previous sections. The wax patterns were invested at Minco, Inc., and casting experiments were conducted at Precision Metalsmiths, Inc. (PMI). Dimensions of the die tooling, wax pattern, and casting were measured using a Coordinate Measurement Machine. Numerical simulations were performed using ProCAST for the investment casting of 17-4PH stainless steel parts in fused silica molds using the thermal expansion obtained on heating and another one with thermal expansion obtained on cooling. Since the fused silica shells had the lowest thermal expansion properties in the industry, the dewaxing phase, including the coupling between wax-shell systems, was neglected. The shell mold was considered to be a pure elastic material. The alloy dimensions were obtained from numerical simulations. For 17-4PH stainless steel parts, the alloy shrinkage factors were over-predicted, as compared with experimental data.

\subsubsection{Thermophysical Material Property for 17-4PH steel}

The first step in predicting alloy shrinkage factors was to obtain data on thermophysical properties of 17-4PH alloy. Experimental data on material properties were reviewed. Experimentally measured data on specific heat and thermal conductivity were provided in Fieldhouse and Lang (1961) for temperatures less than 1200 and $1395{ }^{\circ} \mathrm{C}$, respectively. Experimental data on density and thermal expansion were available from measurements reported for heating by Touloukian et al. (1979) and Rack (1981) (up to $940{ }^{\circ} \mathrm{C}$ ). No experimental data were available for the solidification properties, such as solidus, liquidus, and distribution of solid fraction. Thus, it was found that the material properties for 17-4PH alloy, which were required for the numerical simulations, were not available over the entire temperature domain experienced in the process (from the liquidus to room temperature). In order to obtain the material property data at high temperatures, computational techniques were reviewed. Recent advances in thermodynamics and material science were exploited to obtain data on material properties (Guo and Samonds, 2007). For example, the CompuTherm database (Chen et al., 2003) for molar volume and thermal volume coefficients of expansion (CTE) of liquid, solid solution elements, and intermetallic phases, was used to estimate the densities of the liquid and solid phases (Guo and Samonds, 2007). However, these methods have not been validated for stainless steel alloys, such as 17-4PH. Next, CompuTherm software available with ProCAST ${ }^{\mathrm{TM}}$ was used to obtain the data on specific heat (Figure 4.2a), enthalpy, latent heat, electrical conductivity and resistivity, thermal conductivity (Figure 4.2b), solid fraction (Figure 4.2c), density (Figure 4.2d), and liquid viscosity. Where available, the experimental data are also shown in Figure 4.2. The composition, \% wt, that used in CompuTherm simulations was $\mathrm{Al} 0.002$, B 0.002, Cd 0.2, C 0.027, Cr 15.21, Co 0.05, Cu 3.47, Mn 0.63, Mo 0.1, Ni 4.44, N 0.02, P 0.028, Si 0.43, S 0.026, Ta 0.022, Ti 0.002 , Fe balance. The estimated properties using ProCAST were compared against experimental data. It was found that the following properties were predicted with a high degree of accuracy: 
specific heat, thermal conductivity (above about $750{ }^{\circ} \mathrm{C}$ ), density and thermal expansion during heating.

Based on this good agreement between the experimental and estimated property data, a complete set of material property data was created by combining the experimental data that were available at low/moderate temperatures with estimated data at high temperatures. Table 4.7 shows which experimental and estimated data were used to create the material property data set for thermophysical properties. For example, the density data, which were used in the simulations, were created by shifting the estimated data such that they would be in good agreement with the experimental data (Figure 4.2d). For thermal conductivity, the estimated data below $700{ }^{\circ} \mathrm{C}$ were discarded.

(a)
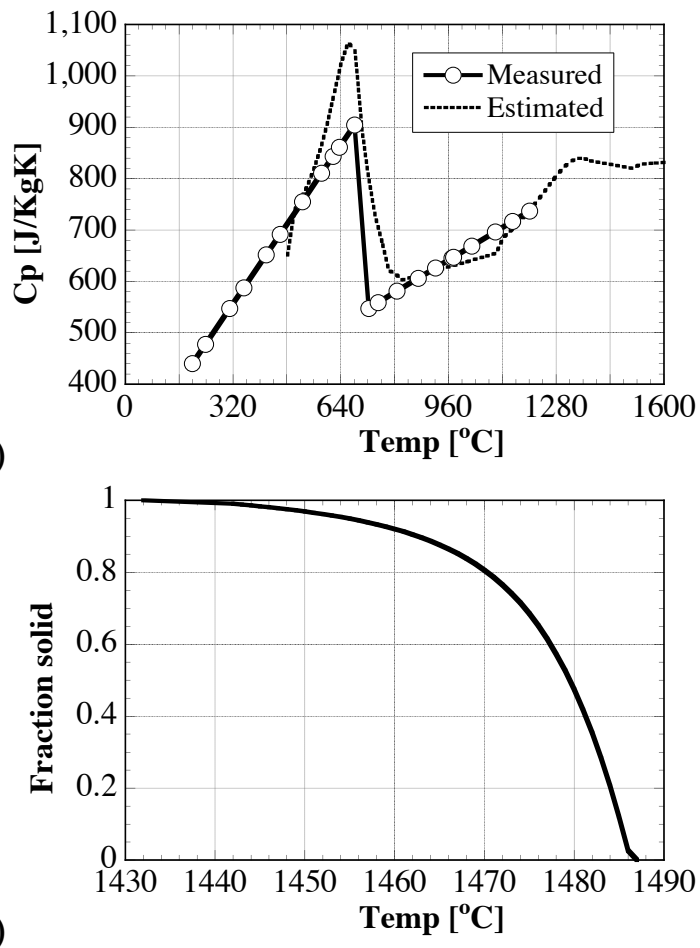

(b)

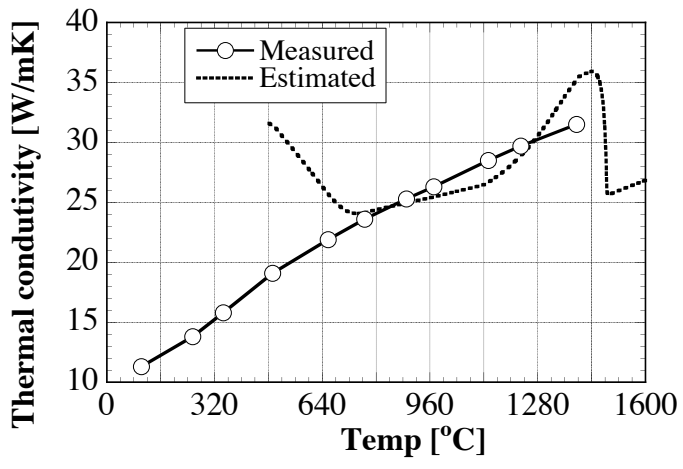

(d)

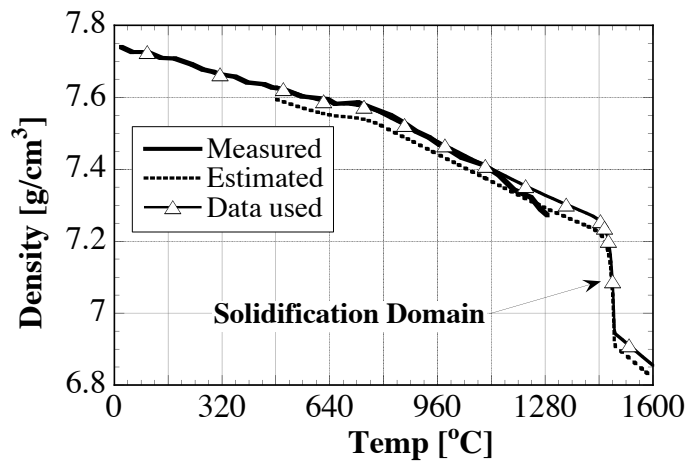

Figure 4.2. Thermophysical properties for 17-4PH alloy, (a) specific heat, (b) thermal conductivity, and (c) fraction solid, (d) density. Density was obtained from thermal expansion data on heating.

Table 4.7 References for Measured Data on Material Property.

\begin{tabular}{|l|l|l|}
\hline Property & Reference for measured data & $\begin{array}{l}\text { Property used in numerical } \\
\text { simulations }\end{array}$ \\
\hline Fraction solid & - & Estimated \\
\hline $\begin{array}{l}\text { Density (Thermal } \\
\text { expansion) }\end{array}$ & Touloukian et al. (1979) & $\begin{array}{l}\text { combined measured and } \\
\text { estimated data }\end{array}$ \\
\hline Specific heat & Fieldhouse and Lang (1961) & estimated \\
\hline Thermal conductivity & Fieldhouse and Lang (1961) & $\begin{array}{l}\text { combined measured and } \\
\text { estimated data }\end{array}$ \\
\hline
\end{tabular}

Thermal contraction during cooling is a very important property for dimensional predictions. Since density and thermal expansion were available only on heating, thermal expansion measurements in the $20-1360{ }^{\circ} \mathrm{C}$ temperature range were carried out using a push rod dilatometer (Porter and Maziasz, 
1993; Frankel et al., 2005). Three measurement runs were performed in flowing helium using heating and cooling rates of $3{ }^{\circ} \mathrm{C} / \mathrm{min}$. The experimental results show an excellent reproducibility (Figure 4.3a) for the three runs considered. The data show that the curves for heating and cooling do not follow the same behavior. During heating the 17-4PH alloy is primarily composed of a tempered martensite phase up to about $700{ }^{\circ} \mathrm{C}$ where this phase starts to transform to the austenite phase. This transformation is accompanied by both a volumetric contraction and a larger CTE for the austenite phase. Both of these effects are evident in the heating curve of Figure 4.3a. During cooling, at approximately $265^{\circ} \mathrm{C}$, the alloy shows an abrupt expansion (rather than continued contraction). This expansion is brought about by the transformation of the high temperature austenite phase back to martensite. The exact temperature for the start of this transformation, $\mathrm{M}_{\mathrm{s}}$, is determined by the chemical composition of the austenite. In the dilatometer runs of this study, conducted at cooling rates of $3{ }^{\circ} \mathrm{C} / \mathrm{min}$, carbides can precipitate below $800{ }^{\circ} \mathrm{C}$ which will change the austenite composition, thus raising $\mathrm{M}_{\mathrm{s}}$ considerably above room temperature (Irvine et al., 1979). The overall thermal expansion/contraction on heating and cooling, from room temperature to high temperatures to room temperature, was about the same.

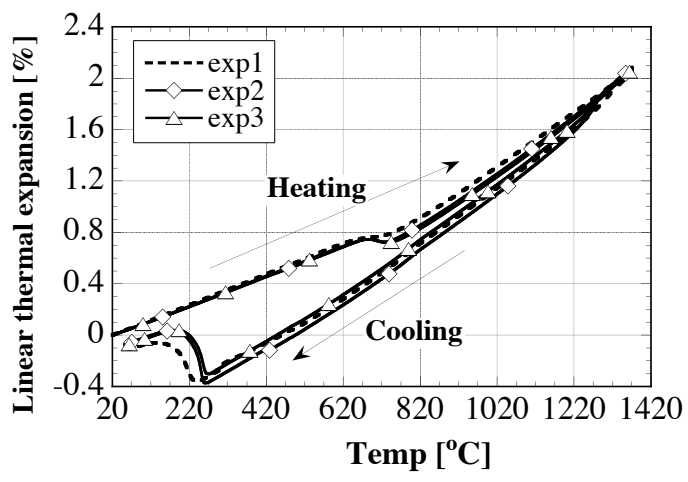

Figure 4.3. Measured linear thermal expansion for 17-4PH alloy on heating and cooling.

\subsubsection{Thermomechanical Material Property for 17-4PH steel}

The data on mechanical properties, which are needed for the numerical simulation of alloy deformation, were not readily available, especially at high temperatures. The experimental data available for the Young's modulus was limited to $900{ }^{\circ} \mathrm{C}$. As with the thermophysical property data, the thermomechanical property data were measured and reported in several references at relatively low temperatures, i.e., $\mathrm{T}<0.5 \mathrm{~T}_{\mathrm{S}}$, where $\mathrm{T}_{\mathrm{S}}=1,430{ }^{\circ} \mathrm{C}$ is the solidus temperature. A literature review was conducted on elasticity and plasticity properties for 17-4PH or 15-5PH (Table 4.8). Using the same methodology from Guo and Samonds (2007) the liquid viscosity, Young's modulus, and Poisson's ratio were estimated. The measured data and estimated data for Young's modulus are shown in Figure 4.4a. For temperatures between $700-900{ }^{\circ} \mathrm{C}$, the estimated Young's modulus was in good agreement with experimental data. The ProCAST data at temperatures lower than $750{ }^{\circ} \mathrm{C}$ were excluded from the newly generated set of data for the Young's modulus. Figure $4.4 \mathrm{~b}$ shows the data For Young's modulus only in the high temperature domain. 
Table 4.8. Thermo-mechanical properties available from suppliers and published references for 17-4PH or 15-5PH stainless steels.

\begin{tabular}{|l|l|l|}
\hline Property & $\begin{array}{l}\text { Temperature } \\
\text { range }\left[{ }^{\circ} \mathrm{C}\right]\end{array}$ & References/Notes \\
\hline Yield strength & $20: 400$ & Wu and Lin (2003) \\
\hline Young's modulus & $20: 500$ & Sandmeyer (2005) \\
\hline $0.2 \%$ YS, Elongation \% & $540: 1090$ & AK Steel, 17-4PH data \\
\hline Young's modulus & $20: 315$ & AK Steel, 15-5PH data \\
\hline Yield strength & $20: 540$ & ASM alloy Center: Materials Property Data \\
\hline $\begin{array}{l}\text { Stress strain curves, Ramberg- } \\
\text { Osgood }\end{array}$ & $25: 480$ & MMPDS, 15-5PH data, compression \\
\hline Stress strain curves & $950: 1250$ & Atlas of Formability (ABAQUS format) \\
\hline
\end{tabular}
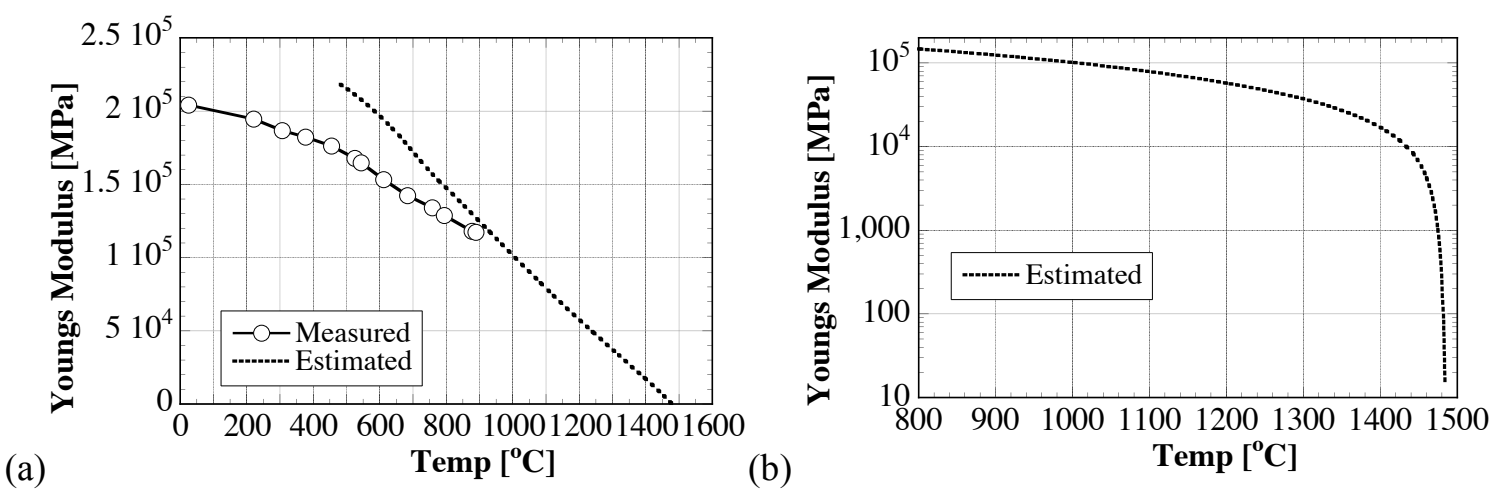

Figure 4.4. Modulus of elasticity for 17-4PH alloy (Experimental data from Rack, 1981)

(a) over large temperature domain, (b) at high temperature.

One important parameter that describes the plasticity behavior is the yield stress. The data on plasticity for these alloys are scarce and do not include the entire temperature domain (Table 4.8). The yield strength, which was estimated from data found in the Appendix A, is shown in Table 4.9. The ASM Alloy Center published data at a temperature range of 25 to $650{ }^{\circ} \mathrm{C}$ (Table 4.9). The data for yield strength near the solidus were not available and ProCAST recommendations were followed for setting the yield strength at those high temperatures. In summary, Table 4.9 shows the yield strength used for simulations was obtained by taking into account the data set from ASM, Atlas of formability, and ProCAST recommendations. In the simulations, a linear temperature variation between consecutive data points was assumed.

Several advanced models for the numerical simulation of stress, strain, and the ensuing displacement fields during casting have been developed in academia over the last decade (Bellet et al., 1996, Drezet and Rappaz, 1996). These models were recently implemented in commercial simulation software ProCAST $^{\mathrm{TM}}$. According to the small strain theory, the total strain can be decomposed into strain components that correspond to the elastic, viscoplastic, thermal, and liquid-solid phase transformation effects. The elastic strain was related to the internal stresses by Hook's law. For aluminum alloys, Bellet et al. (1996) developed a methodology for modeling casting solidification by including constitutive equations for the mushy zone and liquid regions into a solid model that is based on Perzyna (1963). 
Table 4.9. Yield stress as a function of temperature.

\begin{tabular}{|c|c|c|c|}
\hline Temp. $\left[{ }^{\circ} \mathrm{C}\right]$ & $\begin{array}{c}\mathrm{X}_{\text {Estimated }} \\
(\text { AOF })\end{array}$ & $\begin{array}{c}\text { ASM Alloy } \\
\text { Center }\end{array}$ & $\begin{array}{c}\text { Data used in } \\
\text { this study }\end{array}$ \\
\hline 25 & & 1158 & 1158 \\
\hline 204 & & 958 & 958 \\
\hline 315 & & 931 & 931 \\
\hline 371 & & 903 & 903 \\
\hline 427 & & 889 & 889 \\
\hline 482 & & 814 & 814 \\
\hline 538 & & 696 & 696 \\
\hline 650 & & $283^{*}$ & 283 \\
\hline 950 & 104 to 85 & & 104 \\
\hline 1000 & 45 & & \\
\hline 1050 & 35 & & \\
\hline 1100 & 25 & & \\
\hline 1150 & 17 & & \\
\hline 1200 & 9 & & \\
\hline 1250 & 7 & & \\
\hline $1432 * *$ & & & \\
\hline $1487 * * * 21$ & \\
\hline
\end{tabular}

*Data for $15-5 \mathrm{PH}$

$\mathrm{x}_{\text {Estimated from Atlas of Formability (AOF) data }}$

**solidus point, yield strength for H13 steel available in ProCAST

***liquidus point, yield strength above $5 \mathrm{MPa}$ for fs $<50 \%$ (ProCAST recommendations)

The stress module was coupled with the fluid flow module in ProCAST, such that appropriate constitutive equations were available for the liquid, semi-solid, and solid states that coexist during casting solidification. The elasto-plastic model based on the linear hardening law is defined as:

$\sigma_{Y}=\sigma_{o}+H \varepsilon^{p l}$

where $\sigma_{o}=$ the yield stress, $\varepsilon^{p l}=$ the plastic strain, and $H=$ the plastic modulus, and $\sigma_{Y=\text { the }}$ modified yield stress due to linear hardening. Depending on the amount of solid fraction, deformation and/or fluid flow phenomena take place. The transition from fluid dynamics to solid dynamics was considered to take place at a certain solid fraction. Since no experimental data were available for the critical solid fractions for thermomechanical behavior of $17-4 \mathrm{PH}$, the fluid-solid dynamics transition was considered to occur at the solid fraction of 0.90 , which was found to be appropriate for the numerical simulation of shrinkage deformation of A356 aluminum alloy (Sabau, 2006).

Plastic models with isotropic hardening are used in continuous casting modeling due to their easy computational implementation. A more complex treatment for thermo-mechanical behavior is the viscoplastic model, in which the strain rate dependence is considered. Fachinotti and Cardona (2003) reviewed data on mechanical behavior of steels, not precipitation hardening alloy in particular, and concluded that the strain-rate dependence at high temperature could have an important contribution to the mechanical behavior during continuous casting. The viscoplastic behavior is described by the following equation: 
$\dot{\varepsilon}^{p l}=\frac{1}{\eta}\left\langle|\sigma|-\sigma_{Y}\right\rangle^{n} \frac{\sigma}{|\sigma|}$,

where $\sigma$ is the applied stress, $n$ is the power exponent, $\eta$ is a viscous parameter. The operator $<$. $>$ is defined as $\langle f\rangle=f$ when $f \geq 0$ and zero otherwise. Both $n$ and $\eta$ are temperature dependent coefficients. For example, at low temperatures when the alloy tends to behave elastoplastic, $n$ has very large values while $\eta$ has very small values. The plasticity property data did not cover the entire temperature range needed and the data for plastic modulus were especially difficult to find.

The only data available to estimate $n$ and $\eta$ parameters were the true-stress true-strain data from the Atlas of Formability. The limited temperature range for the Atlas of Formability data hinders the use of this data, as data at low temperatures and near the solidus are not available. Other options would be to use viscoplastic data that were obtained for other steels (Table 4.10). Pierer et al. (2005) used the data provided by Kozlowski et al. (1992) for the Ramberg-Osgood and Norton's law for ST 52 steel. Thus, for isotropic linear hardening, ProCAST recommends the use of a fraction of the Young's modulus, i.e., $\mathrm{H}=\mathrm{E} / 20$.

Table 4.10 Mechanical properties for other steels than 17-4PH.

\begin{tabular}{|l|l|l|l|l|}
\hline Property & Material & Equation, Property & $\begin{array}{l}\text { Temperature } \\
\text { Range }\left({ }^{\circ} \mathrm{C}\right)\end{array}$ & Reference \\
\hline$E, Y_{0.2}$ & $\begin{array}{l}\text { Stainless steel } \\
(304)\end{array}$ & $\begin{array}{l}\text { Ramberg-Osgood, } \\
\text { stress-strain model }\end{array}$ & RT & Abdella (2006) \\
\hline $\begin{array}{l}E, Y_{0.2}, Y_{0.5}, \\
Y_{1.5}, Y_{2.0}\end{array}$ & $\begin{array}{l}\text { EN 1.4462, AISI } \\
304\end{array}$ & stress strain model & RT to 960 & Chen and Young (2006) \\
\hline Creep rate & $\begin{array}{l}\text { Continuous } \\
\text { casting steel }\end{array}$ & $\begin{array}{l}\text { Creep law, stress-strain } \\
\text { model }\end{array}$ & Below solidus & Kajitani et al. (2001) \\
\hline Creep rate & Austenitic steels & Norton's law & Below solidus & Kozlowski et al. (1992) \\
\hline E, creep rate & $\begin{array}{l}\text { Low carbon } \\
\text { steels }\end{array}$ & $\begin{array}{l}\text { Viscoplasticity, } \\
\text { hardening }\end{array}$ & Below solidus & $\begin{array}{l}\text { Fachinotti and Cardona } \\
(2003)\end{array}$ \\
\hline
\end{tabular}

E - Young's modulus, $\mathrm{Y}_{\mathrm{X}}-$ Yield strength at $\mathrm{x} \%$ of strain, $\mathrm{T}-$ temperature

\subsubsection{Experimental Results for Alloy Shrinkage Factors}

Parts with six steps were examined in this study (Figure 4.5). The 2.54-cm-thick step is considered to be Step 1. Two types of stepped parts were made: parts without holes and parts with holes on steps 3 and 5. In the remainder of this study, alloy castings and wax patterns are simply referred to as parts and patterns. The patterns without holes and patterns with two holes are referred to as no-hole, or unrestrained, patterns and two-hole, or restrained, patterns, respectively. The two-hole patterns were made by placing cores in the die. The two cores provided geometrical restraint on the length dimension of the part. For this work, wax patterns were made at M. Argueso \& Co by injection of liquid unfilled wax, Cerita $^{\mathrm{TM}} 29-51$, at a pressure of $1.7 \mathrm{MPa}(250 \mathrm{psi})$, at $65^{\circ} \mathrm{C}\left(150^{\circ} \mathrm{F}\right)$, with a dwell time of $120 \mathrm{~s}$.

The casting configuration considered in this study contains a downsprue, a runner, and one casting (Fig. 4.6). The sprue was dimensioned such that there was enough metallostatic head to fill the entire part. The height of the downsprue and pouring cup is $17 \mathrm{~cm}$ and $6.35 \mathrm{~cm}$, respectively. The section dimensions for the pouring cup were $6.35 \times 6.35,2.54 \times 2.54$, and $2.54 \times 1.9 \mathrm{~cm}$ at the top of pouring cup, end of pouring cup, and end of sprue, respectively. The molds were preheated at temperatures of $1000^{\circ} \mathrm{C}\left(1830^{\circ} \mathrm{F}\right)$ for $45 \mathrm{~min}$. 


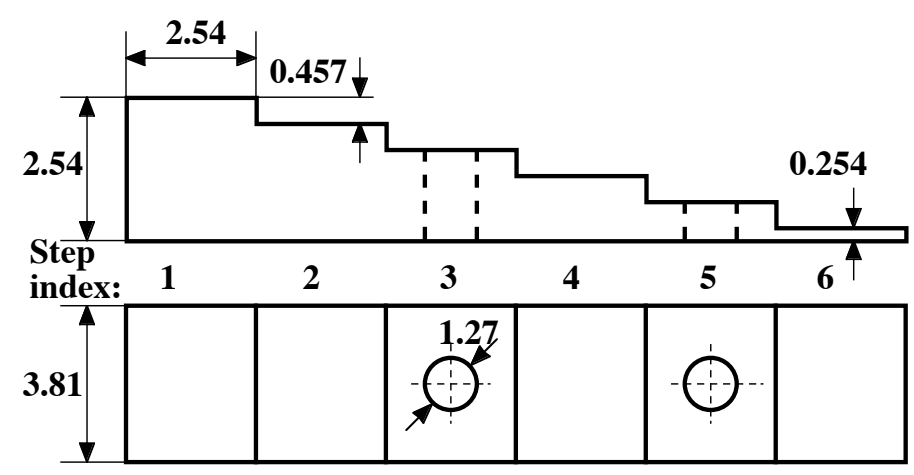

Figure 4.5: Wax pattern dimensions $[\mathrm{cm}]$ and step index.

(a)

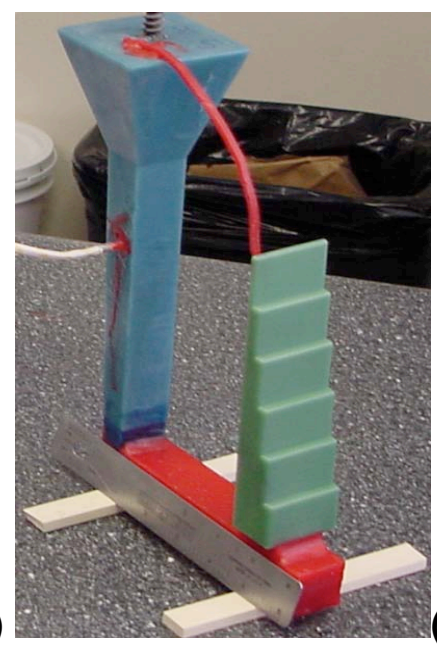

(b)

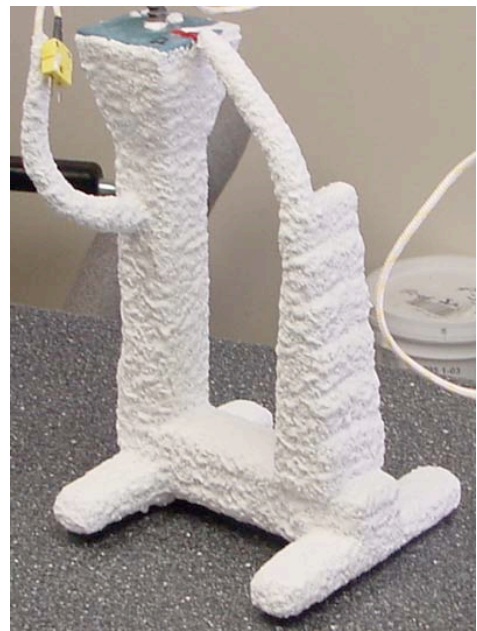

(c)

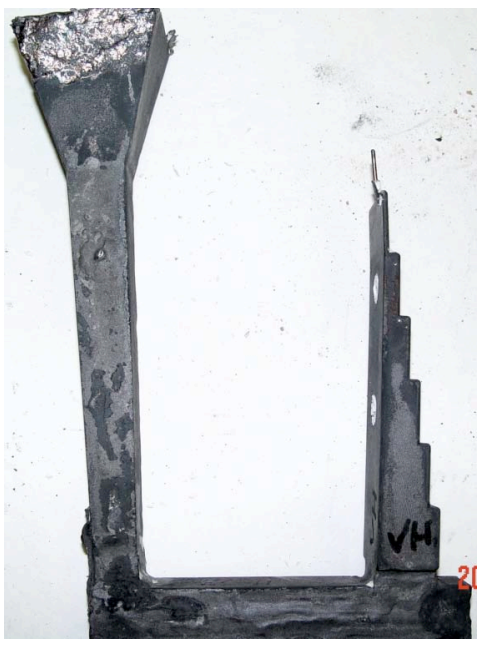

Fig. 4.6. Shell molds invested at Minco and cast at PMI: (a) wax pattern; (b) shell mold; (c) steel casting.

Dimensions of the die tool, wax patterns, and casting were measured at the same locations using a Coordinate Measurement Machine (CMM). CMMs are widely used throughout manufacturing industries to meet the high quality standards and dimensional accuracy. The probe size of the CMM was $3 \mathrm{~mm}$ diameter. The probe tips were round to within $0.0005 \mathrm{~mm}$ and the diameters were within $0.003 \mathrm{~mm}$ of nominal diameter. The probe tip actual diameter was calibrated against a reference sphere with a roundness uncertainty of plus or minus $0.0001 \mathrm{~mm}$ and a diameter uncertainty of $0.0002 \mathrm{~mm}$. The measurement precision was plus or minus $0.02 \mathrm{~mm}$.

Wax pattern dimensions were measured to provide a base line for casting dimensions. The wax patterns were examined under magnification to insure that no deformation was present in the surfaces after probing. The position of CMM measurement points are shown in Figure 4.7. The width shrinkage was calculated from the width coordinates for each pair of points, which were located at the same length and height but situated at opposite sides of the pattern. A representative length dimension was chosen to be $L 2 \_5$, between the ends of Steps 2 and 5. Four no-hole patterns and four two-hole patterns were injected. Since the wax pattern showed good reproducibility, only two castings were made for each case. The parts were labeled as shown in Table 4.11. 


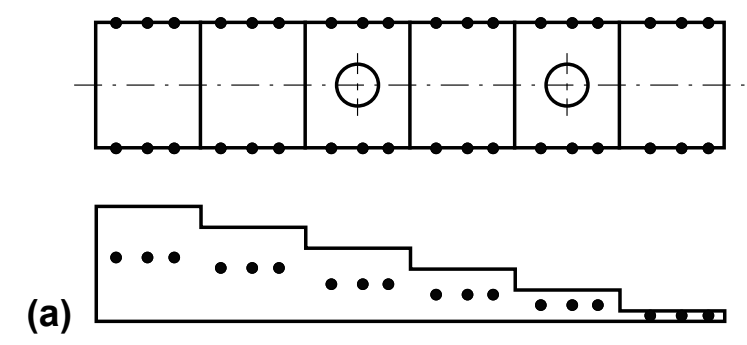

(b)

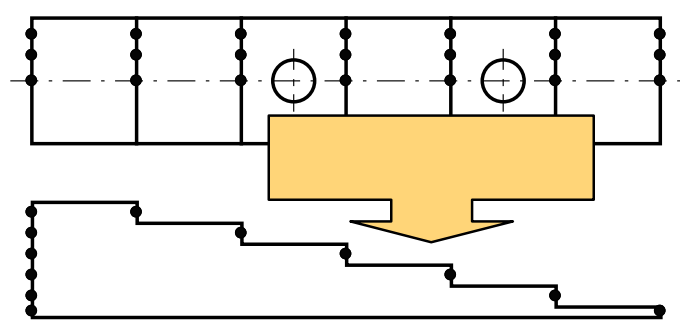

Fig. 4.7. The position of coordinate measurement points for (a) the width dimensions and $(b)$ length L2-5, between ends of Steps 2 and 5.

Table 4.11. Index of wax patterns and castings

\begin{tabular}{ccc}
\hline Part index & No. of holes in part & Part no. \\
\hline 0b1 & - & 1 \\
0b2 & - & 2 \\
2b1 & 2 & 1 \\
${ }^{*} 2 \mathrm{~b} 2$ & 2 & 2 \\
\hline
\end{tabular}

*The last step in the casting was incompletely filled and dimensions were not measured

The dimensional variations for the casting were calculated using the following relationship:

$$
\text { Casting shrinkage }\left(\mathrm{c}_{\mathrm{s}}\right)=\underline{\text { Pattern dimensions- }} \text { - Casting Dimensions }
$$

The percentage of the shrinkage was calculated for the width dimension and length dimension (Figures 4.8). The width shrinkage was almost the same for cases $2 \mathrm{~b} 1$ and $0 \mathrm{~b} 2$. Part $0 \mathrm{~b} 1$ showed lower shrinkage factors for steps 3, 4, 5, and 6, than the other two parts. For the L2_5 dimension, the points with a zero width coordinate were located on the symmetry plane of the patterns, or centerline. The shrinkage was minimal at the centerline and largest at the edges. Smaller length shrinkage was measured for the restrained pattern, case $2 \mathrm{~b} 1$. As indicated in Figure $4.8 \mathrm{~b}$ for the case of overall casting shrinkage, the unrestrained parts shrink more than the restrained ones. The following general observations can be made concerning the dimensional measurements: (a) the width shrinkage factors were almost uniform, (b) the length shrinkage factors were larger at the edges than at the centerline, (c) the dimension, L2_5, for the two-hole restrained part showed smaller shrinkage than the unrestrained part. 

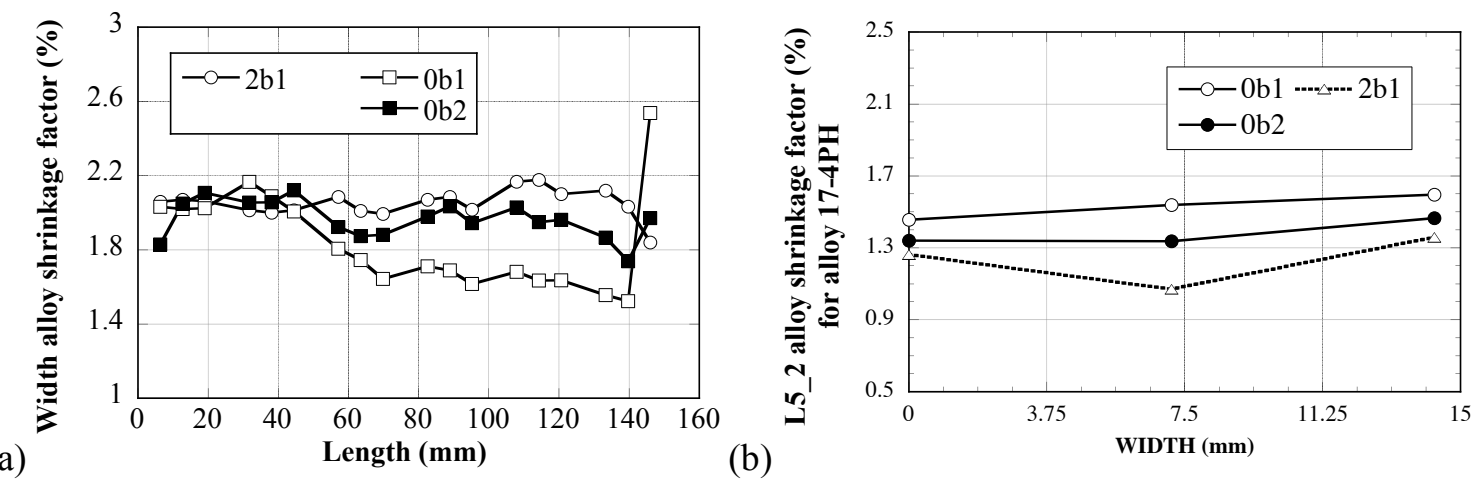

(b)

Figure 4.8: Alloy shrinkage factors for the (a) width dimension and (b) length dimension, L2-5.

\subsubsection{Numerical Simulation Results for Casting Dimensions}

Numerical simulations of heat transfer, solidification, and deformation during casting and subsequent cooling were conducted with ProCAST (Waite and Samonds, 1990) using the casting parameters, material properties, and boundary conditions given in the previous sections and Sabau (2005). The mesh was created using the shelling feature in MeshCAST, a module of ProCAST (Fig. 4.9). One mesh layer of $0.66 \mathrm{~mm}(0.026 \mathrm{in}$.) was used for the zircon face coat and another layer of $0.9 \mathrm{~mm}$ (0.036 in.) for the intermediate fused silica coat. Three layers of $1.2 \mathrm{~mm}(0.048 \mathrm{in}$.) each were used to model the fused silica back-up coats.

(a)

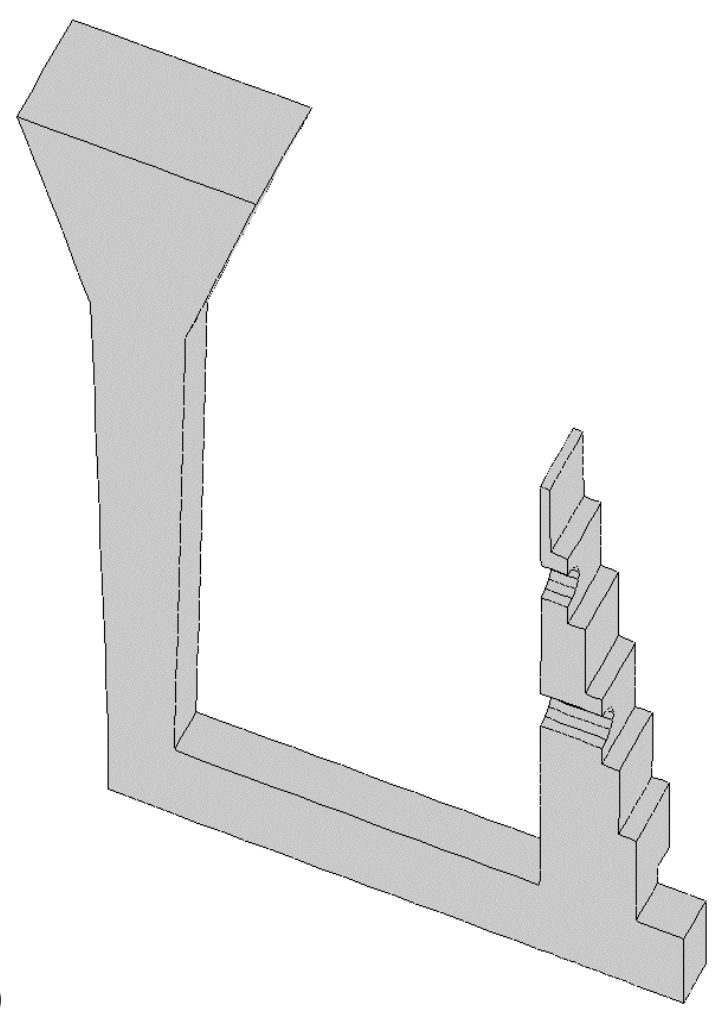

(b)

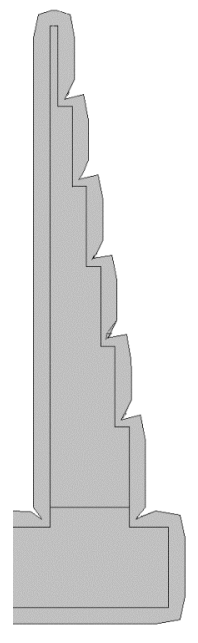

(c)

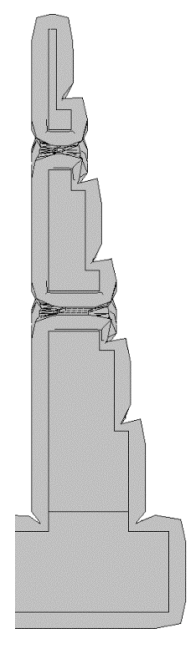

Fig. 4.9. Casting configuration for numerical simulations: (a) alloy material, and shell mold around the part; (b) part without cores, having unrestrained deformation; $(c)$ part with cores, with length and width dimensions are partially constrained by cores. 
The heat transfer coefficients (HTC) for this study were those used in Sabau (2005) and Sabau (2006). For the casting configuration in this study, the support structure was attached directly to the wax pattern. The mold support was invested [Figure 4.6(a)], allowing a more uniform cooling around the stepped pattern. HTC for the mold-air interface around the part, sprue, and runner were assumed to be 17,38 , and $7.5 \mathrm{~W} / \mathrm{m}^{2} \mathrm{~K}$, respectively, while HTC for the metal surface at the top sprue, bottom surface of the mold in contact with the sand, and metal-mold interface were assumed to be 30,42 , and $850 \mathrm{~W} / \mathrm{m}^{2} \mathrm{~K}$, respectively.

In addition to material parameters, there were software parameters that were used in the discretization of the stress-strain equations. These numerical parameters were introduced to increase the convergence rate or even to attain convergence. Preliminary simulations show that, due to the larger thermal contraction to room temperature, the steel casting deforms more than the aluminum alloys, requiring very robust solvers for the stress-strain equations. In Figure 4.10a, the evolution of the computed fraction solid in the center of the steps is shown. The part solidifies in approximately 2 min from the onset of pouring. The computed cooling curves are shown in Figures $4.10 \mathrm{~b}$ and $4.10 \mathrm{c}$ for times of 0-30, and 30-90 min, respectively.

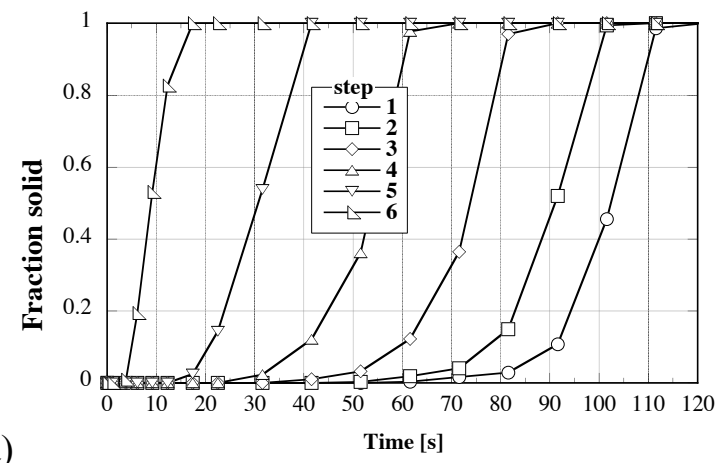

(a)
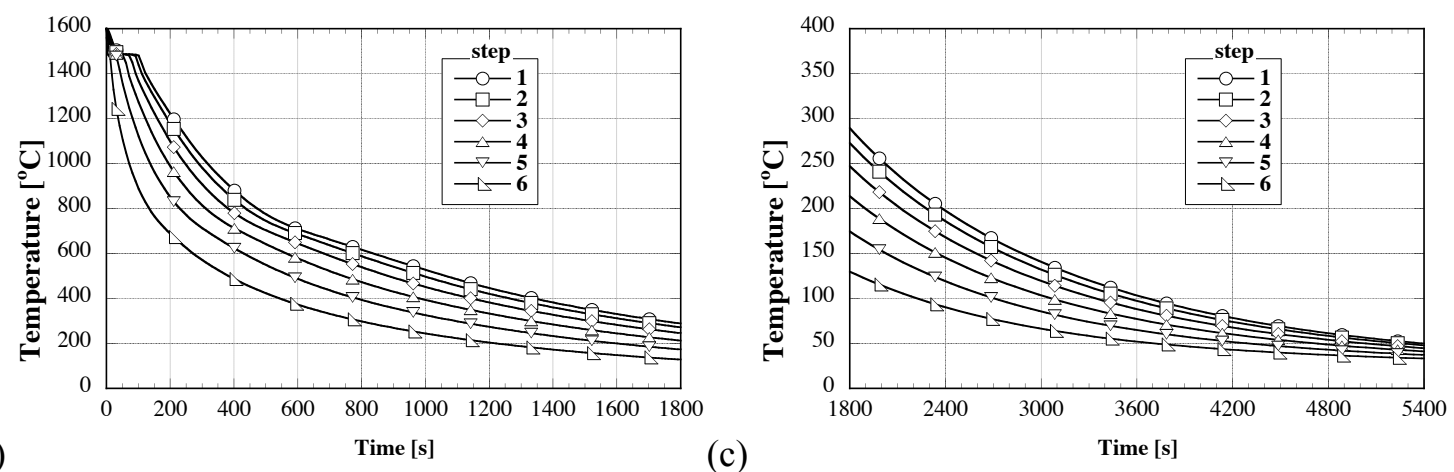

Figure 4.10: Evolution of the calculated solid fraction and temperature in the center of the steps (a) solid fraction (b) temperature (time $<1,800 \mathrm{~s}$ ), and (c) temperature at longer times.

Most numerical simulations presented in other studies use thermal expansion data from heating measurements. As emphasized in the section on thermophysical properties, due to the distinct evolution of the thermal expansion of the alloy/shell during heating and cooling, two generic simulations were carried out, one with thermal expansion data obtained on heating and the other one with thermal expansion data obtained during cooling. The results obtained with these two options 
will be referred in figures to as "heating" (or $\left.\alpha_{\text {heat }}\right)$ and "cooling" (or $\left.\alpha_{\text {cool }}\right)$. The results obtained with $\alpha_{\text {heat }}$ and $\alpha_{\text {cool }}$ will be compared.

The evolution of the calculated shrinkage factor, for the L2_5 dimension at the part centerline, is shown in Figure 4.11. There was an abrupt variation of the shrinkage in the first $300 \mathrm{~s}$, as it increased to 1.5 and $0.9 \%$ for the no-hole and two-hole patterns, respectively. This shrinkage was approximately $3 / 4$ of the entire shrinkage computed at a time of 5,400s $(90 \mathrm{~min})$ from the onset of pouring. By looking at Figures 9 and 10, the abrupt shrinkage variation was found to occur when the temperature in the part was above $1,000{ }^{\circ} \mathrm{C}$. The shrinkage evolution diverges for the $\alpha_{\text {heat }}$ and $\alpha_{\text {cool }}$ cases, shortly after the initial abrupt variation. At longer times, at approximately $3,000 \mathrm{~s}$, the results for the $\alpha_{\text {cool }}$ case come close to those of the $\alpha_{\text {heat }}$ case. Then, the cooling shrinkage shows a slow winding variation due to the passing of different regions in the casting through the martensitic domain at temperatures below $260{ }^{\circ} \mathrm{C}$. For the two-hole pattern, the difference between the $\alpha_{\text {heat }}$ and $\alpha_{\text {cool }}$ cases is more evident at longer times (around $90 \mathrm{~min}$ ), when the temperature in entire casting was below $85{ }^{\circ} \mathrm{C}$.
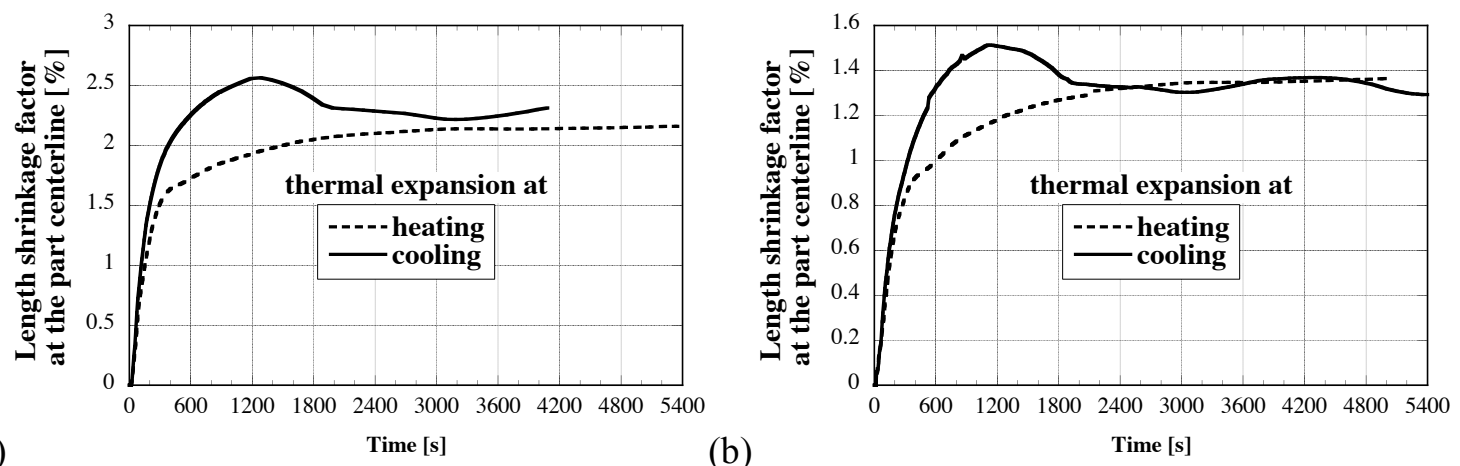

Figure 4.11: Evolution of the calculated shrinkage the L5_2 dimension at the centerline for the (a) no-hole pattern, (b) two-hole pattern.

The evolution of the shrinkage factor for the width dimension is shown in Figure 4.12 at the center of steps 2, 4, and 6. For these steps, the width dimension should exhibit approximately similar amounts of shrinkage, since along this dimension there are no mold features that provide the geometrical restraint. For the no-hole patterns (Figures 4.12a and 4.12b), the width shrinkage evolves asymptotically for the $\alpha_{\text {heat }}$ while for the $\alpha_{\text {cool }}$ case the shrinkage raises to higher values and then drops to those of the $\alpha_{\text {heat }}$ case. The same value is attained at longer times for all the steps considered. This is expected for unrestrained dimensions, as the overall thermal expansion for $\alpha_{\text {heat }}$ while for the $\alpha_{\text {cool }}$ cases is the same. Similar behavior is shown for the two-hole patterns (Figures $4.12 \mathrm{c}$ and 4.12d) as for the no-hole patterns, with the exception of the shrinkage for step 6 . The shrinkage fraction in step 6 is less than that in the other steps. As will be seen later, this is due to the proximity of step 6 to the hole in step 5, which deforms much more than that in step 3, affecting the shape of the casting. 

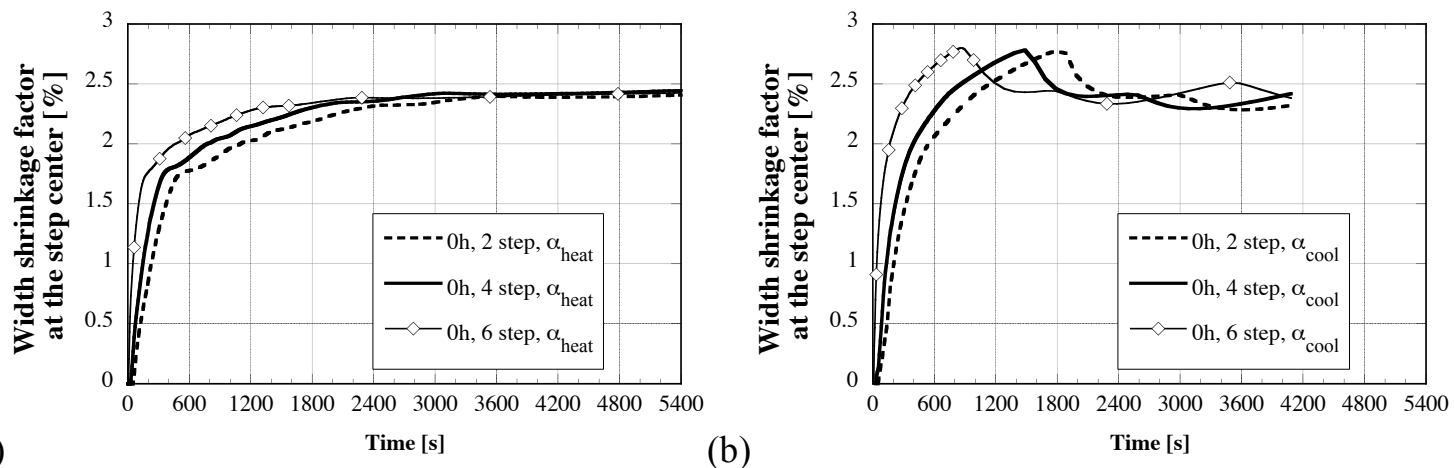

(a)

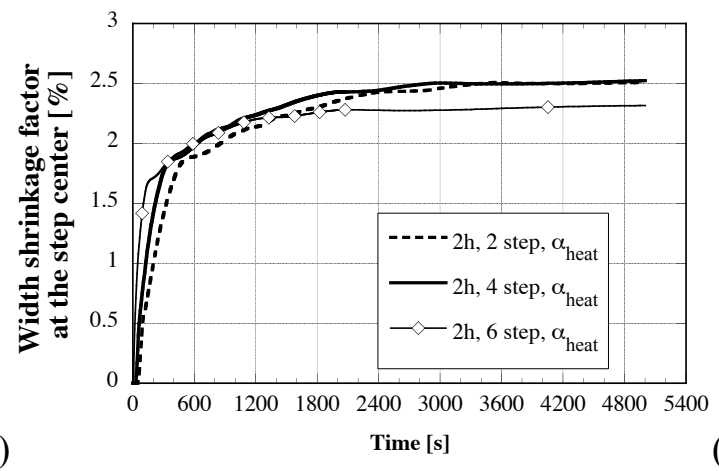

(b)

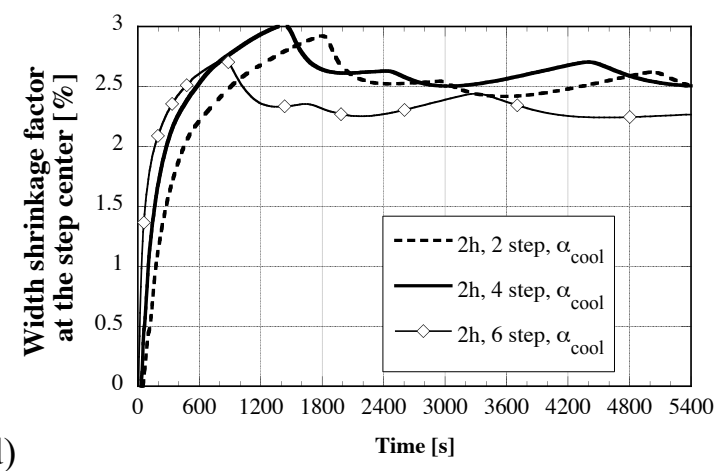

Figure 4.12: Evolution of the shrinkage the width dimension at the center of steps 2, 4, and 6 for the $(a, b)$ no-hole pattern and (c, d) two-hole pattern. Thermal expansion of heating and cooling was used for results shown in $(a, c)$ and $(b, d)$, respectively.

The numerical simulation results are compared to experimental final shrinkage factors when the maximum temperature in part dropped below $85{ }^{\circ} \mathrm{C}$, which was attained approximately 80-90 min from the onset of pouring. The comparison of the alloy shrinkage is shown in Figures 4.13 and 4.14 for the length and width dimensions, respectively. The measured dimensions were grouped according to the level of mold constraints. The unrestrained dimension groups include the length $L 2$ - 5 for the no-hole pattern, and width, $W$, for the no-hole pattern and two-hole pattern. The length $L \overline{2}-5$ for the two-hole pattern was restrained by the shell mold. The shrinkage factors for both unrestrained and restrained dimensions were slightly over-predicted. Nonetheless, with the exception of the L2_5 results for the no-hole part, the predicted shrinkage values are close enough to the measured values to allow a quantitative prediction of the shrinkage factors. The numerical results were very close for the $\alpha_{\text {heat }}$ and $\alpha_{\text {cool }}$ cases, with more differences for the width dimension (steps 5 and 6 , distances of 90 to $140 \mathrm{~mm}$ in Figure 4.14b). It is likely that these differences may be amplified for more complex parts. There was no obvious reason for the shrinkage over-prediction. The over-prediction of shrinkage values could be due to assumptions used in the mechanical properties, especially at high temperatures, where most of the shrinkage occurred (Figure 4.11 and 4.12). For example, no experimental data for plastic modulus was found and ProCAST recommendations were followed to set its values. In order to find the reason for over-prediction, more experimental properties data are needed and a sensitivity study on plasticity properties needs to be performed. 

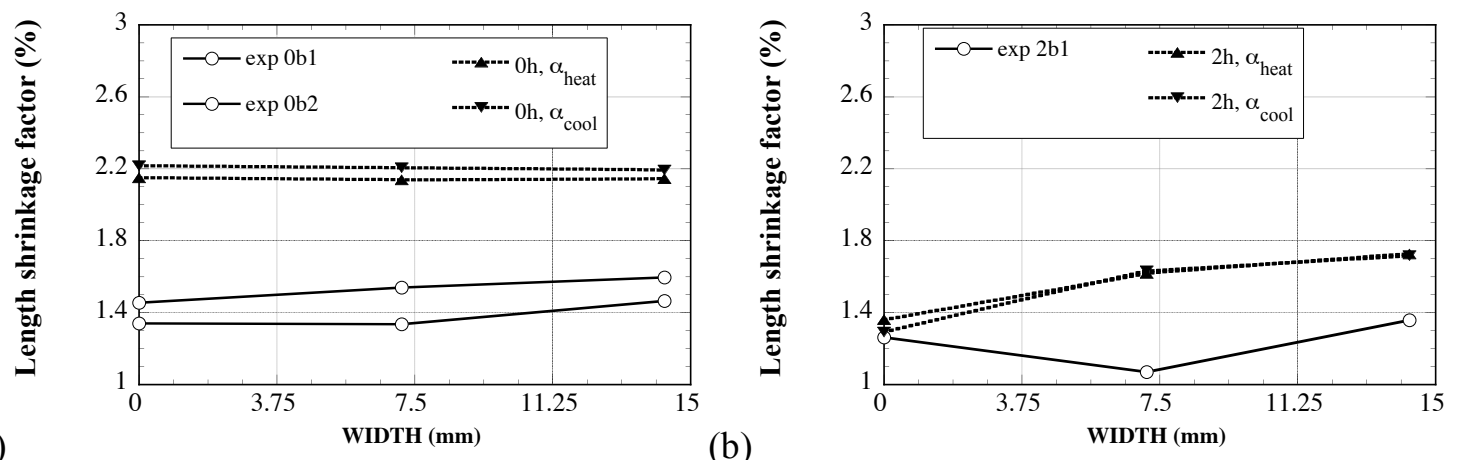

(a)

(b)

Figure 4.13: Comparison between the experimental results and computed results for the length dimension, L5_2: (a) part with no-holes and (b) part with two-holes.
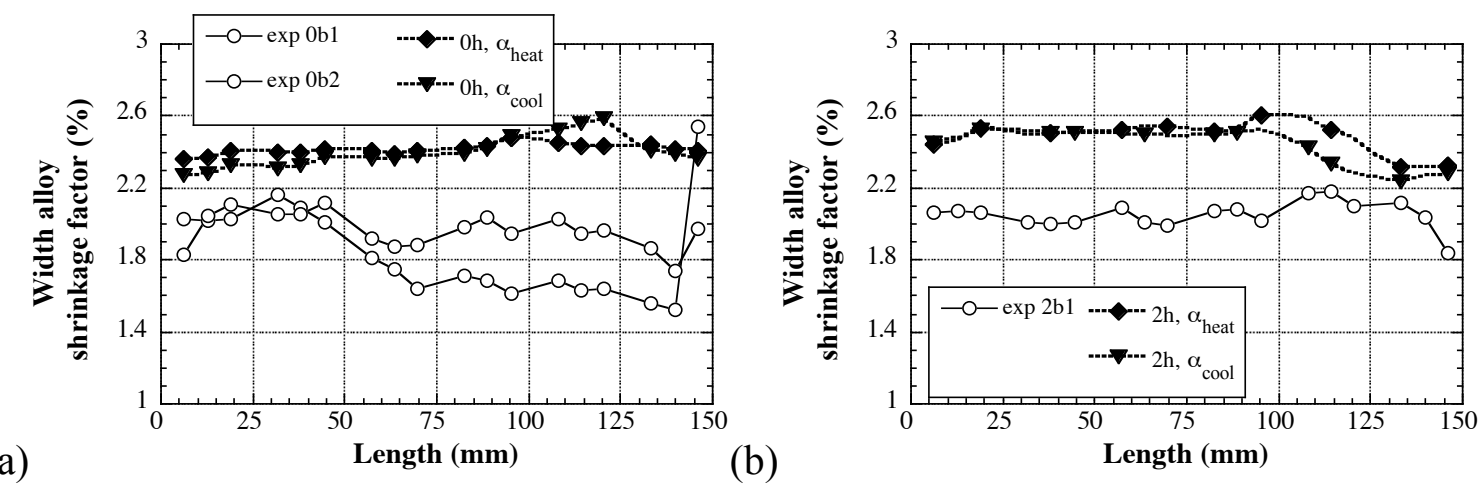

Figure 4.14: Comparison between experimental and computed shrinkage factors for the width dimension along the length: (a) part with no-holes and (b) part with two-holes.

The casting distortion was obtained from the numerical simulation results. Information on casting distortion can be used by engineers to visualize the distribution of the deformation. The deformation results shown in Figure 4.15 were obtained at a time of 4,080 s for the $\alpha_{\text {heat }}$ case. The same scale was used for both figures. As shown in Figure $14 \mathrm{~b}$ for the width dimension, the effect of the hole in step 5 results in a necking feature between steps 4 and 5 while step 5 and 6 are largest among all steps. It is important to assess the extent of plastic deformation, since the elastic deformation will be relieved. Figure 4.16 shows the distribution of the equivalent plastic strain for the no-hole pattern.

The $\alpha_{\text {heat }}$ results show evidence of plastic deformation in the step corners. On the other hand, for $\alpha_{\text {cool }}$ case, in which more accurate properties were used for the thermal expansion of the alloy and shell mold, the plastic deformation in the step corners was removed, and as expected, no plastic deformation takes place in the part, the region with highest plastic strain being located at the end of the runner. Figure 4.17 shows the distribution of the equivalent plastic strain for the two-hole pattern.

Significant plastic deformation is shown for the hole in step 5. As for the no-hole pattern, $\alpha_{\text {heat }}$ results shows evidence of plastic deformation in the step corners, plastic deformation that was removed for the $\alpha_{\text {cool }}$ case. The highest plastic strain was located for the two-hole part in the part and not at the end of the runner, as it was for the no-hole case. This was due to the geometry of the entire casting, including the runner system. The two-hole part was "anchored" in the runner and was pulled away from the two holes towards the bottom of the part, where thick regions solidified well after the thin steps six and five. As a result of the geometrical constraint, the two-hole part did not deform 
freely in the lengthwise direction, its shrinkage was less than the no-hole part, and thus, the two-hole part was longer.

(a)

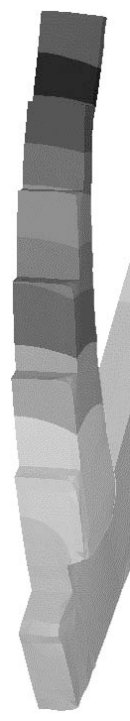

(b)

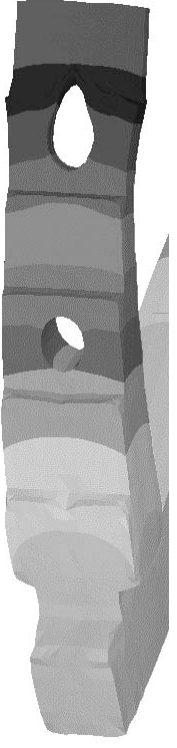

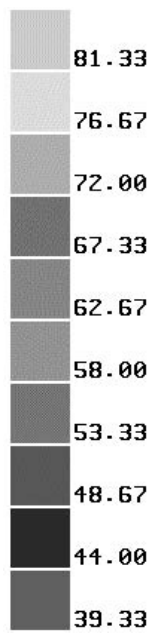

Figure 4.15: Temperature profile and part shape at 4,080 s. Thermal expansion from heating was used. (a) no-hole part, half of the part shown only, (b) two hole-casting.

Deformation was magnified 15 times.

(a)

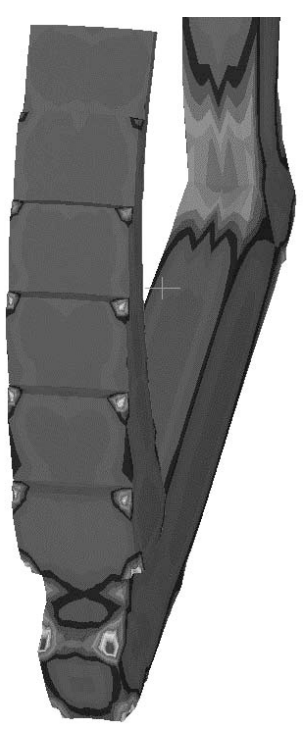

(b)

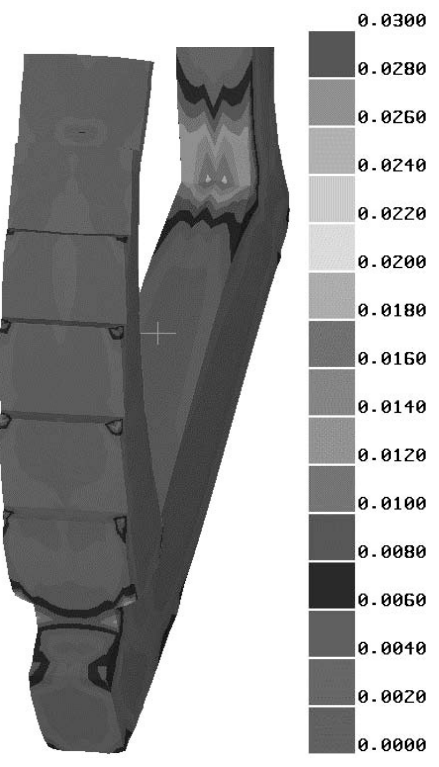

Figure 4.16: Equivalent plastic strain at 5,400s for the no-hole casting when thermal expansion used was that measured on (a) heating and (b) cooling.

Deformation was magnified 15 times. 

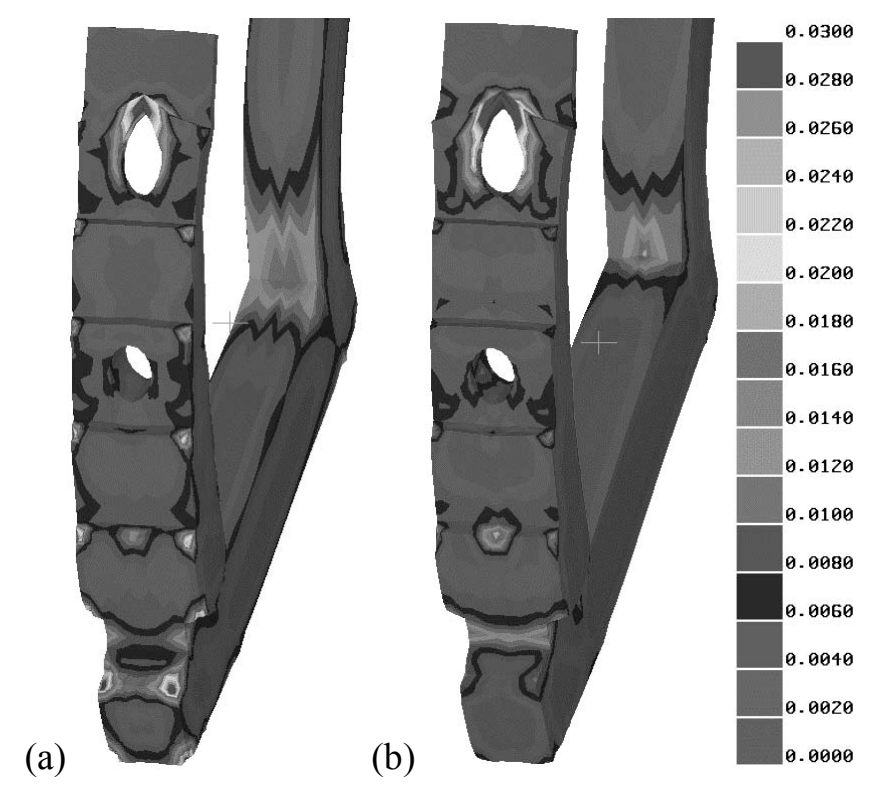

\section{Figure 4.17: Equivalent plastic strain at 5,400s for the two-hole casting when thermal expansion used was that measured on (a) heating and (b) cooling. Deformation was magnified 15 times.}

This study is the first attempt to determine shrinkage factors for the investment casting of stainless steels. The experimental data for $17-4 \mathrm{PH}$ stainless steel, did not cover the entire temperature range necessary for process simulation. Some property data had to be estimated using CompuTherm methodologies and recommendations from ProCAST. No experimental data for plastic modulus were found and ProCAST recommendations were followed to set its values. Numerical simulations were conducted to predict the alloy tooling allowances based on a combined analysis of heat transfer and deformation phenomena for 17-4PH stainless steel parts. Although the numerical results showed that the shrinkage evolution in time was quite different for the $\alpha_{\text {heat }}$ and $\alpha_{\text {cool }}$ cases, there was only a small difference in the final shrinkage factors predicted for these cases. The shrinkage factors were over-predicted for both the unrestrained dimensions and restrained dimensions. However, the effect of reduced shrinkage for restrained dimensions was adequately reproduced. With the exception of the L2 5 results for the no-hole part, the predicted shrinkage values are close enough to the measured values to allow a quantitative prediction of the shrinkage factors. The over-prediction of shrinkage values are likely due to assumptions used in the mechanical properties, especially at high temperatures, for which no experimental data were available. As expected, results showed that the plastic deformation occurred only in the two-hole casting. 


\subsection{Measurements of Material Properties for Filled Waxes}

Additional $R \& D$ focus was placed on obtaining material property data for filled waxes, waxes that are common in the industry. The wax pattern dimensions are determined by the wax's thermophysical and thermomechanical properties, restraint of geometrical features by the metal die, and process parameters such as die temperature, platen temperature, injection pressure, injection temperature, and dwell time. In this report, material property data that is needed to determine dimensional changes associated with the wax system are provided.

The following waxes were chosen by participating companies for testing: Cerita F20-6, Cerita F20844B, and Remet PR-15. For Cerita F20-6 wax, the filler was terepthalic acid, filler weight $42 \%$, and filler volume of $31.6 \%$. The test bar mold was fabricated by Independent Tool, Inc. Test bars specimens of three waxes were injected at Schrey \& Sons, Inc and McCaughin, Inc., commercial foundries. Rheometry measurement of filled waxes was conducted at ORNL. Material property measurements were conducted in this study for three filled waxes with the aim of obtaining a complete set of data that can be used as input in computer simulation software for predicting wax pattern dimensions. The measurement of viscoelastic properties of waxes is not a trivial task since the investment casting waxes are complex blend of polymers that exhibit a wide range of behaviors. The analysis of the rheometry data to obtain viscoelastic properties was not completed due to the reduction in the budget of the project (approximately 50\% funds were received).

\subsubsection{Thermophysical Properties of Waxes}

In order to predict wax tooling allowances, all the properties that determine dimensional changes associated with wax processing must be evaluated. The Investment Casting Institute developed standard tests for the investment casting industry. For waxes, most of these tests are concerned with engineering properties, such as flow, softening point, strength, and sink. The available tests provide the information only for handling and processing wax patterns but are not useful for die design.

Data provided by the suppliers contains information on wax properties (Table 4.12), dimensional characteristics (Table 4.13), and operating conditions (Table 4.14). Aside from specific heat, which is necessary for thermal analysis, and thermal expansion property, none of the other data can be used to predict the shrinkage of complex investment casting patterns. Specific heat and thermal conductivity was measured for all the waxes considered (Figure 4.18). The results for the unfilled wax, Cerita ${ }^{\mathrm{TM}}$ 29-51, were also reported in Figure 4.18 for comparison with the other filled waxes.

Table 4.12. Properties for the F20-6 wax provided by the wax supplier.

\begin{tabular}{|l|l|}
\hline Property & Value \\
\hline ring \& ball softening point & $159.5^{\circ} \mathrm{F} / 70.8^{\circ} \mathrm{C}$ \\
\hline drop melt point & $178.2^{\circ} \mathrm{F} / 81.2^{\circ} \mathrm{C}$ \\
\hline hardness $450 \mathrm{grm}$. load & $14.5 \mathrm{DMM}$ \\
\hline specific gravity & 1.129 \\
\hline ash content $\left(1800^{\circ} \mathrm{F} / 982 \mathrm{c}, 30 \mathrm{~min}\right)$ & $0.0015 \%$ \\
\hline filler content & $42.0 \%$ \\
\hline Viscosity & table data \\
\hline Specific heat (and DSC data) & table data \\
\hline Thermal expansion & table data \\
\hline
\end{tabular}


Table 4.13. Dimensional data.

\begin{tabular}{|l|l|}
\hline Property & Value \\
\hline step shrinkage in/in $(\mathrm{mm} / \mathrm{mm})$ & 0.0060 \\
\hline step - cavitation in/face $(\mathrm{mm} /$ face $)$ & $0.0107 / 0.2718$ \\
\hline 10 " linear shrinkage bar in/in $(\mathrm{mm} / \mathrm{mm})$ & 0.0060 \\
\hline
\end{tabular}

Table 4.14. Operating parameters

\begin{tabular}{|l|l|}
\hline wax temperature & $155^{\circ} \mathrm{F} / 68.3^{\circ} \mathrm{C}$ \\
\hline nozzle temperature & $157^{\circ} \mathrm{F} / 69.4^{\circ} \mathrm{C}$ \\
\hline platen temperature & $68^{\circ} \mathrm{F} / 20^{\circ} \mathrm{C}$ \\
\hline pressure & $300 \mathrm{psi} / 21 \mathrm{bar}$ \\
\hline flow control & $30 \%$ \\
\hline dwell time & $60 \mathrm{sec}$ \\
\hline
\end{tabular}

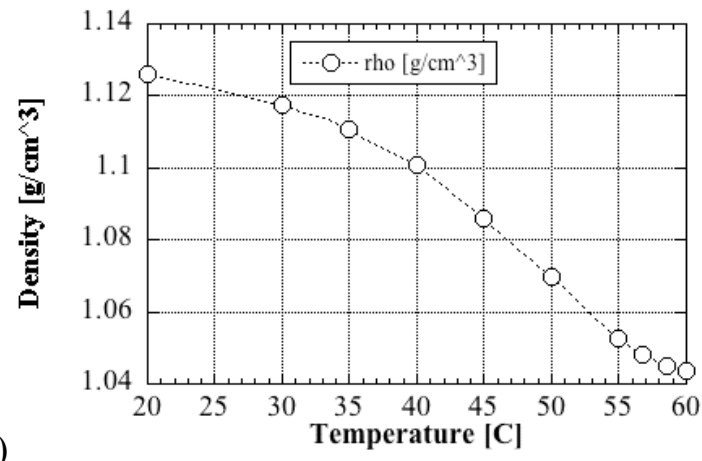

(a)

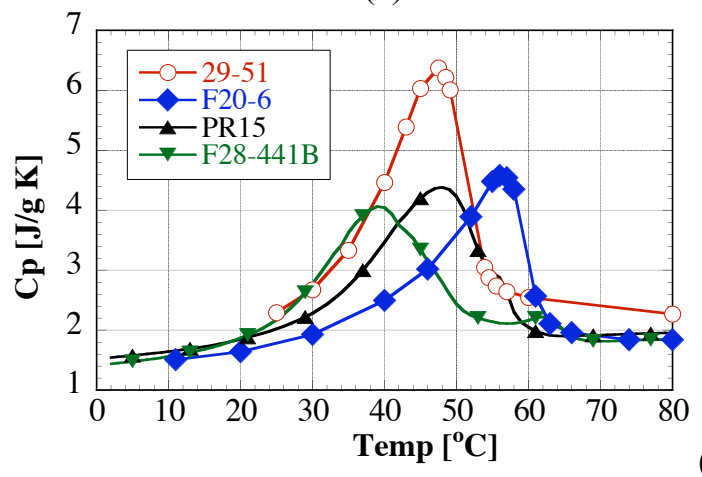

(b)

Figure 4.18. Density for Cerita ${ }^{\mathrm{TM}}$ F20-6 wax (a), specific heat (a) and thermal conductivity (b) for one unfilled wax, Cerita ${ }^{\mathrm{TM}}$ 29-51 wax, and three filled waxes.

\subsubsection{Measurement techniques for thermomechanical properties of waxes}

One of the main difficulties in using computer models for the prediction of wax dimensions is the lack of material properties of the wax. In particular, data on thermomechanical properties of waxes are scarce or nonexistent. The measurement of viscoelastic properties of waxes is not a trivial task since the investment casting waxes are complex blend of polymers that exhibit a wide range of behaviors (Sabau, 2004). Waxes used in the investment casting industry are a blend of semicrystalline polymers, additives and fillers. For waxes tested, the glassy region occurs at temperatures below $20{ }^{\circ} \mathrm{C}$. As temperature increases, waxes soften gradually. It was only recently that Sabau and Viswanathan (2000 and 2001) reported on a successful measurement of the thermomechanical

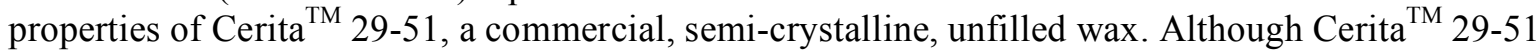


wax is a semicrystalline material, Sabau and Viswanathan (2000 and 2001) showed that in a paste state, the wax is a thermo-rheologically simple material that obeys the time-temperature superposition principle.

As waxes are viscoelastic materials, their thermomechanical properties can be determined using measurements techniques that were developed for polymers, such as dynamical mechanical analysis (DMA) measurements (Menard, 1999). In (DMA) tests, an oscillatory strain is applied to the material and the resulting stress is separated into elastic and viscous components. There are several ASTM standards for conducting DMA measurements and other industries have their own standards (Table 4.15).

Table 4.15 ASTM Standard for the DMA.

\begin{tabular}{|l|l|}
\hline ASTM Standard & Test description \\
\hline D4440 & Measurement of Polymer Melts \\
\hline D5023 & DMA in Three Point Bending \\
\hline D5024 & DMA in Compression \\
\hline D5026 & DMA in Tension \\
\hline D5279 & DMA of Plastics in Tension \\
\hline D5418 & DMA in Dual Cantilever \\
\hline D6648-01 & $\begin{array}{l}\text { BBR }: \text { Flexural Creep Stiffness of Asphalt Binder } \\
\text { (Standard) }\end{array}$ \\
\hline D4 P 245 & BBR: Flexural Creep Stiffness of Asphalt Binder (Test) \\
\hline
\end{tabular}

The wax material was tested using various fixtures and different instruments with higher sensitivity until appropriate test instruments, procedures, and fixtures were identified (Table 4.16). In Table 4.16, few other measurement techniques used in the investment casting community were also included. Based on our experience in measuring the viscoelastic properties of waxes and review of polymer testing, tests and fixtures, which we recommend for wax testing, are highlighted in Table 4.17. The tests and fixtures depend on material consistency.

It was observed that waxes exhibit a transition from a soft paste to that of a viscous liquid with less elasticity at a certain temperature, which is less than the melting point. For the sake of simplicity we refer to that temperature as the softening point temperature, $T_{S P}$. $T_{S P}$ is given by the temperature at which the thermal expansion curve and DSC curve attain their peaks. $T_{S P}$ can be associated with either an $\alpha$ transition for the crystalline component of the wax or a transition in the amorphous component of the wax. The former is due to the slippage of the crystallites past each other while the latter is related to the movement of coordinated segments reducing the viscosity (Menard, 1999). 
Table 4.16. Tests used for determining wax properties

\begin{tabular}{|c|c|c|c|}
\hline Property & Tests/Sample shape & ASTM Standard & Test instruments \\
\hline $\begin{array}{l}\text { Density and thermal } \\
\text { expansion }\end{array}$ & $\begin{array}{l}\text { Thermomechanical analysis } \\
\text { (TMA) }\end{array}$ & E831 & Dupont TMA \\
\hline $\begin{array}{l}\text { Specific heat (latent } \\
\text { heat for phase changes) }\end{array}$ & $\begin{array}{l}\text { Differential scanning } \\
\text { calorimetry (DSC) }\end{array}$ & $\begin{array}{l}\text { E1269 } \\
\text { (ISO 11357) }\end{array}$ & Netzsch DSC 404C \\
\hline Thermal conductivity & $\begin{array}{l}\text { Transient line-source } \\
\text { technique }\end{array}$ & D 5930-97 & \\
\hline $\begin{array}{l}\text { Shear modulus } \\
\text { (liquid) })^{1,3}\end{array}$ & $\begin{array}{l}\text { Shear oscillatory: melt } \\
\text { rheology/parallel plate }\end{array}$ & D4440-01 & RFSII rheometer $(\mathrm{RS})^{2}$ \\
\hline Shear modulus (liquid) & $\begin{array}{l}\text { melt rheology/cone, } \\
\text { concentric cylinder, capillary }\end{array}$ & $\begin{array}{l}\text { D4440-95A, } \\
\text { D3835-02 }\end{array}$ & $\begin{array}{l}\text { Rotational viscosimeter } \\
\text { and capillary rheometer }\end{array}$ \\
\hline Shear modulus (paste) & $\begin{array}{l}\text { Torsion oscillatory/ } \\
\text { rectangular geometry }\end{array}$ & $\begin{array}{l}\text { D5279 } \\
\text { (ISO 6721) }\end{array}$ & $\begin{array}{l}\text { Advanced Rheometric } \\
\text { Expansion System } \\
\left(\text { ARES) }(\mathrm{RS})^{2}\right.\end{array}$ \\
\hline Shear modulus (paste) & Shear oscillatory/disk & $\begin{array}{l}\text { D5279 } \\
(\text { ISO 6721) }\end{array}$ & 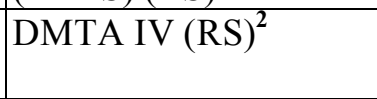 \\
\hline
\end{tabular}

${ }^{1}$ liquid, temperature above the ring and ball softening point

${ }^{2} \mathrm{RS}$ indicates Rheometrics Scientific.

${ }^{3}$ For the wax tested, at temperatures of 60,65 , and $70^{\circ} \mathrm{C}$, reproducible data could not be obtained using either the Rheometrics Scientific ARES or melt rheometers.

${ }^{4}$ Bending beam rheometer may provide better data than the ARES system in the solid state.

Table 4.17. Tests and fixtures recommended for investment casting waxes.

\begin{tabular}{|l|l|l|l|l|}
\hline $\begin{array}{l}\text { Stiffness/ } \\
\text { material form }\end{array}$ & Test & Fixture & $\begin{array}{l}\text { Temperature } \\
\left.\text { range [ }{ }^{\circ} \mathbf{C}\right]\end{array}$ \\
\hline Hard/solid & $\begin{array}{l}\text { Flexural } \\
\text { (3-pt. Bending) }\end{array}$ & $\begin{array}{l}\text { BBR (D6648) } \\
\text { 3-pt. (D5023) }\end{array}$ & $\begin{array}{l}\text { Rectangular } \\
\text { bar }\end{array}$ & $\begin{array}{l}\text { RT }<\mathrm{T}<40(\mathrm{BBR}) \\
\mathrm{RT}<\mathrm{T}<T_{S P}-5(3-\mathrm{pt})\end{array}$ \\
\hline $\begin{array}{l}\text { Hard/hard paste or } \\
\text { Soft/paste }\end{array}$ & Torsion oscillatory & DMA (D5279) & $\begin{array}{l}\text { Rectangular } \\
\text { bar }\end{array}$ & RT $<\mathrm{T}<T_{S P^{-}} 5$ \\
\hline $\begin{array}{l}\text { Soft and Gooey/ } \\
\text { Paste }\end{array}$ & Shear oscillatory & DMA (D4440) & Disk & $T_{S P^{-}} 10<\mathrm{T}<T_{S P}$ \\
\hline Liquid & Shear oscillatory & Melt rheometer (D4440) & Disk & $T_{S P}+5<\mathrm{T}<T_{S P}+20$ \\
\hline
\end{tabular}

\subsubsection{Viscoelastic property data of filled waxes}

Experimental data on thermomechanical properties were first obtained for Cerita F20-6, a commercial, filled wax. The DMA testing for Cerita ${ }^{\mathrm{TM}}$ F20-6 wax using the bending-beamrheometer (Sabau, 2004) was incomplete since the BBR method/fixture, which was originally designed for testing asphalt binders, could only be used for temperatures less than $40{ }^{\circ} \mathrm{C}$. The shear modulus was determined from DMA measurements using the torsion bar fixture at Abatech, Inc. The wax was melted, stirred to suspend filler as much as possible and poured into a mold to form torsion

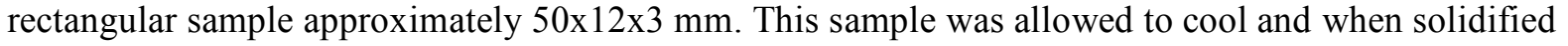
the beam was mounted in a Rheometrics ARES DSR and tested. The test was a temperature frequency sweep from $20^{\circ} \mathrm{C}$ to $50^{\circ} \mathrm{C}$ in $10^{\circ} \mathrm{C}$ increments covering the frequency range of 0.05 to 100 radians/sec using 10 test points per decade. The targeted strain level was $0.15 \%$. A strain sweep had been conducted at $35^{\circ} \mathrm{C}$ (the mid point of the temperature range) and we found that at $0.15 \%$ strain we were at $94.8 \%$ of the initial complex modulus $G^{*}$ value measured at $0.01 \%$ strain. The two sets of 
data are measured from DMA are shown in Figure 4.19. This data is not ready for the direct use in computer simulation software and it must be post-processed to obtain data in a simpler format as shown in Appendix A. The post-processing steps are described in the remainder of this section.

(a)

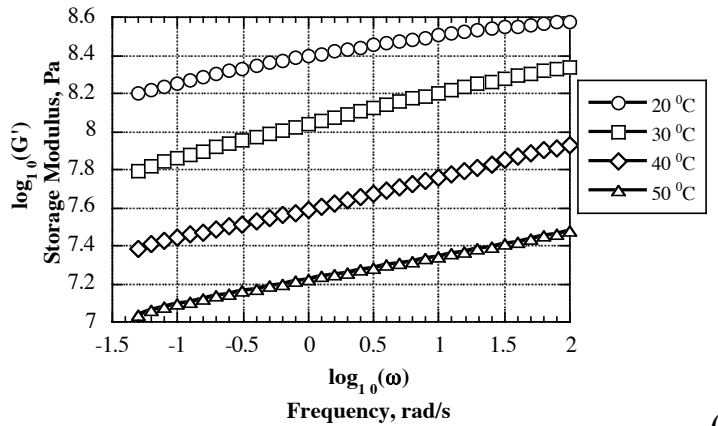

(b)

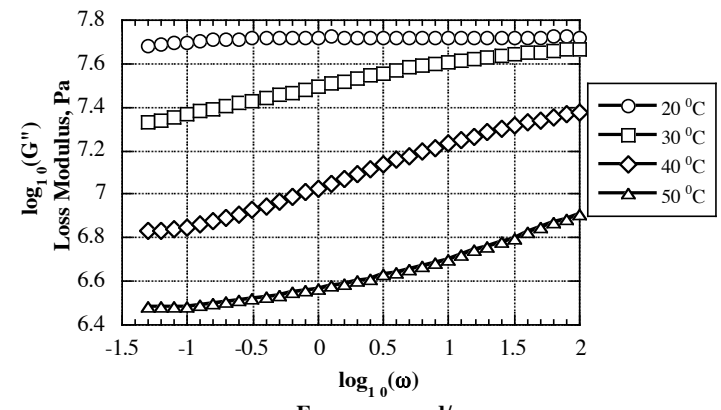

Frequency, rad/s

Figure 4.19. DMA experimental results for the (a) storage shear modulus, and (b) the loss shear modulus as a function frequency (Cerita ${ }^{\mathrm{TM}} \mathrm{F20-6}$ wax, torsion geometry at Abatech, Inc.).

The three filled waxes were tested at the High Temperature Materials Laboratory (HTML) at ORNL using a DMA Q800 machine (TA Instruments, Inc.). It is worth noting that a different fixture and rheometer was used at ORNL than at Abatech, Inc., where the original measurements for Cerita ${ }^{\mathrm{TM}}$ F20-6 wax were performed. Thus, to insure testing consistency and compatibility between the measurements at ORNL and Abatech, Inc., F20-6 wax was tested first. The HTML wax samples were molded into a die tool that was designed and manufactured at industrial partners. The wax sample tested at ORNL using DMA Q800 had the following dimensions $60 \times 10 \times 4 \mathrm{~mm}$. DMA measurements were performed using a 3-point bend fixture from 0 to $55^{\circ} \mathrm{C}$ at $5{ }^{\circ} \mathrm{C}$ temperature increments. The slender beam of wax was simply supported and loaded with a constant force at mid span. The deflection was monitored with time and used for calculation of stiffness as a function of time. The raw data from the DMA measurements are shown in Appendix B for all the three filled waxes considered. The data on storage and loss modulus, which are shown in tables in the Appendix, were calculated for the Youngs modulus, and not for the shear modulus. The shear modulus, G, can be obtained from Youngs modulus, E, as:

$$
\mathrm{G}=\mathrm{E} /(2 *(1+v))
$$

where $v$ is the Poisson ratio. In Figure 4.20, the shear modulus data is shown for the CeritaTM F20-6 wax. However, the data at $55^{\circ} \mathrm{C}$ was discarded as the sample yielded during the run at $55^{\circ} \mathrm{C}$.

After shifting the data horizontally, continuous curves were obtained over a very large frequency scale for both of the loss and storage moduli (Figure 4.21a and 4.21b). For Cerita F20-6, the shape of the master curve obtained at torsion and 3-point bending are in excellent agreement. The data on bending DMA shows larger values than those obtained on torsion DMA. This effect needs to be further understood. The same extent of horizontal shifting was applied to both the storage modulus, G', and loss modulus, $G$ " (Rowe and Sharrock, 2000). The fact that it was possible to obtain continuous master curves for both moduli over very large frequency ranges by the use of the same shift factors proves that the time-temperature superposition principle can be applied to the wax considered. The shift factors, defined as shown in Appendix B, were obtained for both sets of data (Figure 4.22). For Cerita F20-6, the shift factors obtained at torsion and 3-point bending are in excellent agreement, validating the use of 3-point bending testing for filled waxes. 


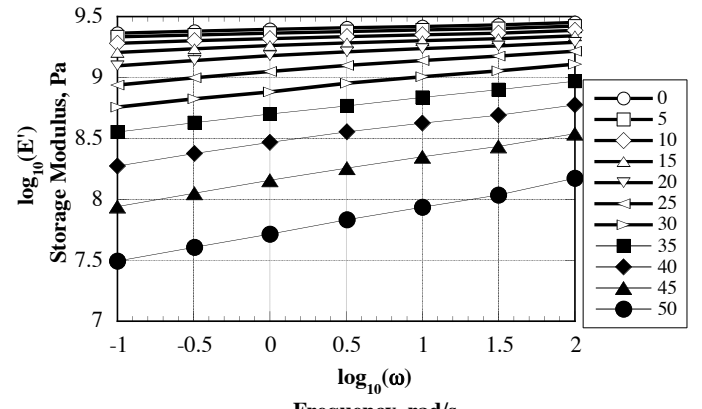

(a)

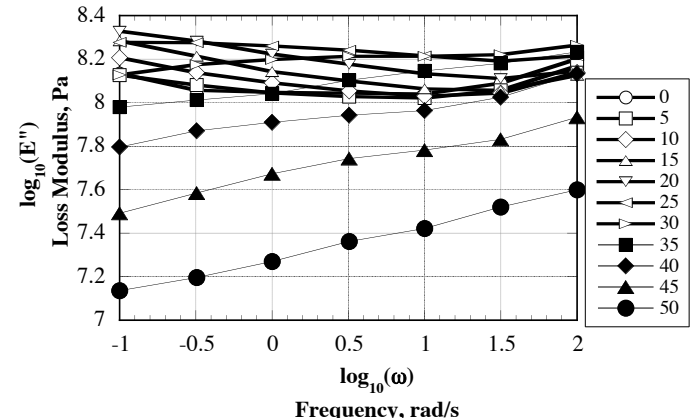

(b)

Frequency, rad/s

Figure 4.20: DMA experimental results for the (a) Youngs loss modulus, and (b) Youngs storage modulus as a function of frequency (3-point bending).
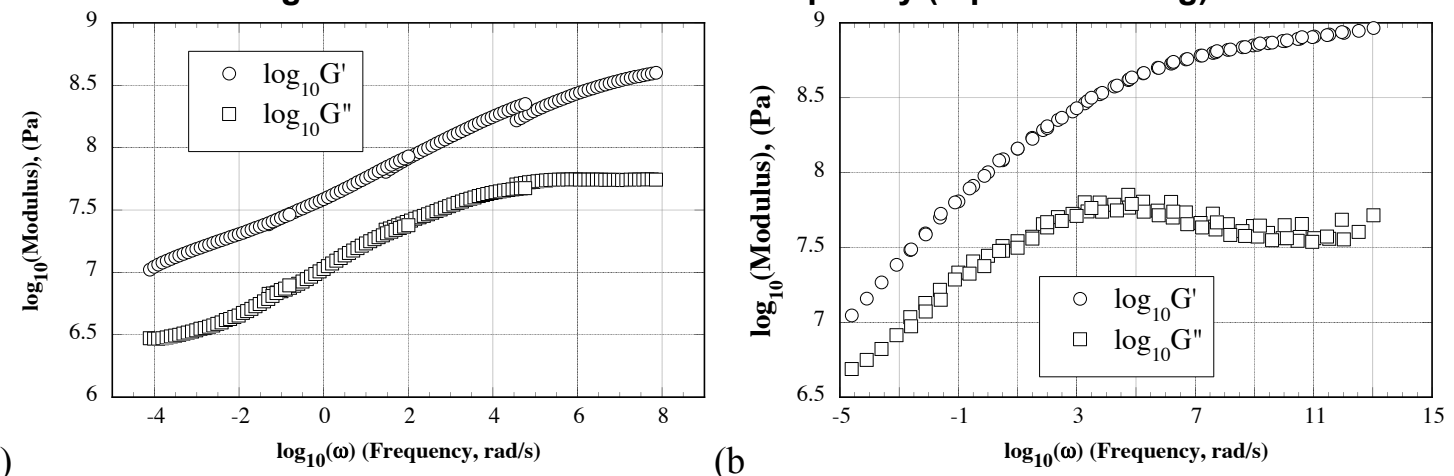

Figure 4.21. Master curves for the storage (G') and loss moduli (G") at the reference temperature of $40^{\circ} \mathrm{C}$ from experimental data on (a) torsion and (b) 3-point bending (Cerita ${ }^{\mathrm{TM}}$ F20-6 wax).

The next step was to perform a nonlinear regression from the master curves for the storage modulus, $G^{\prime}$, and loss modulus, G', in order to obtain Prony series terms (Appendix A), which are the material parameters that can be used directly in computer simulation software (Sabau and Viswanathan, 2000). This analysis was performed for the DMA on torsion at Abatech, Inc. and the data for the Prony series is shown in Appendix B. The DMA data for the Cerita F20-844B and Remet PR-15 waxes, which is shown in Appendix C, need to be post-processed in the same manner as that for Cerita F20-6 in order to obtain data for computer simulation software.

For the first time in the investment casting industry, the thermo-mechanical properties of unfilled and filled waxes were measured. Recommendations were made to Investment Casting Institute on measurement techniques for waxes. Recommendations for mechanical testing of waxes were made based on testing one unfilled wax and one filled wax. The recommendations made could be used to establish new testing guidelines for waxes in the investment casting industry. 


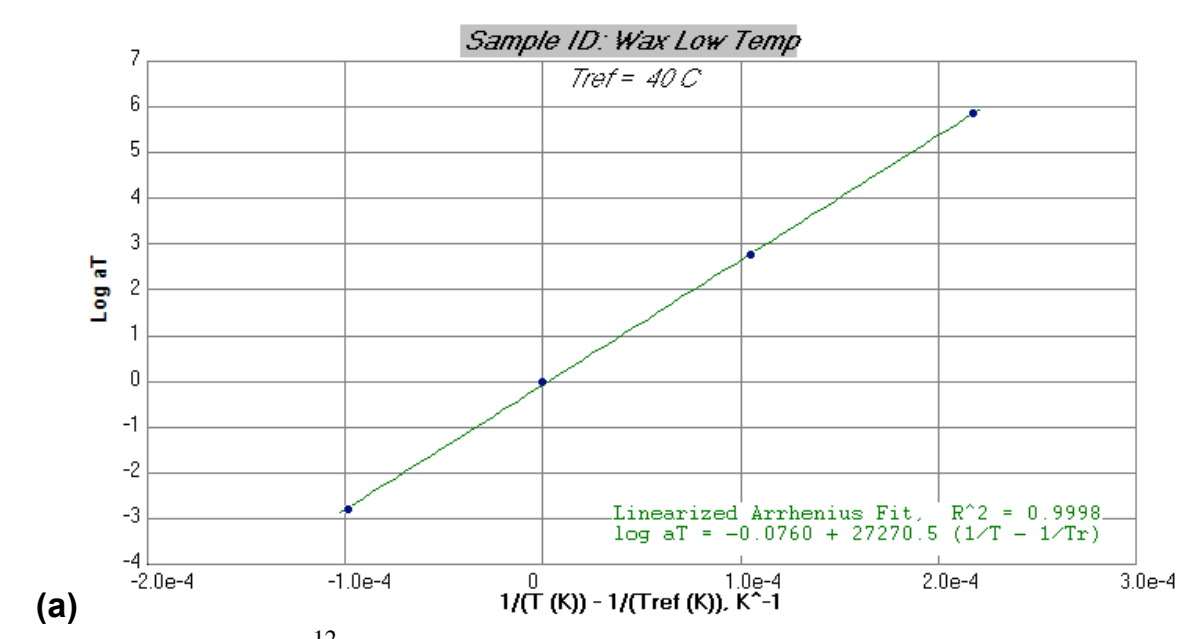

(a)

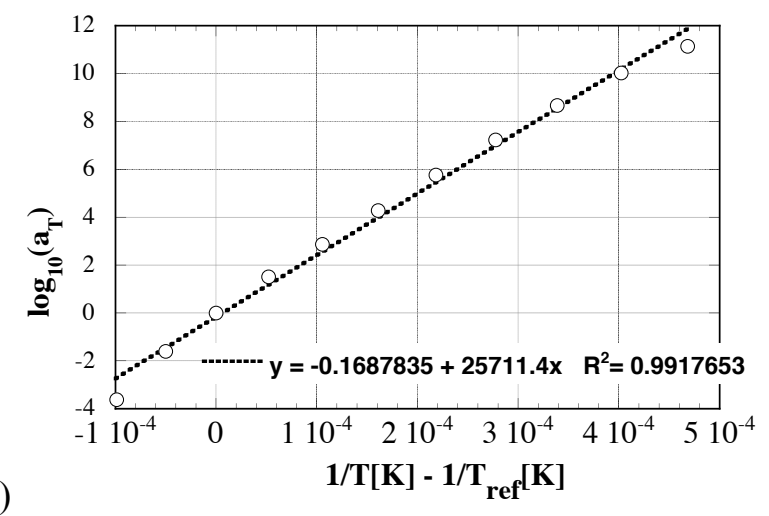

Figure 4.22: Linearized Arrhenius shift factor experimental data at $\mathrm{T}_{\text {ref }}=40^{\circ} \mathrm{C}$ on (a) torsion and (b) 3-point bending (Cerita ${ }^{\mathrm{TM}}$ F20-6 wax).

It was found that dynamical mechanical analysis (DMA) can be used to analyze both elastic and viscous behavior of filled waxes. As the ASTM standards for DMA were developed for other applications and industries than those in investment casting, the study for the applicability of ASTM standards to investment casting waxes was initiated and partially completed. Results for DMA performed on torsion were obtained for one filled wax, Cerita F20-6. Results for DMA performed on 3-point bending were obtained for three filled waxes. For Cerita F20-6, the shape of the master curve and the shift factors obtained at torsion and 3-point bending are in excellent agreement, validating the use of 3-point bending testing for filled waxes. 


\section{Accomplishments}

For convenience, a web site containing pertinent papers, reports and other information on this project has been established at http://www.ms.ornl.gov/mpg/sabau.htm.

\subsection{Shell Mold}

The data on properties of alumino-silicates materials used for shell molds are reviewed and material property data, which were not available from material suppliers, was obtained.

\subsection{Alloy Shrinkage Factors}

This study is the first attempt to predict shrinkage factors for the investment casting of stainless steels. The experimental data for 17-4PH stainless steel, did not cover the entire temperature range necessary for process simulation. Some property data had to be estimated using CompuTherm methodologies and recommendations from ProCAST. A comparison between the predicted material property data and measured property data was made. It was found that most material properties were accurately predicted only over several temperature ranges. No experimental data for plastic modulus were found. Thus, several assumptions were made and ProCAST recommendations were followed in order to obtain a complete set of mechanical property data at high temperatures. Thermal expansion measurements for the 17-4PH alloy were conducted during heating and cooling. As a function of temperature, the thermal expansion for both the alloy and shell mold materials showed different evolution on heating and cooling.

Numerical simulations were conducted to predict the alloy tooling allowances based on a combined analysis of heat transfer and deformation phenomena for 17-4PH stainless steel parts. Although the numerical results showed that the shrinkage evolution in time was quite different for the $\alpha_{\text {heat }}$ and $\alpha_{\text {cool }}$ cases, there was only a small difference in the final shrinkage factors predicted for these cases. The shrinkage factors were over-predicted for both the unrestrained dimensions and restrained dimensions. However, the effect of reduced shrinkage for restrained dimensions was adequately reproduced. With the exception of the L2_5 results for the no-hole part, the predicted shrinkage values are close enough to the measured values to allow a quantitative prediction of the shrinkage factors. The over-prediction of shrinkage values are likely due to assumptions used in the mechanical properties, especially at high temperatures, for which no experimental data were available.

In this section, the first attempt to determine shrinkage factors for the investment casting of stainless steels is presented. For all the properties of $17-4 \mathrm{PH}$ stainless steel, the experimental data available in the literature did not cover the entire temperature range necessary for process simulation. Thus, some material properties were evaluated using ProCAST, based on CompuTherm database.

\subsection{Wax Properties}

For the first time in the investment casting industry, the thermo-mechanical properties of unfilled and filled waxes were measured. Recommendations were made to Investment Casting Institute on measurement techniques for waxes. Recommendations for mechanical testing of waxes were made based on testing one unfilled wax and one filled wax. The recommendations made could be used to establish new testing guidelines for waxes in the investment casting industry. 
In this report, material property data that is needed to determine dimensional changes associated with the wax system are provided. The following waxes were chosen by participating companies for testing: Cerita F20-6, Cerita F20-844B, and Remet PR-15. It was found that dynamical mechanical analysis (DMA) can be used to analyze both elastic and viscous behavior of filled waxes. As the ASTM standards for DMA were developed for other applications and industries than those in investment casting, the study for the applicability of ASTM standards to investment casting waxes was initiated and partially completed. Results for DMA performed on torsion were obtained for one filled wax, Cerita F20-6. Results for DMA performed on 3-point bending were obtained for three filled waxes. For Cerita F20-6, the shape of the master curve and the shift factors obtained at torsion and 3-point bending are in excellent agreement, validating the use of 3-point bending testing for filled waxes.

\subsection{Technology Transfer}

The techniques developed and material property data obtain in this project were documented in several publications and conference presentations. Detailed reports on alloy and shell mold materials were also issued to the participating companies. Through the ORNL work conducted in this project, the areas of material property measurement and modeling of material behavior has matured, allowing the software vendors to develop appropriate modules in their codes, the next steps in technology transfer. Over the course of the project, ORNL assisted ProCAST with advice, information, material property data, mesh files, ProCAST setup files, allowing immediate dissemination of the information to industry.

Recommendations were made to Investment Casting Institute on measurement techniques for waxes. Recommendations for mechanical testing of waxes were made based on testing one unfilled wax and one filled wax, both used by the industry. The recommendations made could be used to establish new testing guidelines for waxes in the investment casting industry.

\subsection{Publications and Patents Resulting from Project}

This project resulted in the following conference papers and archival journal articles reflecting results throughout the project:

Sabau, A.S., 2004, “Tests For Determining Viscoelastic Properties Of Investment Casting Waxes," Paper No. 1, 48th Annual Technical Meeting, Investment Casting Institute.

Sabau, A.S., 2005, "Numerical simulation of the investment casting process," Transactions of American Foundry Society, 2005, paper 05-160, pp. 407-417.

Sabau, A.S. 2006, "Alloy Shrinkage Factors For The Investment Casting Process," Metallurgical and Materials Transactions B, Vol. 37B, pp. 131-140.

Sabau, A.S. 2006, Prediction of Alloy Shrinkage Factors for the Investment Casting Process, 110th Metalcasting Congress, April 18-21 2006, Columbus, OH, paper 06-004.

Sabau, A.S. 2007, Shrinkage Prediction for the Investment Casting of Stainless Steels, 111th Metalcasting Congress, May 15-18 2007, Houston, TX, paper 07-042.

Sabau, A.S. and Porter, W.D., 2007, Alloy Shrinkage Factors for the Investment Casting of 17-4PH stainless Steel Parts, In print “Metallurgical and Materials Transactions B.” 2008. 


\section{Conclusions}

In this study, the alloy shrinkage factors were obtained using numerical simulations for the first time for the investment casting of 17-4PH stainless steel parts, a high melting point alloy. There is a high probability that the experimental data available in the literature for material properties did not cover the entire temperature range necessary for process simulation. Thus, assumptions must be made in order to obtain material property data, especial mechanical properties at high temperature. The alloy dimensions were obtained from numerical simulation results of solidification, heat transfer, and deformation phenomena. As compared with experimental results, the numerical simulation results for the shrinkage factors were over-predicted.

For the first time in the investment casting industry, the thermo-mechanical properties of unfilled and filled waxes were measured. Recommendations were made to Investment Casting Institute on measurement techniques for waxes. Recommendations for mechanical testing of waxes were made based on testing one unfilled wax and one filled wax. The recommendations made could be used to establish new testing guidelines for waxes in the investment casting industry.

It was found that dynamical mechanical analysis (DMA) can be used with confidence to analyze both elastic and viscous behavior of filled waxes. As the ASTM standards for DMA were developed for other applications and industries than those in investment casting, the study for the applicability of ASTM standards to investment casting waxes was initiated and partially completed. For Cerita F20-6, the shape of the master curve and the shift factors obtained at torsion and 3-point bending are in excellent agreement, validating the use of 3-point bending testing for filled waxes. The data on bending DMA shows larger values than those obtained on torsion DMA. This effect needs to be further understood.

These findings are very important for future investigations and for the enhancement of commercial investing casting software. Pending availability of material property data, the computer simulation software is mature enough to quantitatively predict shrinkage factors for high melting point alloys with an accuracy less than that for light cast alloys. 



\section{Recommendations}

Prediction of shrinkage factors with high accuracy is possible in the investment casting industry, pending that material properties are measured and appropriate material models are available in commercial casting software. In order to obtain data for a specific foundry, combined experimental and computational programs must be conducted. The experimental program should concentrate on measuring material properties. The experimental program could be relatively small, since it could be carried only once for each material. Based on the results presented in previous sections, the following recommendations were made for the use of numerical simulation in the investment casting process.

\subsection{Shell}

Additional work must be performed to account for creep properties during investment casting of heavy sections. Recommendations for the shell mold presented in the progress report for phase II need to be followed (Sabau, 2005).

\subsection{Alloy}

Several assumptions need to be made in order to obtain a complete set of mechanical property data at high temperatures. The quality of the estimated data based on assumptions need to be assessed by comparison with experimental data. Due to phase transformations, the thermal expansion of the alloy is different on cooling than on heating. Thermal expansion data for the alloy must be obtained on cooling, not on heating, as is usually reported in the literature.

\subsection{Wax}

The users need help in dealing with the post-processing of the DMA data. Commercial software vendors, such as ProCAST to bridge the gap between the raw data provided by measurements and the data needed in viscoelastic models in a simpler format, such as the shift factor and Prony series. The computer implementation of this post-processing would have the benefit of reducing the cost for testing the wax material and enabling more resources towards the simulations. Another possibility would be to take as input the creep test data for a viscoelastic material, without asking the user for Prony series.

\subsection{Technology Transfer}

Additional work is needed to enhance the wax model. The viscoelastic module implemented in ProCAST needs to be validated. Mechanical properties for the alloy, especially at high temperature need to be measured.

Echoing the foundry industry needs, the project steering committee members informed the wax suppliers of the increasing demand for wax properties. Foundries can now effectively use the wax property data as the new wax module was recently added to the software suite for the investment casting by ProCAST. The commercialization of wax module will provide an incentive for the wax suppliers to provide the data on mechanical properties of waxes, whose use in foundries will lead to significant advances in the investment casting industry. 


\section{References}

Abdella, K., International Journal of Non-Linear Mechanics, Vol. 41, 2006, pp. 456-463

Achari, S. and L.N. Satapathy, Mullite-Based Refractories for Molten-Metal Applications, American Ceramic Society Bulletin, Vol. 82, pp. 2, 2003.

AK Steel, Product Data Bulletin, http://www.aksteel.com/markets_products/stainless_precipitation.asp

ASM alloy Center: Materials Property Data, http://products.asminternational.org/matdb/index.jsp

Atlas of Formability, Concurrent Technologies Corporation, 1996, http://www.nmc.ctc.com/ekb/ekb atlas.cfm

Bellet, M.; Decultieux, F.; Menai, M.; Bay, F.; Levaillant, C.; Chenot, J. L.; Schmidt, P.; and Svensson, I. L. 1996, "Thermomechanics of the Cooling Stage in Casting Processes: ThreeDimensional Finite Element Analysis and Experimental Validation," Metallurgical and Materials Transactions, Vol. 29B, pp. 81-99.

Browne, D.J., and Sayers, K., 1995, "Experimental Measurement of Investment Shell Properties and Use of the Data in Casting Simulation Software," Proc. 7-th Conference Model. Casting Welding Adv. Solid. Process.

Chen, S. L.; F. Zhang, S. Daniel, F. Y. Xie, X. Y. Yan, Y. A. Chang, R. Schmid-Fetzer, W. A. Oates, "Calculating phase diagrams using PANDAT and PanEngine," JOM, 2003, vol. 55, pp. 48-51.

Chen, J. and Young, B., 2006, Vol. 28, pp. 229-239.

Drezet, J.-M., and Rappaz, M. 1996. "Modeling of Ingot Distortion during Direct Chill Casting of Aluminum Alloys," Metallurgical and Materials Transactions, Vol. 27A, pp. 3214-3225.

Fachinotti, V. D. \& Cardona A., J. of Materials Processing Technology, Vol. 135, pp. 30-43, 2003

Fieldhouse, I. B. and Lang J. I., Measurement of Thermal Properties, Wright Air Development Division, Report 1-119, 1961.

Frankel, J.I. Porter, W.D., and Sabau, A., Journal of Thermal Analysis and Calorimetry, 2005, Vol. 82, pp. 171-177.

Fukuhara, M. and A. Sanpei, Japanese Journal of Applied Physics, Vol. 33, pp. 2890-2893 (1994).

Goodson, C.C., Simulation of Microwave Heating of Mullite Rods, Master's Thesis, Virginia Polytechnic Institute and State University, 1997

Guo J, Samonds MT, Journal of phase equilibria and diffusion, Vol. 28, pp. 58-63, 2007.

Hammond VH, Elzey DM, Elevated temperature mechanical properties of partially sintered alumina, Composites Science and Technology, vol. 64, pp. 1551-1563, 2004.

Irvine, K.J. et al, Controlled-transformation stainless steels, in The Metallurgical Evolution of Stainless Steels, ed. F.B Pikering, American Society for Metals, Metals Park, Ohio, 1979, pp. 121-141.

Jones S.; Jolly M.R.; Lewis K. Development of techniques for predicting ceramic shell properties for investment casting, British Ceramic Transactions, Volume 101, pp. 106-113.

Kajitani, T., Drezet, J.-M. and M. Rappaz, Met. Mater. Trans., Nr. 32A, pp. 1479-88, 2001.

Kozlowski, P. F., J. A. Azzi, B. G. Thomas and H. Wang, Metallurgical Transactions A, Vol. 23A, 1992, pp. 903-918.

Menard, K.P., 1999, "Dynamic Mechanical Analysis: A Practical Introduction to Techniques and Applications," CRC Press, Boca Raton, Florida.

Metallic Materials Properties Development and Standardization (MMPDS). U.S. Department of Transportation, 2003. 
Munro RG, Analytical representations of elastic moduli data with simultaneous dependence on temperature and porosity, Journal of Research of the National Institute of Standards and Technology, Vol. 109, pp. 497-503, 2004.

Munro RG, Effective medium theory of the porosity dependence of bulk moduli, Journal of the American Ceramic Society, vol. 84, pp. 1190-1192, 2001.

Munro RG, Evaluated Material Properties for a Sintered alpha- $\mathrm{Al}_{2} \mathrm{O}_{3}$, Journal of the American Ceramic Society, Vol. 80, pp. 1919-1928,1997.

Perzyna, P.: Quarterly Applied Math., 1963, vol. 20, pp. 321-332.

Porter, W.D. and Maziasz, P.J., Scripta Metallurgica et Materialia, 1993, Vol. 29, pp. 1043-1048.

Pierer, R., Bernhard, C. and C. Chimani, Transactions on Modelling and Simulation, Vol 41, 20-22, Malta (2005), pp. 757-768.

O'Mahoney D., Browne D.J., "Use of Experiment and an Inverse Method to Study Interface Heat Transfer During Solidification in the Investment Casting Process", Exper. Ther. Fluid Sci., 22(3-4), 2000, pp. 1-12.

Rack, H.J., 1981, "Physical and Mechanical Properties of Cast 17-4 PH Stainless Steel," 1981, Sandia Report, SAND-80-2302, TTC-0161, Issued Febr. 1981.

Rowe, G. M., and Sharrock, M. J. 2000. "Development of Standard Techniques for the Calculation of Master Curves for Linear-Visco Elastic Materials," First International Symposium on Binder Rheology and Pavement Performance, University of Calgary, Alberta, Canada, August 14-15.

Russell, L. M., L. F. Johnson, D.P.H. Hasselman, and R. Ruth, 'Thermal Conductivity/Diffusivity of Silicon Carbide Whisker Reinforced Mullite', J. Am. Soc. Vol. 70:C-226-229, 1987.

Sabau, A.S., Metallurgical and Materials Transactions, 2006, Vol. 37B, pp. 131-140.

Sabau, A.S. and Viswanathan, S., Thermophysical Properties of Zircon and Fused Silica-based Shells used in the Investment Casting Process, Transactions of American Foundry Society, 2004, Vol. 112, paper 04-081

Sahai V. and R.A. Overfelt: AFS Trans., 1995, vol. 103, pp. 627-32.

Sabau, A. S. 2005. "Numerical Simulation of the Investment Casting Process," Transactions of American Foundry Society, paper 05-160.

Sabau, A. S., and Viswanathan, S. 2000. "Material Properties for Predicting Wax Pattern Dimensions in Investment Casting," Paper No. 4, 48th Annual Technical Meeting, Investment Casting Institute, Dallas, TX, Oct. 15-18.

Sabau, A. S., and Viswanathan, S. 2001. "Determining Wax Pattern Dimensions in Investment Casting Using Viscoelastic Models," Paper No. 3, 49th Annual Technical Meeting, Investment Casting Institute, Orlando, FL, Oct. 7-10.

Sabau, A. S., and Viswanathan, S. 2003. "Material Properties for Predicting Wax Pattern Dimensions in Investment Casting," Materials Science \& Engineering A, Vol. 362A, pp. 125-134.

Sabau, A. S., and Viswanathan, S. 2001. "Critical Material Properties for Predicting Pattern Tooling Dimensions in Investment Casting," Transactions of American Foundry Society, Paper No. 01017, pp. 1-18.

Sabau, A. S., and Viswanathan, S. 2001. "Numerical Simulation of Wax Pattern Dimensions in Investment Casting," Proceedings of Computational Modeling of Materials, Minerals, and Metals Processing, 2001 Annual Fall TMS Meeting, San Diego, CA, Sept. 23-26, pp. 431-440.

Sabau, A. S., and Viswanathan, S. 2001. "Determining Wax Pattern Dimensions in Investment Casting Using Viscoelastic Models," Investment Casting Institute 49th Annual Meeting, Orlando, FL, October 7-10, 2001, paper no. 3.

Sandmeyer Steel Company, 2005, Property data sheet, http://www.stainlessplate.com/images/174PH-Spec-Sheet.pdf 
Schwerdtfeger, K.; M. Sato, and K-H. Tacke: Metallurgical and Materials Transactions, 1998, vol. 29B, pp. 1057-1068.

Snow, J. D., in Proceedings of 43rd Annual Meeting of the Investment Casting Institute, Dallas, TX, 1995, Oct. 29-Nov. 1, Paper no. 18.

Snow, J. D., 2004, personal communication.

Straton, R. R., et al. Ceramics Testing Guidebook, Investment Casting Institute.

Touloukian, Y.S., Thermal Radiative Properties, Vol. 8, New York-Washington, p.142, 1972.

Touloukian Y. S. et al., 1979, Thermophysical Properties of Matter, (now Thermophysical Properties of Matter Database, https://cindasdata.com)

Wereszczak, A. A., K. Breder, M.K. Ferber, T.P. Kirkland, A. Payzant, C. Rawn, E. Krug, C. L. LaRocco, R.A. Pietras, and M. Karakus, "Dimensional Changes and Creep of Silica Core Ceramics Used in Investment Casting of Superalloys," Journal of Mat. Science, 37 4235-45 (2002).

Waite, D. M., and Samonds, M. T. 1990. "Finite Element Solidification Analysis of Investment Castings," 38th Annual Technical Meeting, Investment Casting Institute.

Weddington, V. L.; Reddy, G. P.; and Mobley, C. E. 1990. Dimensional Control in the Investment Casting Process, Report EMTEC/CT/TR-90-14, Edison Materials Technology Center, Dayton, $\mathrm{OH}$.

Wu JH, Lin CK, Journal of materials science, 2003, vol. 38, pp. 965-971. 


\section{Appendix A. Thermo-Mechanical Models of Alloys}

The analysis performed for the Atlas of Formability data is described below. According to the information from the Atlas of Formability, the plastic flow behavior of 17-4 PH stainless steel was studied by conducting compression tests at various temperatures $\left(950-1250{ }^{\circ} \mathrm{C}\right)$ and strain rates of 0.001:20 1/sec. The testing procedures involved isothermal compression tests on a servo-hydraulic MTS machine of cylindrical specimens with a diameter of $12.7 \mathrm{~mm}$ and a height of $15.9 \mathrm{~mm}$. Load and stroke data were acquired during the tests and subsequently converted to true stress-true strain curves. The stress-strain curves available from the Atlas of Formability were used to estimate the yield stress at temperatures of 950 to $1250{ }^{\circ} \mathrm{C}$. Typical true-stress true-strain data are shown in Figure A.1 at temperatures of 950 and $1250{ }^{\circ} \mathrm{C}$ for all the strain rates available. Data available at the strain rate of 0.001 1/sec shown in Figure A.2 was used to estimate the yield strength.
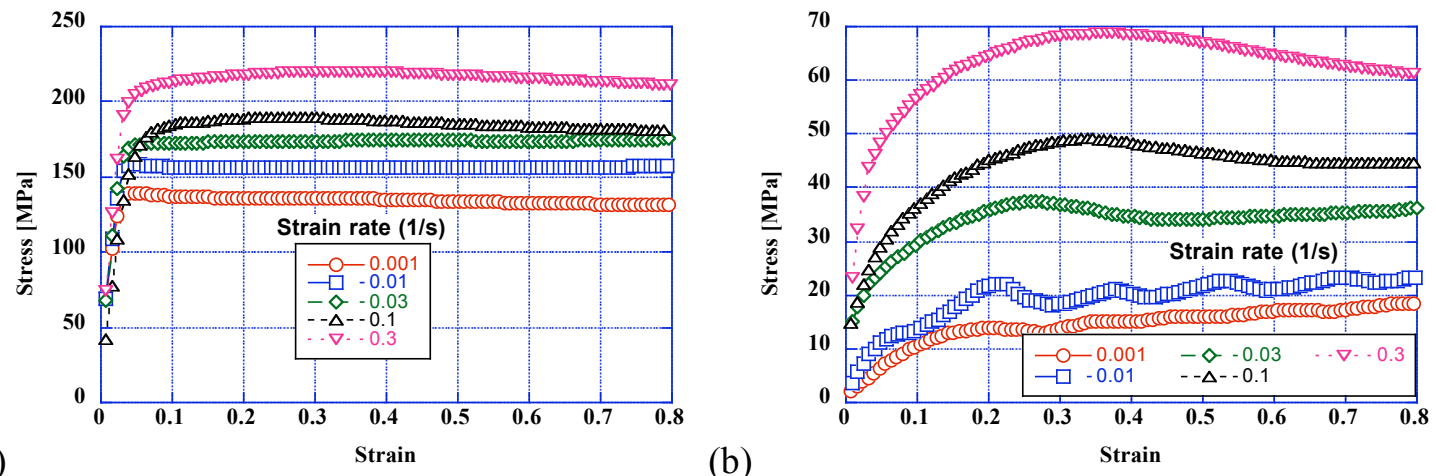

(a)

(b)

Figure A.1. True-strain true-stress data at temperatures of (a) 950 and (b) $1250{ }^{\circ} \mathrm{C}$ (Atlas of Formability).

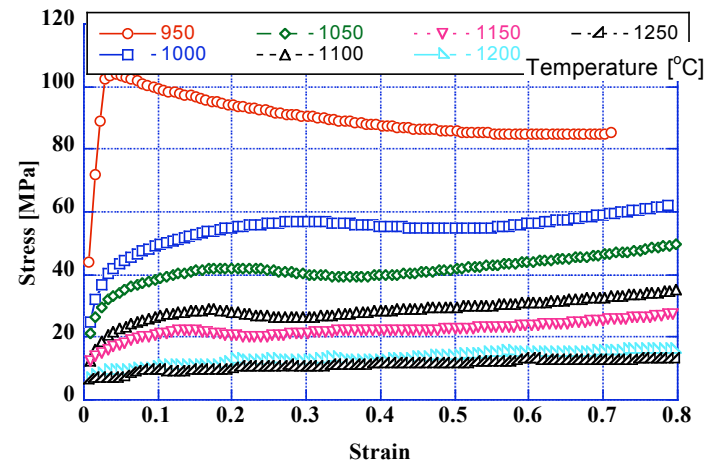

Figure A.2. True-strain true-stress data at a strain rate of $0.001 \mathrm{~s}^{-1}$ as a function of temperature used to estimate the yield stress (Atlas of Formability).

\section{Appendix A References}

Atlas of Formability, Concurrent Technologies Corporation, 1996, http://www.nmc.ctc.com/ekb/ekb_atlas.cfm 


\section{Appendix B. Constitutive Equations for Modeling Wax Deformation}

The principle of time-temperature superposition is based on the observation that time and temperature have an equivalent influence on the viscoelastic properties; an increase in temperature corresponds to an extension of the time scale of the experiment. The frequency domain in the master curve must be large enough to cover the relevant domain for our process. As we can see from these relationships, if the shear modulus must be obtained over a time domain $\left[t_{1}: t_{2}\right]$, the required frequency test domain is $\left[0.1 / t_{2}: 10 / t_{1}\right]$. The time domain over which shear modulus is needed depends on size of the part and thermal diffusivity of waxes (Sabau, 2004) was estimated for small patterns of thickness less than one inch to be approximately $[0: 24$ hours $]$, or $\left[0.01: 10^{5}\right]$ seconds. This would correspond to a frequency domain of $\left[10^{-6}: 10^{3}\right] \mathrm{rad} / \mathrm{seconds}$. The modulus for thermo-rheologically simple materials is given by

$$
G(t-s, T)=G\left(\xi(t)-\xi(s), T_{0}\right),
$$

where the reduced time, $\xi(t)$, is given as a function of the shift factor, $a_{T}$, as

$$
\xi(t)=\int_{0}^{t} \frac{1}{a_{T}(T(\phi))} d \phi .
$$

For a generalized Maxwell-material, the shear relaxation modulus as a function of time, $t$, is given as

$$
G(t)=g_{0}+\sum_{i=1}^{N} g_{i} \exp \left(-t / \lambda_{i}\right)
$$

where $\lambda_{i}$ is the relaxation time and $g_{i}$ is the relaxation strength. These material constants were determined by a nonlinear regression of the master curve data, using the IRIS software (Baumgaertel and Winter 1989), and are shown in Table B.1 for DMA data obtained using the torsion fixture data.

Table B.1. Relaxation times, $\lambda_{i}$, and relaxation strengths, $g_{i}$, determined from experimental measurements by nonlinear regression analysis at the reference temperature of $40^{\circ} \mathrm{C}$ for Cerita F20-6 wax (torsion DMA).

\begin{tabular}{|l|l|l||l|l|l|}
\hline No. & \multicolumn{1}{|c|}{$\left.g_{i} \mathbf{( P a}\right)$} & \multicolumn{1}{|c|}{$\boldsymbol{\lambda}_{i}(\mathbf{s})$} & \multicolumn{1}{c|}{ No. } & \multicolumn{1}{c|}{$g_{i} \mathbf{( k P a )}$} & $\boldsymbol{\lambda}_{i}(\mathbf{s})$ \\
\hline 1 & $3.14 \mathrm{e}+08$ & $1.97 \mathrm{E}-09$ & 10 & $1.95 \mathrm{e}+07$ & $3.54 \mathrm{E}-02$ \\
\hline 2 & $6.29 \mathrm{e}+07$ & $4.63 \mathrm{E}-08$ & 11 & $1.45 \mathrm{e}+07$ & $1.97 \mathrm{E}-01$ \\
\hline 3 & $5.69 \mathrm{e}+07$ & $2.55 \mathrm{E}-07$ & 12 & $1.08 \mathrm{e}+07$ & $1.18 \mathrm{E}+00$ \\
\hline 4 & $5.66 \mathrm{e}+07$ & $1.36 \mathrm{E}-06$ & 13 & $7.75 \mathrm{e}+06$ & $7.22 \mathrm{E}+00$ \\
\hline 5 & $5.36 \mathrm{e}+07$ & $7.43 \mathrm{E}-06$ & 14 & $5.78 \mathrm{e}+06$ & $4.71 \mathrm{E}+01$ \\
\hline 6 & $4.77 \mathrm{e}+07$ & $4.09 \mathrm{E}-05$ & 15 & $4.52 \mathrm{e}+06$ & $3.35 \mathrm{E}+02$ \\
\hline 7 & $4.02 \mathrm{e}+07$ & $2.25 \mathrm{E}-04$ & 16 & $3.97 \mathrm{e}+06$ & $2.67 \mathrm{E}+03$ \\
\hline 8 & $3.22 \mathrm{e}+07$ & $1.22 \mathrm{E}-03$ & 17 & $1.00 \mathrm{e}+07$ & $5.65 \mathrm{E}+04$ \\
\hline 9 & $2.57 \mathrm{e}+07$ & $6.51 \mathrm{E}-03$ & & & \\
\hline
\end{tabular}




\section{Appendix B References}

Baumgaertel, M., and Winter, H. H. 1989. "Determination of Discrete Relaxation and Retardation Time Spectra from Dynamic Mechanical Data," Rheol. Acta, Vol. 28, p. 511.

Sabau, A.S., 2004, "Tests For Determining Viscoelastic Properties Of Investment Casting Waxes," Paper No. 1, 48th Annual Technical Meeting, Investment Casting Institute. 


\section{Appendix C. DMA data from measurements conducted at HTML/ORNL}

The DMA measurements were performed using a 3-point bend fixture from 0 to $55^{\circ} \mathrm{C}$ at $5{ }^{\circ} \mathrm{C}$ temperature increments. The raw data from the DMA measurements are shown in this Appendix for all the three filled waxes considered in Tables $\mathrm{C} 1, \mathrm{C} 2$, and $\mathrm{C} 3$. The data on storage and loss modulus shown in these tables were calculated the Youngs modulus, and not for the shear modulus. The storage and loss modulus were evaluated in Tables C1-3 using the following relationships:

Modulus $=$ Stiffness $*$ GF

$G F=\frac{0.25}{W}\left[\left(\frac{L_{O}}{H}\right)^{3}+0.75(1+v) \frac{L_{O}}{H}\right]$

\section{(C.1)}

GF was the geometry factor, given above for the 3-point bending test. The distance between the clamps $L o$ was $50 \mathrm{~mm}$. The thermal expansion of the wax was not considered when the storage and loss modulus were evaluated in the tables below, i.e., the sample width and thickness were 10 and $4 \mathrm{~mm}$. The values shown in the three tables below can be changed to account for the thermal expansion of the wax by allowing for a temperature dependence of the width and thickness dimension in the geometry factor shown above. This thermal expansion conversion was performed for the result shown in the body of the report for Cerita F20-6 wax.

Table C1. DMA results for Cerita F20-6 wax.

\begin{tabular}{|c|c|c|c|c|c|c|c|c|c|c|c|c|c|c|}
\hline Time & Temp. & $\begin{array}{l}\text { Youngs } \\
\text { Storage } \\
\text { Modulus }\end{array}$ & $\begin{array}{l}\text { Youngs } \\
\text { Loss } \\
\text { Modulus }\end{array}$ & Stress & Freq. & $\begin{array}{l}\text { Drive } \\
\text { Force }\end{array}$ & Amplitude & Strain & $\begin{array}{c}\text { Displace- } \\
\text { ment }\end{array}$ & $\begin{array}{l}\text { Static } \\
\text { Force }\end{array}$ & Position & Length & Force & Stiffness \\
\hline$(\min )$ & $\left({ }^{\circ} \mathrm{C}\right)$ & (MPa) & (MPa) & $(\mathrm{MPa})$ & $(\mathrm{Hz})$ & $(\mathrm{N})$ & $(\mu \mathrm{m})$ & $(\%)$ & $(\mu \mathrm{m})$ & $(\mathrm{N})$ & $(\mathrm{mm})$ & $(\mathrm{mm})$ & $(\mathrm{N})$ & $(\mathrm{N} / \mathrm{m})$ \\
\hline 16.2907 & $-4.78 \mathrm{E}-03$ & 2263.87 & 133.686 & 0.215952 & 0.1 & 0.463897 & 9.99926 & 0.00953904 & 42.0452 & 0.572541 & 3.1894 & 50.0418 & 0.472287 & 47232.1 \\
\hline 44.7935 & 4.97162 & 2127.6 & 132.095 & 0.202969 & 0.1 & 0.436582 & 10 & 0.00953978 & 46.8486 & 0.579749 & 3.19421 & 50.0475 & 0.443893 & 44389.1 \\
\hline 72.102 & 9.94321 & 1891.96 & 159.447 & 0.180668 & 0.1 & 0.390074 & 10.01 & 0.00954924 & 47.5955 & 0.514014 & 3.19493 & 50.0477 & 0.395121 & 39472.7 \\
\hline 99.7457 & 14.9468 & 1603.97 & 191.309 & 0.153252 & 0.1 & 0.332911 & 10.0155 & 0.00955454 & 48.1825 & 0.429428 & 3.19548 & 50.048 & 0.335162 & 33464.3 \\
\hline 127.821 & 19.9488 & 1248.99 & 213.035 & 0.119298 & 0.1 & 0.261883 & 10.0124 & 0.00955157 & 47.141 & 0.338631 & 3.1944 & 50.0472 & 0.260904 & 26058.1 \\
\hline 155.694 & 24.9678 & 871.731 & 190.298 & 0.083218 & 0.1 & 0.184966 & 10.0069 & 0.00954629 & 40.0769 & 0.23875 & 3.18729 & 50.0404 & 0.181998 & 18187.3 \\
\hline 183.873 & 29.9772 & 577.683 & 135.51 & 0.0552325 & 0.1 & 0.12356 & 10.0223 & 0.00956104 & 52.1502 & 0.156965 & 3.19933 & 50.0523 & 0.120793 & 12052.4 \\
\hline 212.41 & 34.9795 & 363.911 & 97.1682 & 0.0346992 & 0.1 & 0.0784081 & 9.99512 & 0.00953509 & 96.9641 & 0.0986726 & 3.24412 & 50.097 & 0.0758872 & 7592.42 \\
\hline 242.387 & 39.9842 & 193.283 & 64.4409 & 0.0184252 & 0.1 & 0.0425144 & 9.99266 & 0.00953274 & 155.963 & 0.053063 & 3.3031 & 50.1558 & 0.0402959 & 4032.55 \\
\hline 272.204 & 44.9911 & 91.4388 & 32.5279 & 0.0087347 & 0.1 & 0.0203687 & 10.0134 & 0.0095525 & 267.271 & 0.0253699 & 3.4144 & 50.2671 & 0.0191028 & 1907.73 \\
\hline 302.498 & 50.006 & 33.4324 & 14.6521 & 0.00321093 & 0.1 & 0.0077709 & 10.0676 & 0.00960424 & 570.732 & 0.0098413 & 3.71785 & 50.566 & 0.0070223 & 697.514 \\
\hline
\end{tabular}




\begin{tabular}{|c|c|c|c|c|c|c|c|c|c|c|c|c|c|c|}
\hline Time & Temp. & $\begin{array}{l}\text { Youngs } \\
\text { Storage } \\
\text { Modulus } \\
\end{array}$ & $\begin{array}{c}\text { Youngs } \\
\text { Loss } \\
\text { Modulus } \\
\end{array}$ & Stress & Freq. & $\begin{array}{l}\text { Drive } \\
\text { Force }\end{array}$ & Amplitude & Strain & $\begin{array}{c}\text { Displace- } \\
\text { ment }\end{array}$ & $\begin{array}{l}\text { Static } \\
\text { Force }\end{array}$ & Position & Length & Force & \\
\hline$(\min )$ & $\left({ }^{\circ} \mathrm{C}\right)$ & $(\mathrm{MPa})$ & $(\mathrm{MPa})$ & (MPa) & $(\mathrm{Hz})$ & $(\mathrm{N})$ & $(\mu \mathrm{m})$ & $(\%)$ & $(\mu \mathrm{m})$ & $(\mathrm{N})$ & $(\mathrm{mm})$ & $(\mathrm{mm})$ & $(\mathrm{N})$ & \\
\hline 21.1596 & 0.00251995 & 359.28 & 11.699 & 224714 & 0.32 & 0.482021 & 9.98424 & 0.0095247 & 43.3743 & 0.584771 & 3.19074 & & 0.491451 & 22.7 \\
\hline 49.6624 & & 202.02 & 18.797 & & 0.32 & & & & & & & & & \\
\hline & & 983.7 & 135.909 & & 0.32 & & & & & & & & & \\
\hline 104.615 & & 16.02 & 162. & & 0.32 & & & & & & & & & \\
\hline 132.69 & & 383.11 & 191 & & 0.32 & & & & & & & & & \\
\hline 160. & +01 & 1003.67 & 189. & 85 & 0.32 & 0.2 & & & & & & & & \\
\hline 188.742 & 994 & 74.834 & 151 & & 0.32 & 0.1 & & & & & & & & \\
\hline & 35 & & 104 & & 0.32 & $0.0 s$ & 01 & & & & & & & \\
\hline 256 & 9964 & 245.202 & 76.4 & 091 & 0.32 & 87 & & & .314 & 645 & & & & \\
\hline 277.073 & & 7.842 & 40.3585 & 314 & 0.32 & 34 & & & 3.237 & 2825 & & 2774 & & \\
\hline $30 \varepsilon$ & & 758 & 16.8 & & 0.32 & & & & & & 463 & 5991 & & \\
\hline 22.5552 & 518 & 2438.94 & 109.368 & & 1 & & 748 & 0.0 & 4.0292 & 4188 & 1914 & & & \\
\hline 51. & & 5.24 & 9.39 & & 1 & & & & .055 & & & & & \\
\hline 78.348 & 254 & 7.86 & 122.296 & & 1 & & & & 4633 & 405 & 958 & & & \\
\hline 106.03 & & .54 & 138 & & 1 & & & & & & & & & \\
\hline 134.106 & 946 & 9.97 & 7.14 & & 1 & & & & & & & & & \\
\hline 16 & 977 & 9.61 & 031 & & 1 & & & & & & 409 & & & \\
\hline 190.263 & & 366 & 159.324 & & 1 & & & & & 061 & & & & \\
\hline 218.7 & & 847 & & & 1 & & & & & & & & & \\
\hline 248.679 & & 571 & & & 1 & & & & & 6642 & & & & \\
\hline & & & & & 1 & & & & & 217 & & & & \\
\hline 309.582 & $E+01$ & 134 & 544 & & 1 & & 9769 & & 1.828 & 3317 & 195 & 329 & & \\
\hline & & & & & 3.2 & & & & & & & & & \\
\hline 165 & 702 & 9.74 & & & 3.2 & & & & 4622 & & & & & \\
\hline 3248 & & 7.59 & & & 3.2 & & 34 & & & & & & & \\
\hline 107.346 & $\mathrm{E}+01$ & 4.27 & 227 & & 3.2 & 2673 & & & 5696 & & & & & \\
\hline 135.422 & & 7.49 & & & 3.2 & & & & & & & & & \\
\hline 163.402 & .0027 & 5.62 & & & 3.2 & 2639 & & & & 5508 & 7756 & & & \\
\hline 192.305 & 30 & 0.248 & 5.101 & & 3.2 & & 9723 & & 7964 & 4279 & 2301 & & & 907.4 \\
\hline 220.377 & 921 & 97.234 & & & 3.2 & & & & & & & & & \\
\hline & & & .3202 & & 3.2 & & & & .774 & 893434 & 3493 & & 76 & 782 \\
\hline & & & 58.0324 & & 3.2 & & & & & & & & & \\
\hline & & & & & 3.2 & & & & & & & & 0.0152059 & \\
\hline
\end{tabular}




\begin{tabular}{|c|c|c|c|c|c|c|c|c|c|c|c|c|c|c|}
\hline Time & Temp. & \begin{tabular}{|l|} 
Youngs \\
Storage \\
Modulus
\end{tabular} & $\begin{array}{l}\text { Youngs } \\
\text { Loss } \\
\text { Modulus }\end{array}$ & Stress & Freq. & $\begin{array}{l}\text { Drive } \\
\text { Force } \\
\end{array}$ & Amplitude & Strain & $\begin{array}{c}\text { Displace- } \\
\text { ment }\end{array}$ & $\begin{array}{l}\text { Static } \\
\text { Force }\end{array}$ & Position & Length & Force & Stiffness \\
\hline$(\min )$ & $\left({ }^{\circ} \mathrm{C}\right)$ & (MPa) & (MPa) & $(\mathrm{MPa})$ & $(\mathrm{Hz})$ & $(\mathrm{N})$ & $(\mu \mathrm{m})$ & $(\%)$ & $(\mu \mathrm{m})$ & $(\mathrm{N})$ & $(\mathrm{mm})$ & $(\mathrm{mm})$ & $(\mathrm{N})$ & $(\mathrm{N} / \mathrm{m})$ \\
\hline 24.0963 & -0.00821 & 2580.25 & 107.574 & 0.246127 & 10 & 0.5175 & 9.99908 & 0.00953887 & 45.2224 & 0.64116 & 3.19261 & 50.0451 & 0.538279 & 53832.8 \\
\hline 52.3937 & 5.02453 & 2418.69 & 103.472 & 0.23075 & 10 & 0.485312 & 10.0006 & 0.0095403 & 47.8454 & 0.600308 & 3.19522 & 50.0477 & 0.504651 & 50462.1 \\
\hline 79.7405 & 10.0246 & 2222.21 & 106.167 & 0.21198 & 10 & 0.445975 & 9.9994 & 0.00953917 & 49.898 & 0.552461 & 3.19725 & 50.0497 & & 46362.9 \\
\hline 107.762 & 15.0023 & 1996.51 & 115.138 & 0.190439 & 10 & 0.400754 & 9.99883 & 0.00953862 & 52.5503 & 0.494782 & 3.19988 & 50.0523 & 0.416491 & 41654 \\
\hline 135.838 & 19.9998 & 1726.89 & 135.74 & 0.164688 & 10 & 0.346694 & 9.99677 & 0.00953665 & 53.8564 & 0.423202 & 3.20115 & 50.0534 & 0.360172 & 36028.8 \\
\hline 163.819 & 25.0108 & 1389.63 & 164.988 & 0.132562 & 10 & 0.279319 & .99956 & 0.00953932 & 52.703 & 0.337951 & 3.19996 & 50.052 & 0.289912 & 28992.5 \\
\hline 192.723 & 976 & 1026.88 & 164.835 & 0.0979035 & 10 & 915 & 9402 & & 78.3869 & 801 & 3.22561 & 50.0776 & & \\
\hline 220.798 & 35.0063 & 698.759 & 142.542 & 0.0666582 & 10 & 0.138988 & 9.99976 & 0.00953951 & & & 3.27162 & & & \\
\hline 250.42 & $4.00 E+01$ & 435.575 & 94.8187 & 0.0415273 & 10 & 0.0837693 & 9.9939 & 0.00953392 & .529 & 0.105439 & 3.34269 & 50.1935 & 0.0908203 & 9087.57 \\
\hline 280.276 & 44.9986 & 235.367 & 63.5149 & 0.0224737 & 10 & 0.0421804 & 10.009 & 0.00954834 & 326.351 & 0.0570544 & 3.47349 & 50.3235 & 0.0491499 & 4910.57 \\
\hline 311.121 & 49.9986 & 92.3245 & 28.2548 & 0.00880329 & 10 & 19845 & & & & 0.026 & 666 & 064 & & 1926.2 \\
\hline 24.7002 & .00564271 & 2655.14 & 120.592 & 0.253224 & 31.6 & 0.448645 & & & & & 329 & & 802 & \\
\hline 52.9122 & $5.03 E+00$ & 2490.42 & 112.421 & 0.237513 & 31.6 & 0.415762 & 9.9972 & 0.00953707 & 48.3801 & 0.616555 & 3.19576 & 50.0482 & 0.519441 & 51958.7 \\
\hline 80.4308 & 0.0246 & 2294.53 & 109.49 & 0.218862 & 31.6 & 6681 & .99863 & 843 & 50.7755 & 1476 & 3.19813 & 505 & 651 & 47871.7 \\
\hline 108.452 & 134 & 2074.98 & 113.509 & 0.197921 & 31.6 & 2779 & 867 & 847 & 3874 & 164 & 3.20122 & 535 & 854 & 43291.1 \\
\hline 136.529 & .0086 & 1820.04 & 129.126 & 0.173601 & & & 9847 & & & 801 & 353 & & 9665 & 72.3 \\
\hline 164.511 & 25.0052 & 1507.07 & 155.931 & 0.143723 & 31.6 & 0.219646 & 9.99668 & 0.00953657 & 56.7074 & 0.366445 & 3.20398 & 554 & 4322 & 31442.6 \\
\hline 193.42 & 29.9973 & 1147.42 & 167.914 & 0.109449 & 31.6 & 0.148346 & 9.99891 & 0.0095387 & 84.1225 & 0.277171 & 3.23136 & 50.082 & 364 & 23939 \\
\hline 221.88 & 4.9997 & 809.367 & 154.194 & 0.0771433 & 31.6 & 0.0817464 & 9.99117 & 0.00953132 & 143.542 & 0.209976 & 3.29075 & 50.1363 & 0.168712 & 16886.2 \\
\hline 251.228 & & & 109.071 & 31992 & 31.6 & 0.0273735 & & & & 502 & 5842 & & & \\
\hline 281.055 & 44.9989 & 285.981 & 71.1598 & 0.0272866 & 31.6 & 0.0377228 & 10.0017 & 0.00954139 & 351.724 & 0.0697814 & 3.49887 & 50.3433 & 6757 & 66.54 \\
\hline 311.991 & 49.9952 & 116.266 & 35.4453 & 0.0110881 & 31.6 & 0.0696304 & 9.99697 & 0.00953685 & 744.408 & 0.0288975 & 3.89153 & \begin{tabular}{|l|}
50.7304 \\
\end{tabular} & 0.0242496 & 2425.7 \\
\hline 24.9907 & .00087751 & 2779.26 & 155.864 & 0.265284 & 100 & 0.346467 & 10.0056 & 0.00954513 & .9039 & 0.701048 & 3.19432 & 50.0466 & 176 & 57984.8 \\
\hline 53.2012 & 5.02361 & 2611.4 & 145.181 & 0.249156 & 100 & 0.37939 & 10.0014 & 0.00954111 & 49.5027 & 0.659935 & 3.1969 & 491 & 0.544904 & 54482.6 \\
\hline 80.7213 & 10.018 & 2411.94 & 136.207 & 0.230142 & 100 & 0.418975 & 10.0021 & 0.00954175 & 52.0464 & 0.612352 & 3.19942 & 50.0516 & 0.50332 & 50321.3 \\
\hline 108.761 & 15.0125 & 2194.04 & 132.923 & 0.209345 & 100 & 0.462481 & 10.0018 & 0.0095415 & 55.7559 & 0.5614 & 3.20311 & 50.0551 & 0.457837 & 45775.2 \\
\hline 136.838 & 20.0243 & 1945.65 & 139.783 & 0.185634 & 100 & 0.51242 & 10.0013 & 0.00954099 & 59.1206 & 0.499515 & 3.20645 & 50.0582 & 0.405983 & 40593 \\
\hline 164.838 & 25.0132 & 1651.79 & 165.025 & 0.157583 & 100 & 0.571977 & 10.0004 & 0.00954013 & 61.9635 & 0.429401 & 3.20926 & 50.0604 & 0.344634 & 34462 \\
\hline 193.747 & 30.0116 & 1299.81 & 185.476 & 0.124027 & 100 & 0.643771 & 10.0023 & 0.00954194 & 92.833 & 0.343527 & 3.24009 & 50.0903 & 0.271248 & 27118.5 \\
\hline 222.189 & 35.0011 & 950.666 & 174.441 & 0.0906726 & 100 & 0.71464 & 9.99798 & 0.00953781 & 154.517 & 0.257905 & 3.30174 & 50.1512 & 0.198301 & 19834.1 \\
\hline 251.519 & 39.9912 & 614.597 & 140.114 & 0.0586314 & 100 & 0.783538 & 10.0001 & 0.00953981 & 233.111 & 0.175519 & 3.3803 & 50.2272 & 0.128227 & 12822.6 \\
\hline 281.346 & 44.9809 & 362.49 & 89.9761 & 0.0345817 & 100 & 0.835335 & 10.0003 & 0.00954007 & 390.177 & 0.113844 & 3.53734 & 50.3792 & 0.0756303 & 7562.77 \\
\hline 312.28 & 49.9928 & 159.962 & 42.5137 & 0.0152634 & 100 & 0.877356 & 10.0022 & 0.00954184 & 842.68 & 0.065737 & 3.98982 & 50.8136 & 0.033381 & 3337.36 \\
\hline
\end{tabular}


Table C2. DMA results for Remet PC-15 wax (former RR-15).

\begin{tabular}{|c|c|c|c|c|c|c|c|c|c|c|c|c|c|c|}
\hline Time & Temp. & \begin{tabular}{|l|} 
Youngs \\
Storage \\
Modulus \\
\end{tabular} & $\begin{array}{l}\text { Youngs } \\
\text { Loss } \\
\text { Modulus }\end{array}$ & Stress & Freq. & $\begin{array}{l}\text { Drive } \\
\text { Force }\end{array}$ & Amplitude & Strain & Displacement & $\begin{array}{l}\text { Static } \\
\text { Force }\end{array}$ & Position & Length & Force & Stiffness \\
\hline$(\min )$ & $\left({ }^{\circ} \mathrm{C}\right)$ & (MPa) & (MPa) & (MPa) & $(\mathrm{Hz})$ & $(\mathrm{N})$ & $(\mu \mathrm{m})$ & $(\%)$ & $(\mu \mathrm{m})$ & $(\mathrm{N})$ & $(\mathrm{mm})$ & $(\mathrm{mm})$ & $(\mathrm{N})$ & $(\mathrm{N} / \mathrm{m})$ \\
\hline 22.5783 & -0.0253868 & 2414.88 & 182.122 & 0.45279 & 0.1 & 0.937148 & 19.9982 & 0.01875 & 10.716 & 1.4487 & 3.47696 & 50.011 & 0.945324 & 47270.4 \\
\hline 46.2017 & 5.01196 & 2202.02 & 197.449 & 0.412872 & 0.1 & 0.85643 & 19.9979 & 0.0187497 & & 1.34428 & & & & \\
\hline 68.9107 & 9.99137 & 1933.31 & 204.661 & 0.362608 & 0.1 & 0.754356 & 20.0045 & 0.0187559 & 17.4574 & 1.19733 & 3.48364 & 50.0184 & 0.757045 & 37843.7 \\
\hline 95.1933 & 15.0116 & 1636.76 & 228.904 & 0.306989 & 0.1 & 0.642238 & 20.0045 & 0.0187559 & 17.8374 & 1.0129 & 3.48397 & 50.0194 & 0.640925 & 32039 \\
\hline 122.194 & 20.01 & 1293.57 & 212.003 & 0.242779 & 0.1 & 0.51062 & 20.0176 & 0.0187681 & 10.8538 & 0.80407 & 3.47693 & 50.013 & 0.506868 & \\
\hline 149.575 & 25.0119 & 934.94 & 183.88 & 0.175412 & 0.1 & 0.37176 & & 0.0187619 & & & 3.45519 & & & \\
\hline 178.108 & 30.0123 & 637.233 & 137.277 & 0.119525 & 0.1 & 0.254697 & 20.0056 & 0.0187569 & -29.8802 & 0.400474 & 3.4361 & 49.9731 & 542 & 12473.6 \\
\hline 206.342 & 35.0059 & 375.76 & 86.3268 & 0.0703411 & 0.1 & 0.150629 & 19.9659 & 0.0187197 & 13.0895 & 0.237851 & 3.47903 & 50.0168 & 857 & 7355.36 \\
\hline 232.254 & 39.9968 & 202.874 & 47.4921 & 0.03 & 0.1 & 0.0817423 & 20.0071 & 0.0187583 & 608 & 0.128759 & 3.60952 & 50.1472 & 517 & \\
\hline 258.269 & & 91.1625 & 25.1729 & 0.01 & 0.1 & & & & & & & & & \\
\hline 287.186 & 49.9962 & 23.8368 & 8.5778 & 0.00449185 & 0.1 & 0.0101482 & 987 & 0.018 & 1737.73 & 0.013391 & 5.20362 & 51.8333 & 0.00937799 & 466.596 \\
\hline 20.2076 & -0.0200101 & 2528.07 & 166.184 & 0.473428 & 0.32 & 0.978639 & 19.9736 & 0.0187269 & 11.26 & 1.49586 & 3.47751 & 50.0106 & 0.988413 & 49485.9 \\
\hline 43.6608 & 4.9913 & 2328.28 & 171.877 & 0.436793 & 0.32 & 0.904305 & 20.0093 & 0.0187604 & 17.2343 & 1.42832 & 3.48347 & 50.0175 & 1927 & 45575.2 \\
\hline & & 2087.36 & 187.232 & & 0.32 & 0.81 & & 0.0187765 & & & & & 272 & \\
\hline 92.4834 & 14.9942 & 1791.25 & 203.987 & 0.336141 & 0.32 & 0.70039 & 20.015 & 0.0187657 & 21.9785 & 1.10934 & 3.48814 & 50.0228 & 0.701788 & 663.1 \\
\hline 119.481 & 20.0003 & 1446.67 & 212.52 & 0.271621 & 0.32 & 0.569349 & 20.0255 & 0.0187756 & 17.0085 & 0.90022 & 3.48311 & 50.0192 & 0.567084 & 28318.1 \\
\hline 146.525 & 24.9981 & 1083.91 & 191.888 & 0.203605 & 0.32 & 0.429626 & 20.0349 & 0.0187844 & -1.01179 & 0.678758 & 3.46504 & 50.0027 & 0.425083 & 21217.1 \\
\hline 175.227 & 29.9991 & 745.774 & 146.502 & 0.140108 & 0.32 & 0.297236 & 20.0377 & 0.018787 & -20.6884 & 0.467178 & 3.44531 & 49.983 & 0.292515 & 14598.2 \\
\hline 203.459 & 34.9993 & 453.058 & 101.448 & 0.0851701 & 0.32 & 0.182031 & 20.0505 & 0.018799 & 23.5002 & 0.289466 & 3.48945 & 50.0251 & 0.177816 & 8868.44 \\
\hline 229.536 & 40 & 240.758 & 58.3993 & 0.0452107 & 0.32 & 0.0972269 & 20.0286 & 0.0187785 & 152.831 & 0.155676 & 3.61875 & 50.1543 & 0.0943899 & 4712.75 \\
\hline 255.536 & 44.994 & 109.924 & 29.5528 & 0.0206022 & 0.32 & 0.0447235 & 19.9899 & 0.0187421 & 441.975 & 0.0718859 & 3.90787 & 50.4405 & 0.0430128 & 2151.73 \\
\hline 281.6 & 49.9926 & 32.2374 & 10.8335 & 0.00604506 & 0.32 & 0.0134936 & 20.0001 & 0.0187517 & 1521.93 & 0.021474 & 4.98781 & 51.5211 & 0.0126207 & 631.034 \\
\hline 13.893 & 0.0136531 & 2600.28 & 166.211 & 0.487618 & 1 & 1.00733 & 20.001 & 0.0187525 & 9.8712 & 1.54057 & 3.47614 & 50.0104 & 804 & 50899.4 \\
\hline 39.017 & 4.94825 & 2453.93 & 165.634 & 0.460109 & 1 & 0.951402 & 19.9981 & 0.0187499 & 18.4634 & 1.49239 & 3.48472 & 50.0189 & 0.960605 & 48034.8 \\
\hline 61.7257 & 9.94548 & 2215.67 & 178.051 & 0.415629 & 1 & 0.86124 & 20.0075 & 0.0187586 & 22.0927 & 1.35563 & 3.48831 & 50.0228 & 0.867741 & 43370.8 \\
\hline 86.1688 & 14.9501 & 1948.06 & 192.694 & 0.365465 & 1 & 0.759538 & 20.0095 & 0.0187605 & 25.2353 & 1.18963 & 3.49141 & 50.0261 & 0.76301 & 38132.4 \\
\hline 111.496 & 19.9496 & 1625.18 & 202.018 & 0.304942 & 1 & 0.63654 & 20.0127 & 0.0187636 & 24.7028 & 1.00204 & 3.49083 & 50.0261 & 0.63665 & 31812.3 \\
\hline 138.54 & 24.9626 & 1235.72 & 202.223 & 0.231658 & 1 & 0.487197 & 19.9948 & 0.0187468 & 11.8601 & 0.764189 & 3.47793 & 50.0142 & 0.483649 & 24188.7 \\
\hline 166.406 & 29.965 & 866.366 & 167.106 & 0.162394 & 1 & 0.343901 & 19.9922 & 0.0187443 & -6.0261 & 0.537876 & 3.45999 & 49.9968 & 0.339043 & 16958.8 \\
\hline 196.309 & 34.9782 & 534.077 & 110.692 & 0.100053 & 1 & 0.212841 & 19.9809 & 0.0187338 & 33.9653 & 0.336128 & 3.49993 & 50.037 & 0.208888 & 10454.4 \\
\hline 223.221 & 39.9761 & 288.642 & 65.3018 & 0.0541269 & 1 & 0.115769 & 20.0007 & 0.0187523 & 164.67 & 0.18511 & 3.6306 & 50.1678 & 0.113005 & 5650.05 \\
\hline
\end{tabular}




\begin{tabular}{|c|c|c|c|c|c|c|c|c|c|c|c|c|c|c|}
\hline Time & Temp. & \begin{tabular}{|l|} 
Youngs \\
Storage \\
Modulus \\
\end{tabular} & $\begin{array}{l}\text { Youngs } \\
\text { Loss } \\
\text { Modulus }\end{array}$ & Stress & Freq. & $\begin{array}{l}\text { Drive } \\
\text { Force } \\
\end{array}$ & Amplitude & Strain & Displacement & $\begin{array}{l}\text { Static } \\
\text { Force }\end{array}$ & Position & Length & Force & Stiffness \\
\hline$(\min )$ & $\left({ }^{\circ} \mathrm{C}\right)$ & (MPa) & (MPa) & $(\mathrm{MPa})$ & $(\mathrm{Hz})$ & $(\mathrm{N})$ & $(\mu \mathrm{m})$ & $(\%)$ & $(\mu \mathrm{m})$ & $(\mathrm{N})$ & $(\mathrm{mm})$ & $(\mathrm{mm})$ & $(\mathrm{N})$ & $(\mathrm{N} / \mathrm{m})$ \\
\hline 250.057 & 44.9724 & 133.278 & 32.5063 & 0.0250081 & 1 & 0.0537752 & 20.0131 & 0.0187639 & 447.422 & 0.0857401 & 3.91332 & 50.451 & 0.0522114 & 2608.86 \\
\hline 276.119 & 50.007 & 40.8343 & 12.2927 & 0.00766254 & 1 & 0.0167536 & 20.0142 & 0.0187649 & 1541.06 & 0.0267092 & 5.00695 & 51.5467 & 0.0159977 & 799.317 \\
\hline 13.4013 & 0.0286729 & 2707.69 & 161.312 & 0.507425 & 3.2 & 1.04572 & 19.9878 & 0.0187402 & 11.0436 & 1.6017 & 3.47732 & 50.0111 & 1.05939 & 53002 \\
\hline 38.64 & 4.94988 & 2558.97 & 159.619 & 0.480042 & 3.2 & 0.990078 & 20.0081 & 0.0187592 & 19.871 & 1.55257 & 3.48614 & 50.0202 & 1.00222 & 50090.8 \\
\hline 61.3302 & 9.94655 & 2337.73 & 164.157 & 0.438579 & 3.2 & 0.905862 & 20.0099 & 0.0187609 & 24.0338 & 1.42693 & 3.49027 & 50.0245 & 0.915655 & 45760.1 \\
\hline 85.7533 & 14.957 & 2072.65 & 176.474 & 0.388847 & 3.2 & 0.804929 & 20.0098 & 0.0187608 & 27.6611 & 1.26165 & 3.49386 & 50.0284 & 0.811826 & 40571.4 \\
\hline 111.062 & 19.9489 & 1766.87 & 192.674 & 0.331524 & 3.2 & 0.688648 & 126 & 0.0187634 & 559 & 1.0917 & 3.49491 & 50.0299 & & \\
\hline 138.07 & 24.9566 & 1393.46 & 199.598 & 0.261448 & 3.2 & 0.54607 & 20.0116 & 0.0187625 & & 0.867506 & 3.48486 & 50.0208 & 0.545844 & \\
\hline 165.937 & 29.97 & 998.902 & 176.349 & 0.187425 & 3.2 & 0.393837 & 20.0122 & 0.0187631 & 3386 & 0.623414 & 3.46847 & 50.0053 & 0.391302 & 19553.1 \\
\hline 195.858 & 34.9837 & 625.782 & 125.221 & 0.117404 & 3.2 & 0.247649 & 20.0102 & 0.0187612 & 42.8516 & 0.392533 & 3.50883 & 50.0454 & 0.245114 & 12249.4 \\
\hline 222.807 & 39.9659 & 343.431 & 79.9512 & 0.0644329 & 3.2 & 0.13635 & & 0.0187615 & 174.166 & 0.218686 & 3.6401 & 50.177 & 522 & 6722.53 \\
\hline 249.642 & 44.9831 & 158.549 & 40.0204 & 0.0297472 & 3.2 & 0.0624805 & 20.0112 & 0.0187622 & & & & 50.4601 & 056 & \\
\hline 275.701 & 50.0044 & 51.1409 & 15.2087 & 0.00959376 & 3.2 & 0.0193966 & 20.0083 & 0.0187594 & 1559.02 & 0.0334248 & 5.02491 & 51.5686 & 0.0200296 & 1001.06 \\
\hline 11.7295 & 0.0449494 & 2798.81 & 161.64 & 0.524856 & 10 & 1.0644 & .0012 & 0.0187528 & 4401 & 1.66067 & 3.47773 & 50.0119 & 1.09578 & 54785.7 \\
\hline 37.663 & 4268 & 2670.81 & 160.319 & 00968 & 10 & 1.0159 & 059 & 0.0187572 & 1376 & 1026 & 3.48742 & 50.0215 & 591 & 52280 \\
\hline 60.353 & .94521 & 2449.32 & 161.932 & & 10 & & & & 5721 & 1.48582 & & 50.026 & 9196 & \\
\hline 84.4375 & 14.9597 & 2193.51 & 169.002 & 0.411437 & 10 & 0.834059 & 20.0058 & 0.018757 & 30.0382 & 1.3318 & 3.49625 & 50.0308 & 0.85899 & 42937.1 \\
\hline 109.746 & 19.9456 & 1905.47 & 181.085 & 0.357406 & 10 & 0.724352 & 20.0056 & 0.0187569 & 32.5538 & 1.17096 & 3.49873 & 50.0336 & 0.746184 & 37298.8 \\
\hline 136.588 & 24.9453 & 1545.71 & 196.537 & 28995 & 10 & 0.587489 & 20.0072 & 0.0187584 & 25.254 & 0.956326 & 3.49137 & 50.027 & 0.605351 & 256.7 \\
\hline 164.285 & 29.9616 & 1136.29 & 184.681 & 0.213077 & 10 & 0.430207 & 0003 & 0.0187519 & 9958 & 302 & 3.47805 & & & 42.5 \\
\hline 194.207 & 34.9641 & 723.636 & 139.656 & 0.135712 & 10 & 0.269713 & 20.0028 & 0.0187542 & 52.7273 & 0.450196 & 3.51872 & 50.0562 & 33337 & 14164.9 \\
\hline 221.324 & 39.9549 & 406.922 & 89.6344 & 0.0763322 & 10 & 0.14521 & 20.0072 & 0.0187584 & 186.119 & 0.258377 & 3.65206 & 50.1898 & 0.159365 & 7965.35 \\
\hline 248.326 & 44.9746 & 191.036 & 47.3113 & 0.0358588 & 10 & 0.059717 & 20.0204 & 0.0187707 & 470.152 & 0.123319 & 3.93606 & 50.4749 & 0.0748652 & 3739.45 \\
\hline 274.385 & 50.0007 & 63.7457 & 17.1156 & 0.0120347 & 10 & 0.0104189 & 20.1361 & 0.0188792 & 1598.74 & 0.0415923 & 5.06463 & 51.6072 & 0.0251258 & 1247.8 \\
\hline 11.3838 & 0.0593423 & 2908.96 & 166.977 & 0.545325 & 31.6 & 0.93841 & 19.9944 & 0.0187464 & 12.5223 & 1.72527 & 3.47883 & 50.0126 & 1.13852 & 56941.7 \\
\hline 37.411 & 4.94213 & 2783.82 & 166.177 & 0.522183 & 31.6 & 0.891426 & 20.0065 & 0.0187578 & 22.1208 & 1.66142 & 3.48842 & 50.0222 & 1.0902 & 54492.2 \\
\hline 60.101 & 9.94624 & 2561.87 & 166.731 & 0.480591 & 31.6 & 0.807108 & 20.0083 & 0.0187594 & 26.8118 & 1.53943 & 3.49308 & 50.0269 & 1.00337 & 50147.6 \\
\hline 84.147 & 14.9458 & 2309.58 & 168.936 & 0.433279 & 31.6 & 0.711129 & 20.009 & 0.0187601 & 32.1032 & 1.40465 & 3.49833 & 50.0323 & 0.904591 & 45209.1 \\
\hline 109.455 & 19.9476 & 2036.55 & 176.046 & 0.38204 & 31.6 & 0.607328 & 20.0081 & 0.0187592 & 35.3918 & 1.25025 & 3.50158 & 50.0356 & 0.797616 & 39864.7 \\
\hline 136.279 & 24.9491 & 1691.42 & 193.758 & 0.317293 & 31.6 & 0.476909 & 20.0078 & 0.018759 & 29.6373 & 1.04501 & 3.49578 & 50.0295 & 0.662438 & 33108.9 \\
\hline 163.957 & 29.9592 & 1279.91 & 193.361 & 0.240133 & 31.6 & 0.321418 & 20.0108 & 0.0187617 & 18.8734 & 0.794966 & 3.48495 & 50.0189 & 0.501345 & 25053.7 \\
\hline 193.861 & 34.9674 & 836.346 & 159.446 & 0.156922 & 31.6 & 0.154496 & 20.0119 & 0.0187628 & 61.842 & 0.52011 & 3.52785 & 50.0617 & 0.327618 & 16371.2 \\
\hline 221.016 & 39.9544 & 477.81 & 101.682 & 0.0896069 & 31.6 & 0.0439531 & 20.0022 & 0.0187537 & 195.711 & 0.302058 & 3.66167 & 50.1957 & 0.187079 & 9352.95 \\
\hline
\end{tabular}




\begin{tabular}{|c|c|c|c|c|c|c|c|c|c|c|c|c|c|c|}
\hline Time & Temp. & \begin{tabular}{|l|} 
Youngs \\
Storage \\
Modulus \\
\end{tabular} & $\begin{array}{c}\text { Youngs } \\
\text { Loss } \\
\text { Modulus } \\
\end{array}$ & Stress & Freq. & $\begin{array}{l}\text { Drive } \\
\text { Force }\end{array}$ & Amplitude & Strain & Displacement & $\begin{array}{l}\text { Static } \\
\text { Force }\end{array}$ & Position & Length & Force & Stiffness \\
\hline$(\min )$ & $\left({ }^{\circ} \mathrm{C}\right)$ & (MPa) & (MPa) & $(\mathrm{MPa})$ & $(\mathrm{Hz})$ & $(\mathrm{N})$ & $(\mu \mathrm{m})$ & $(\%)$ & $(\mu \mathrm{m})$ & $(\mathrm{N})$ & $(\mathrm{mm})$ & $(\mathrm{mm})$ & $(\mathrm{N})$ & $(\mathrm{N} / \mathrm{m})$ \\
\hline 248.035 & 44.978 & 230.478 & 57.1574 & 0.0432072 & 31.6 & 0.100122 & 19.9949 & 0.0187468 & 481.186 & 0.14856 & 3.9471 & 50.4828 & 0.0902071 & 4511.51 \\
\hline 274.09 & 50.0011 & 78.7469 & 21.0348 & 0.014771 & 31.6 & 0.156435 & 20.0063 & 0.0187576 & 1626.07 & 0.0519498 & 5.09197 & 51.6728 & 0.0308386 & 1541.44 \\
\hline 10.417 & 0.0605872 & 3051.68 & 171.297 & 0.572471 & 100 & 0.650083 & 20.0081 & 0.0187592 & 11.7995 & 1.79009 & 3.47813 & 50.0114 & 1.19519 & 59735.5 \\
\hline 36.8925 & 4.93866 & 2935.32 & 172.403 & 0.550546 & 100 & 0.694011 & 20.0046 & 0.018756 & 21.4609 & 1.6757 & 3.48776 & 50.0193 & 1.14942 & 57457.7 \\
\hline 59.5825 & 9.93684 & 2714.73 & 177.898 & 0.509157 & 100 & 0.777819 & 20.004 & 0.0187554 & 26.1753 & 1.5589 & 3.49244 & 50.0242 & 1.06301 & 53139.8 \\
\hline 83.4563 & 14.9437 & 2465.66 & 180.806 & 0.462368 & 100 & 0.872485 & 20.0007 & 0.0187523 & 31.5821 & 1.46463 & 3.49783 & 50.031 & 0.965322 & 48264.4 \\
\hline 108.765 & 19.9512 & 2199.67 & 184.173 & 0.412487 & 100 & 0.974021 & 20.0006 & 0.0187522 & 34.2408 & 1.31423 & 3.50045 & 50.0335 & 0.861181 & 43057.8 \\
\hline 135.588 & 24.945 & 1867.12 & 202.026 & 0.350126 & 100 & 1.1018 & 20.0007 & 0.0187522 & 25.701 & 1.09902 & 3.49186 & 50.014 & 0.730986 & 36548.1 \\
\hline 163.096 & 29.9459 & 1460.14 & 210.321 & 0.27377 & 100 & 1.25821 & 19.9978 & 0.0187496 & 14.4168 & 0.875544 & 3.48052 & 49.9982 & 0.57157 & 28581.6 \\
\hline 192.83 & 34.9594 & 992.924 & 189.15 & 0.186192 & 100 & 1.43824 & 20.0002 & 0.0187519 & 56.3861 & 0.616689 & 3.52242 & 50.031 & 0.388727 & 19436.1 \\
\hline 220.07 & 39.9587 & 585.474 & 123.845 & 0.10977 & 100 & 1.59499 & 19.9971 & 0.0187489 & 190.192 & 0.390724 & 3.65617 & 50.1554 & 0.229175 & 11460.4 \\
\hline 247.174 & 44.9894 & 300.191 & 73.6784 & 0.056293 & 100 & 1.70591 & 20.0008 & 0.0187524 & 473.123 & 0.230543 & 3.93906 & 50.4019 & 0.117527 & 5876.13 \\
\hline 273.316 & 50 & 116.897 & 37.5286 & 0.0219203 & 100 & 1.77724 & 20.0001 & 0.0187517 & 1707.72 & 0.134269 & 5.17363 & 51.4832 & 0.0457646 & 2288.22 \\
\hline
\end{tabular}


Table C3. DMA results for Cerita F20-844B wax (former green XP wax).

\begin{tabular}{|c|c|c|c|c|c|c|c|c|c|c|c|c|c|c|}
\hline Time & Temp. & $\begin{array}{c}\text { Youngs } \\
\text { Storage } \\
\text { Modulus } \\
\end{array}$ & $\begin{array}{c}\text { Youngs } \\
\text { Loss } \\
\text { Modulus }\end{array}$ & Stress & Freq. & $\begin{array}{l}\text { Drive } \\
\text { Force }\end{array}$ & Amplitude & Strain & Displacement & $\begin{array}{l}\text { Static } \\
\text { Force } \\
\end{array}$ & Position & Length & Force & Stiffness \\
\hline$(\min )$ & $\left({ }^{\circ} \mathrm{C}\right)$ & (MPa) & (MPa) & $(\mathrm{MPa})$ & $(\mathrm{Hz})$ & $(\mathrm{N})$ & $(\mu \mathrm{m})$ & $(\%)$ & $(\mu \mathrm{m})$ & $(\mathrm{N})$ & $(\mathrm{mm})$ & $(\mathrm{mm})$ & $(\mathrm{N})$ & \\
\hline 42.6148 & 8.94E-05 & 1988.89 & 178.813 & 0.281969 & 0.01 & 0.595072 & 14.968 & 0.0141772 & 63.1875 & 0.732842 & 3.32199 & 50.0627 & 0.602704 & 40266.2 \\
\hline 113.011 & .99074 & 1807.62 & 215.319 & 0.256713 & 0.01 & 0.544332 & 14.9938 & 0.0142017 & 69.4312 & 0.690996 & 3.32822 & 50.0692 & 0.548718 & 96.2 \\
\hline 182.816 & .99434 & 1532.44 & 244.559 & 0.217796 & 0.01 & 0.465482 & 15.0052 & 0.0142124 & 72.7641 & 0.589271 & 3.33151 & 50.0725 & 0.465536 & 31025 \\
\hline 258.73 & & 180.05 & 251.074 & 0.167453 & 0.01 & 0.362448 & 14.9819 & 0.0141904 & 74.0709 & 0.453449 & 3.33275 & & 0.357929 & \\
\hline 338.671 & 19.9966 & 792.688 & 205.852 & 0.112492 & 0.01 & 0.246913 & 14.9828 & 0.0141912 & 69.7036 & 0.31072 & 3.32833 & & & \\
\hline 418.239 & 25.0048 & 494.958 & 115.129 & 0.0702972 & 0.01 & 0.15378 & 14.9949 & 0.0142026 & 59.0341 & 0.195113 & 3.31761 & 50.0594 & 0.150259 & 10020.7 \\
\hline 499.799 & 30.0005 & 313.251 & 77.3613 & .044501 & 0.01 & 0.0978793 & 14.9986 & 0.0142062 & 67.9859 & 0.123824 & 3.32653 & 50.0673 & 0.09512 & \\
\hline 579.116 & & 161.479 & 43.0085 & 0.0229613 & 0.01 & 0.0508859 & 15.0125 & & & 0.0644239 & 3.38261 & & & \\
\hline & 9.9997 & 59.4351 & 22.4397 & $0.00 \varepsilon$ & 0.01 & 0.01 & 15.0165 & 0.0 & 101 & 904 & 3.6386 & 702 & 93 & \\
\hline 863.594 & 45 & 18.7956 & 11.9458 & 0.00267673 & 0.01 & 0.0068944 & 15.0356 & 0.0142413 & 4493.44 & 0.0079999 & 7.75193 & 54.497 & 0.00572145 & 380.526 \\
\hline 994.389 & 50 & 37.7975 & 21.1172 & 0.00536504 & 0.01 & 0.0132529 & 14.9859 & 0.0141942 & 10759.2 & 0.0158361 & 14.0177 & 60.6508 & 0.0114677 & 765.231 \\
\hline & $-1.10 \mathrm{E}-03$ & 2110.83 & & & 0.03 & & & & & & & & & \\
\hline 128.053 & 5.00476 & 1949.46 & 174.539 & 0.276737 & 0.03 & 0.584221 & 14.9874 & 0.0141956 & 429 & 0.707855 & 3.33034 & 50.0708 & 21 & 39467.8 \\
\hline 197.857 & 10.0031 & 1693.91 & 213.657 & 0.240435 & 0.03 & 0.510697 & 14.9858 & 0.0141941 & 284 & 10572 & 3.33428 & 50.0744 & 925 & 34294.1 \\
\hline 280.499 & .9996 & 1360.53 & 239.43 & 3099 & 0.03 & 0.414391 & 847 & 0.014193 & 81.836 & 0.513583 & 3.34055 & 50.05 & 746 & 27544.5 \\
\hline 360.439 & & & 221.085 & & .03 & & & & & & & & & \\
\hline 438.336 & .9997 & 575.966 & 136.211 & 016 & 0.03 & 0.178951 & .9947 & & 61.8098 & 3564 & 3.32039 & 49.9992 & & 11660.7 \\
\hline 519.897 & 30.0021 & 366.347 & 83.6482 & 0.0520457 & 0.03 & 0.113918 & 14.9991 & 0.0142067 & 76.299 & 801 & 3.33485 & 50.0275 & 247 & 7416.88 \\
\hline 597.533 & 35.0014 & 189.827 & 47.3868 & 0.0269935 & 0.03 & 0.0595391 & 5.0132 & \begin{tabular}{|l|}
0.01422 \\
\end{tabular} & 134.088 & 0.0671501 & 3.39261 & 50.1271 & 0.0576982 & 3843.15 \\
\hline 691.034 & 9.998 & 73.4129 & 23.2565 & 0.0104327 & 0.03 & 0.0235398 & 036 & 0.0142109 & 415.279 & 0.0267853 & 3.67378 & 50.4025 & 0.0222996 & 1486.28 \\
\hline 903.698 & 45.0001 & 32.4972 & 16.6376 & 0.00457822 & 0.03 & 0.0111126 & 14.8739 & 4088 & 4532.05 & +323 & 7.79055 & 54.5047 & 0.009 & .923 \\
\hline 1011.11 & 50 & 51.3867 & 27.5942 & 0.00731458 & 0.03 & 0.0178578 & 15.0284 & 0.0142344 & 10792.2 & 0.0184876 & 14.0507 & 60.7792 & 0.0156348 & 1040.35 \\
\hline 59.607 & 0.00118333 & 2198 & 116.502 & 0.312315 & 0.1 & 0.656212 & 15.0016 & 0.014209 & 66.6012 & 0.789952 & 3.32543 & 50.0662 & 0.667569 & 44499.7 \\
\hline 131.842 & 5.00332 & 2064.38 & 133.978 & & 0.1 & 0.617045 & 915 & 0.0141994 & 277 & 741836 & 33183 & 726 & 26561 & 94.5 \\
\hline 201.648 & 10.0049 & 1846.9 & 181.4 & 0.262227 & 0.1 & 0.554528 & 14.9902 & 0.0141982 & 77.6034 & 0.654324 & 3.33637 & 50.0769 & 0.560505 & 37391.4 \\
\hline 285.028 & 14.9958 & 1547.57 & 214.036 & 0.219852 & 0.1 & 0.468315 & 14.9987 & 0.0142063 & 88.5661 & 0.606682 & 3.34732 & 50.0726 & 0.469929 & 31331.3 \\
\hline 365.132 & 19.9966 & 1128.36 & 229.94 & 0.160223 & 0.1 & 0.346309 & 14.9917 & 0.0141997 & 87.3963 & 0.451856 & 3.34608 & 50.0429 & 0.342475 & 22844.2 \\
\hline 442.855 & 24.9934 & 683.32 & 161.773 & 0.0970449 & 0.1 & 0.212083 & 14.9942 & 0.014202 & 66.7656 & 0.251344 & 3.32536 & 50.0085 & 0.207432 & 13834.2 \\
\hline 524.417 & 29.9966 & 428.218 & 93.5064 & 0.060846 & 0.1 & 0.1328 & 15.0017 & 0.0142091 & 83.8136 & 0.170703 & 3.34238 & 50.0406 & 0.130057 & 8669.5 \\
\hline 602.052 & 34.9935 & 226.105 & 54.6241 & 0.03214 & 0.1 & 0.0707055 & 15.0075 & 0.0142146 & 148.969 & 0.0904469 & 3.4075 & 50.1406 & 0.0686986 & 4577.62 \\
\hline 695.195 & 40.0034 & 90.1281 & 24.333 & 0.012796 & 0.1 & 0.0284737 & 14.9896 & 0.0141976 & 430.796 & 0.0321553 & 3.6893 & 50.427 & 0.0273513 & 1824.69 \\
\hline 907.842 & 44.9999 & 43.9507 & 22.6449 & 0.00629075 & 0.1 & 0.0152464 & 15.1116 & 0.0143132 & 4558.85 & 0.0164027 & 7.81735 & 54.5517 & 0.0134464 & 889.806 \\
\hline
\end{tabular}




\begin{tabular}{|c|c|c|c|c|c|c|c|c|c|c|c|c|c|c|}
\hline Time & Temp. & $\begin{array}{l}\text { Youngs } \\
\text { Storage } \\
\text { Modulus }\end{array}$ & $\begin{array}{l}\text { Youngs } \\
\text { Loss } \\
\text { Modulus }\end{array}$ & Stress & Freq. & $\begin{array}{l}\text { Drive } \\
\text { Force }\end{array}$ & Amplitude & Strain & Displacement & $\begin{array}{l}\text { Static } \\
\text { Force }\end{array}$ & Position & Length & Force & Stiffness \\
\hline$(\min )$ & $\left({ }^{\circ} \mathrm{C}\right)$ & (MPa) & (MPa) & (MPa) & $(\mathrm{Hz})$ & $(\mathrm{N})$ & $(\mu \mathrm{m})$ & $(\%)$ & $(\mu \mathrm{m})$ & $(\mathrm{N})$ & $(\mathrm{mm})$ & $(\mathrm{mm})$ & $(\mathrm{N})$ & $(\mathrm{N} / \mathrm{m})$ \\
\hline 1015.08 & 50.0003 & 71.0226 & 39.4213 & 0.0100878 & 0.1 & 0.024767 & 14.9959 & 0.0142036 & 10816.9 & 0.0257837 & 14.0754 & 60.8103 & 0.0215625 & 1437.89 \\
\hline 65.3113 & $3.68 \mathrm{E}-04$ & 2280.26 & 97.1004 & 0.323783 & 0.32 & 0.679476 & 14.9914 & 0.0141994 & 68.2957 & 0.82 & 3.32714 & 50.0677 & 0.69208 & 46165.1 \\
\hline 137.546 & 4.99895 & 2155.31 & 111.923 & 0.306103 & 0.32 & 0.643348 & 14.9945 & 0.0142023 & 74.9843 & 0.773022 & 3.3338 & 50.0743 & 0.65429 & 43635.4 \\
\hline 208.189 & 10.0006 & 1960.38 & 140.323 & 0.27834 & 0.32 & 0.586691 & 14.9902 & 0.0141983 & 81.2723 & 0.697319 & 3.34006 & 50.08 & 0.594946 & \\
\hline 291.569 & 14.9948 & 1697.35 & 182.031 & 0.241017 & 0.32 & 0.510797 & 14.9917 & 0.0141996 & 92.0532 & 0.618316 & 3.35081 & 50.0907 & 0.51517 & 34363.8 \\
\hline 375.066 & 19.9983 & 1294.36 & 218.855 & 0.183738 & 0.32 & 0.394068 & .9871 & 0.0141953 & 96.2912 & 0.485624 & 3.35499 & 50.0722 & 0.392737 & 26205 \\
\hline 452.788 & 24.9979 & 833.657 & 193.261 & 3383 & 0.32 & 056 & 9925 & 0.0142004 & 133 & 591 & 3.33664 & 50.0 & & 77.8 \\
\hline 534.35 & 964 & 497.053 & 108.261 & 0.0705826 & 0.32 & 0.153907 & 4.9923 & 0.0142002 & & 0.188517 & 3.36022 & 50.0546 & & \\
\hline 611.149 & 35.0005 & 269.892 & 63.6364 & 0.0383412 & 0.32 & 0.0841663 & 14.9986 & 0.0142061 & 169.538 & 0.103027 & 3.42807 & 50.1574 & 0.081 & 4.11 \\
\hline 703.438 & 39.9971 & 105.647 & 26.7698 & 0.0150069 & 0.32 & 0.0332192 & 14.9972 & 0.0142049 & 466.724 & 0.0379533 & 3.72523 & 50.4529 & 0.0320771 & 38.87 \\
\hline 916.9 & 45 & 59.5246 & 27.9845 & 0.00849456 & 0.32 & 0.0201788 & 15.0667 & 0.0142707 & 4.93 & 0.0217919 & 7.91 & 54 & & \\
\hline 1022.46 & 50.0007 & 96.6304 & 54.4796 & 0.0137611 & 0.32 & 0.0338604 & 15.0353 & 2409 & & 3396 & 14.161 & 714 & & \\
\hline 66.7068 & 0.00642797 & 2338.49 & 88.374 & 0.332152 & 1 & 0.696432 & 4.996 & 0.0142037 & 69.1259 & \begin{tabular}{|l|}
0.846469 \\
\end{tabular} & 3.32798 & 50.0689 & 0.709969 & 47344 \\
\hline 138.942 & 4.99423 & 2221.84 & 92.9162 & 315632 & 1 & 0.662558 & 14.9983 & 42059 & 217 & 0.801586 & 3.33485 & 50.0758 & 658 & 44982.3 \\
\hline 209.605 & 9.99731 & 2054.31 & 114.674 & 291817 & 1 & 0.613863 & 9974 & 0.0142051 & 656 & 0.735946 & 3.34157 & 823 & 0.623754 & 41590.7 \\
\hline 292.985 & .9984 & 1821 & 149.678 & 258668 & 1 & 54621 & & 0.0142048 & 7008 & 0.651669 & 247 & 932 & & \\
\hline 376.607 & 20.0044 & 1435.54 & 197.79 & 0.203884 & 1 & 0.434572 & 14.9948 & 0.0142026 & 100.032 & 0.542637 & 3.35875 & 50.0804 & 0.435798 & 29063.3 \\
\hline 454.31 & 24.9949 & 983.535 & 209.012 & 0.139712 & 1 & 0.302782 & 14.9975 & 0.0142051 & 83.9427 & 0.368015 & 3.34259 & 50.04 & 0.298632 & 19912.2 \\
\hline 535.872 & 30.0121 & 575.363 & 130.365 & 0.0817414 & 1 & 0.178319 & 14.9994 & 0.0142069 & 104.084 & 0.217725 & 3.36267 & 50.0654 & 0.174721 & 48.5 \\
\hline 612.67 & 0003 & 318.086 & 72.6279 & 1909 & 1 & $0.0 s$ & 996 & 0.0142071 & 177.51 & 0.122124 & 3605 & 50.1715 & 5948 & \\
\hline 704.924 & 39.9977 & 123.945 & 31.2501 & 0.0175974 & 1 & 0.0388047 & 9897 & 0.0141977 & 476.449 & 0.0444863 & 3.73496 & 50.4742 & 76142 & 2509.34 \\
\hline 918.323 & 45.0002 & 77.3532 & 35.2581 & 0.0109393 & 1 & 0.0257216 & 14.9308 & \begin{tabular}{|l|}
0.014142 \\
\end{tabular} & 4675.21 & 0.0270406 & 7.93371 & 54.6713 & 0.0233825 & 1566.06 \\
\hline 1023.98 & 49.9998 & 134.713 & 74.0735 & 0.0191585 & 1 & 0.046727 & 15.015 & 0.0142217 & 10936.5 & 0.0499419 & 14.195 & 60.9288 & 0.0409509 & 2727.33 \\
\hline 67.8525 & $-7.08 \mathrm{E}-04$ & 2401.56 & 85.1793 & 0.341106 & 3.2 & 0.713476 & 14.9958 & 0.0142035 & 70.0425 & 0.870605 & 3.3289 & 50.0697 & 0.729109 & 48620.9 \\
\hline 140.088 & 4.99653 & 2287.02 & 85.2748 & 0.324855 & 3.2 & 0.680132 & 14.9966 & 0.0142043 & 77.1401 & 0.827311 & 3.33598 & 50.0768 & 0.694372 & 46301.9 \\
\hline 210.921 & 10 & 2125.15 & 100.274 & 0.301862 & 3.2 & 0.633042 & 14.9966 & 0.0142043 & 84.7911 & 0.767804 & 3.34361 & 50.0841 & 0.645224 & 43024.7 \\
\hline 294.301 & 15.0035 & 1918.8 & 128.596 & 0.272513 & 3.2 & 0.573037 & 14.9945 & 0.0142023 & 96.6353 & 0.687743 & 3.35542 & 50.0957 & 0.582492 & 38847.1 \\
\hline 377.925 & 19.9977 & 1584.45 & 171.706 & 0.224937 & 3.2 & 0.475866 & 14.9884 & 0.0141966 & 103.956 & 0.565458 & 3.36269 & 50.1023 & 0.4808 & 32078 \\
\hline 456.352 & 25.004 & 1143.91 & 210.344 & 0.162435 & 3.2 & 0.348388 & 14.9921 & \begin{tabular}{|l|}
0.0142 \\
\end{tabular} & 101.139 & 0.429897 & 3.35981 & 50.0601 & 0.347201 & 23159 \\
\hline 537.913 & 30.0008 & 681.5 & 157.666 & 0.0967794 & 3.2 & 0.209933 & 14.9931 & 0.0142009 & 123.388 & 0.256568 & 3.38199 & 50.0355 & 0.206864 & 13797.3 \\
\hline 614.711 & 35.0071 & 371.604 & 82.4956 & 0.0527844 & 3.2 & 0.114046 & 14.9968 & 0.0142045 & 191.923 & 0.141016 & 3.45047 & 50.1815 & 0.112826 & 7523.32 \\
\hline 706.79 & 40.0006 & 146.835 & 39.5212 & 0.0208522 & 3.2 & 0.0449714 & 14.9933 & 0.0142011 & 502.716 & 0.0564361 & 3.76123 & 50.4908 & 0.0445713 & 2972.75 \\
\hline 919.818 & 45.0001 & 101.698 & 45.3787 & 0.0141319 & 3.2 & 0.032037 & 14.6711 & 0.0138959 & 4742.59 & 0.0345629 & 8.00109 & 54.7162 & 0.0302066 & 2058.92 \\
\hline
\end{tabular}




\begin{tabular}{|c|c|c|c|c|c|c|c|c|c|c|c|c|c|c|}
\hline Time & Temp. & \begin{tabular}{|l|} 
Youngs \\
Storage \\
Modulus \\
\end{tabular} & $\begin{array}{c}\text { Youngs } \\
\text { Loss } \\
\text { Modulus } \\
\end{array}$ & Stress & Freq. & $\begin{array}{l}\text { Drive } \\
\text { Force }\end{array}$ & Amplitude & Strain & Displacement & $\begin{array}{l}\text { Static } \\
\text { Force }\end{array}$ & Position & Length & Force & Stiffness \\
\hline$(\min )$ & $\left({ }^{\circ} \mathrm{C}\right)$ & (MPa) & (MPa) & $(\mathrm{MPa})$ & $(\mathrm{Hz})$ & $(\mathrm{N})$ & $(\mu \mathrm{m})$ & $(\%)$ & $(\mu \mathrm{m})$ & $(\mathrm{N})$ & $(\mathrm{mm})$ & $(\mathrm{mm})$ & $(\mathrm{N})$ & $(\mathrm{N} / \mathrm{m})$ \\
\hline 1025.47 & 49.9985 & 177.085 & 96.1464 & 0.0252358 & 3.2 & 0.0603118 & 15.0456 & 0.0142507 & 11040.8 & 0.0662395 & 14.2994 & 61.0042 & 0.053941 & 3585.17 \\
\hline 68.248 & 0.0175263 & 2455.32 & 82.3486 & 0.348797 & 10 & 0.716654 & 14.9982 & 0.0142058 & 70.6713 & 0.892613 & 3.32954 & 50.0705 & 0.745547 & 49709.3 \\
\hline 140.483 & 4.97928 & 2343.86 & 82.2863 & 0.332947 & 10 & 0.684161 & 14.9975 & 0.0142051 & 77.8492 & 0.850584 & 3.3367 & 50.0776 & 0.711668 & 47452.6 \\
\hline 211.336 & 10.0073 & 2188.88 & 88.0828 & 0.310932 & 10 & 0.639003 & 14.9975 & 0.0142051 & 85.8268 & 0.794748 & 3.34466 & 50.0855 & 0.664612 & 44315 \\
\hline 294.716 & 14.997 & 2000.27 & 107.406 & 0.284136 & 10 & 0.584103 & 14.9973 & 0.0142049 & 98.2558 & 0.720688 & 3.35705 & 50.0978 & 0.607335 & 40496.4 \\
\hline 378.341 & 20.0086 & 1699.37 & 147.768 & 0.241378 & 10 & 0.496691 & 14.9963 & \begin{tabular}{|l|}
0.014204 \\
\end{tabular} & 106.618 & 0.604379 & 3.36537 & 50.1058 & 0.51594 & 34404.6 \\
\hline 456.791 & 24.9837 & 1295.75 & 198.777 & 0.184025 & 10 & 0.380029 & 14.9944 & 0.0142022 & 104.51 & 0.460485 & 3.3632 & 50.1031 & 0.39335 & 26233.1 \\
\hline 538.454 & 29.9932 & 804.88 & 179.462 & 0.114353 & 10 & 0.23544 & 15 & 0.0142075 & 131.527 & 0.296744 & 3.39014 & 50.0492 & 0.244428 & 16295.2 \\
\hline 615.252 & 34.9949 & 433.423 & 95.5505 & 0.0615622 & 10 & 0.121012 & 14.996 & 0.0142037 & 200.697 & 0.163945 & 3.45926 & 50.1939 & 0.131588 & 8774.87 \\
\hline 707.277 & 40.005 & 176.95 & 49.7598 & 0.0251638 & 10 & 0.0429877 & 15.0141 & 0.0142208 & 509.442 & 0.0625439 & 3.76796 & \begin{tabular}{|l|}
50.5057 \\
\end{tabular} & 0.0537873 & 3582.46 \\
\hline 920.241 & 44.9999 & 128.27 & 57.128 & 0.0183804 & 10 & 0.0313126 & 15.1288 & 0.0143295 & 4784.06 & 0.0456071 & 8.04257 & 54.7744 & 0.0392878 & 2596.89 \\
\hline 1025.92 & 49.999 & 239.79 & 128.739 & 0.0341676 & 10 & 0.0713378 & 15.0438 & 0.014249 & 11099.7 & 0.0888109 & 14.3582 & 61.0847 & 0.0730327 & 4854.68 \\
\hline
\end{tabular}




\section{Appendix D. Energy Savings}

The cost savings due to the introduction of this technology will primarily come from the increased yield and the elimination of trial and error in the casting design process. This will lead to reduced material and energy needs, and economic benefits. The tools developed will also considerably improve overall productivity and expand markets, although these are somewhat difficult to quantify. Only the energy benefits will be used in calculating energy and environmental savings.

The increased demands for the consolidation of components into fewer parts and the emphasis on netshape parts makes investment casting increasingly attractive for the production of high precision-high integrity castings. In addition, need to increase consistency in investment castings and reduce costs by improving yields and eliminating rework justifies the development of tools for predicting pattern tooling and casting dimensions in investment casting. A large part of the investment casting industry deals with high value iron, nickel, and cobalt-base alloys.

In this program, plant procedures and computational methodologies will be provided to dramatically improve dimensional accuracy of castings through the use of computer simulations. Improving dimensioning practices will reduce the downtime due to mold rework, allow the use of thinner walls by controlling their deformation, increase productivity of the design process, less parts will need machining. Aside from improved casting dimensions, the process analysis will provide information investment casting process that will allow lowering the pouring temperatures assess the effect of wax or shell systems. The technology will specifically result in the following benefits:

- Energy efficiency through scrap reduction and yield increase; (More parts with have their dimensions within blueprint tolerances)

- Pour Molten metal at lower temperatures, resulting from through process analysis.

- Reduced downtime due to mold reworks; Furnace idling; Lost furnace heat. Die rework, and ensuing downtime will be eliminated.

- Less metal: Thinner walls, More structural geometry, less mass, resulting from through process analysis

- Productivity improvements; Less cutting, grinding, rework, heat treat, (More parts with have their dimensions within blueprint tolerances and less part features will need machining)

Assumptions: Scrap deduction from 4\% to 3\%. And increase in yield from 55 to $65 \%$.

Baseline Metric: Existing alloy Melting BTU's/Ton Produced for Investment Casting (IC):

$$
\begin{array}{lll}
\text { HA Steel; IC } & 32.8 \times 10^{6} \mathrm{BTU} / \text { Ton Produced } \mathrm{x} 120,775 \text { Tons Produced } / \mathrm{yr}= & 3.96 \times 10^{12} \mathrm{BTU} / \mathrm{yr} \\
\text { Titanium; IC } & 35.0 \times 10^{6} \mathrm{BTU} / \text { Ton Produced x 8,627 Tons Produced } / \mathrm{yr}= & 0.30 \times 10^{12} \mathrm{BTU} / \mathrm{yr} \\
\text { Aluminum; IC } & 7.5 \times 10^{6} \mathrm{BTU} / \text { Ton Produced } \mathrm{x} 43,134 \text { Tons Produced } / \mathrm{yr}= & 0.32 \times 10^{12} \mathrm{BTU} / \mathrm{yr}
\end{array}
$$

$$
4.58 \times 10^{12} \mathrm{BTU} / \mathrm{yr}
$$

New technology would enable reductions in scrap for all alloy families from $4 \%$ to $3 \%$, on average New technology would enable in increase in yield for all alloy families from $55 \%$ to $65 \%$ on average

New/Old Ratio will be the same for all alloys so it will be determined first: 
All IC alloys $\quad$ 165,900 Tons Shipped x 1.03 (Tons Shipped + Scrap)/Tons Shipped $=$ 170,877 Tons Produced

170,877 Tons Produced $/((55 \%$ existing yield $+10 \%$ yield increase $) / 100)=$ 262,888 Tons Melted

262,888 Tons Melted New Technology / 313,702 Tons Melted Old Technology = 0.838 New/Old Ratio

○ HA steel 116,130 Tons Shipped x 1.03 (Tons Shipped + Scrap)/Tons Shipped $=$ 119,614 New Tons Produced

119,614 Tons Produced $/((55 \%$ existing yield $+10 \%$ yield increase $) / 100)=$ 184,021 New Tons Melted

$0.838 \mathrm{New} /$ Old Ratio $\mathrm{x}\left(32.8 \times 10^{6}\right.$ Old Melting BTU/Ton Produced $)=$ $27,5 \times 10^{6}$ New Melting BTU/Ton Produced

$27.5 \times 10^{6}$ New Melting BTU/Ton Produced x 119,614 New Tons Produced/yr = $3.29 \times 10^{12} \mathrm{BTU} / \mathrm{yr}$

○ Ti 8,295 Tons Shipped x 1.03 (Tons Shipped + Scrap)/Tons Shipped $=$ 8,544 New Tons Produced

8,544 Tons Produced $/((55 \%$ existing yield $+10 \%$ yield increase $) / 100)=$ 13,145 New Tons Melted

$0.838 \mathrm{New} /$ Old Ratio $\mathrm{x}\left(35.0 \times 10^{6}\right.$ Old Melting BTU/Ton Produced $)=$ $29.33 \times 10^{6}$ New Melting BTU/Ton Produced

$29.33 \times 10^{6}$ New Melting BTU/Ton Produced x 8,544 New Tons Produced/yr $=$ $0.25 \times 10^{12} \mathrm{BTU} / \mathrm{yr}$

○ Al 43,134 Tons Shipped x 1.03 (Tons Shipped + Scrap)/Tons Shipped = 43,719 New Tons Produced

43,719 Tons Produced $/((55 \%$ existing yield $+10 \%$ yield increase $) / 100)=$ 65,722 New Tons Melted

$0.838 \mathrm{New} /$ Old Ratio x $\left(7.5 \times 10^{6}\right.$ Old Melting BTU/Ton Produced $)=$ 6.29x $10^{6}$ New Melting BTU/Ton Produced $6.29 \times 10^{6}$ New Melting BTU/Ton Produced x 43,719 New Tons Produced/yr $=$ $0.28 \times 10^{12} \mathrm{BTU} / \mathrm{yr}$

Table D.1. Comparison of energy used and energy saved for existing versus new technology

\begin{tabular}{|c|c|c|}
\hline Investment casting material & Assumptions & $\begin{array}{c}\text { Energy used/saved } \\
\left(\times 10^{12} \mathrm{Btu} / \mathrm{year}\right)\end{array}$ \\
\hline \multicolumn{3}{|l|}{ Baseline metric } \\
\hline HA steel & $32.8 \times 10^{6} \mathrm{Btu} /$ ton $\times 120,775$ tons/year & 3.96 \\
\hline Titanium & $35.0 \times 10^{6} \mathrm{Btu} /$ ton $\times 8,627$ tons/year & 0.30 \\
\hline Aluminum & $7.5 \times 10^{6} \mathrm{Btu} / \mathrm{ton} \times 43,134$ tons/year & 0.32 \\
\hline Total energy use, baseline & & 4.58 \\
\hline \multicolumn{3}{|l|}{ New technology metric } \\
\hline HA steel & $27.5 \times 10^{6} \mathrm{Btu} /$ ton $\times 119,614$ tons/year & 3.29 \\
\hline Titanium & $29.3 \times 10^{6} \mathrm{Btu} / \mathrm{ton} \times 8,544$ tons/year & 0.25 \\
\hline Aluminum & $6.29 \times 10^{6} \mathrm{Btu} /$ ton $\times 43,719$ tons/year & 0.28 \\
\hline $\begin{array}{l}\text { Total energy use, new } \\
\text { technology }\end{array}$ & & 3.82 \\
\hline Energy savings & & 0.76 \\
\hline
\end{tabular}

